SANDIA REPORT SAND83-0583 • Unlimited Release • UC-62b",

Printed January 1985

\title{
The Shenandoah Parabolic Dish Solar Collector
}

George S. Kinoshita

\author{
Prepared by \\ Sandia National Laboratories \\ Albuquerque, New Mexico 87185 and Livermore, California 94550 \\ for the United States Department of Energy \\ under Contract DE-AC04-76DP00789
}

\section{When printing a copy of any digitized SAND Report, you are required to update the markings to current standards.}


Issued by Sandia National Laboratories, operated for the United States Department of Energy by Sandia Corporation.

NOTICE: This report was prepared as an account of work sponsored by an agency of the United States Government. Neither the United States Government nor any agency thereof, nor any of their employees, nor any of their contractors, subcontractors, or their employees, makes any warranty, express or implied, or assumes any legal liability or responsibility for the accuracy, completeness, or usefulness of any information, apparatus, product, or process disclosed, or represents that its use would not infringe privately owned rights. Reference herein to any specific commercial product, process, or service by trade name, trademark, manufacturer, or otherwise, does not necessarily constitute or imply its endorsement, recommendation, does not necessarily constitute or imply its endorsement, recommendation, their contractors or subcontractors. The views and opinions expressed herein do not necessarily state or reflect those of the United States Government, any agency thereof or any of their contractors or subcontractors.

Printed in the United States of America

Available from

National Technical Information Service

U.S. Department of Commerce

5285 Port Royal Road

Springfield, VA 22161

NTIS price codes

Printed copy: A06

Microfiche copy: A01 
SAND83-0583

Distribution

Unlimited Release

Category UC $-62 b$

Printed January 1985

\title{
The Shenandoah Parabolic Dish Solar Collector
}

\author{
George S. Kinoshita \\ Distributed Receiver Projects Division \\ Sandia National Laboratories \\ Albuquerque, NM 87185
}

\begin{abstract}
The objectives of the Shenandoah, Georgia, Solar Total Energy System are to design, construct, test, and operate a solar total energy system to obtain experience with large-scale hardware systems for future applications. This report describes the initial design and testing activities conducted to select and develop a collector that would serve the need of such a solar total energy system. The parabolic dish was selected as the collector most likely to maximize energy collection as required by this specific site. The fabrication, testing, and installation of the parabolic dish collector incorporating improvements identified during the development testing phase are described.
\end{abstract}




\section{Contents}

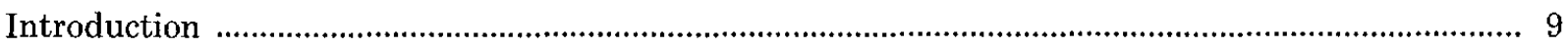

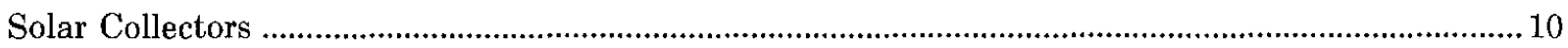

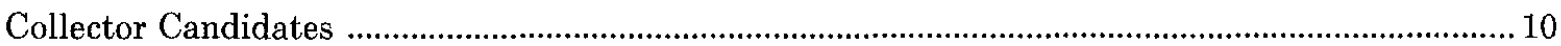

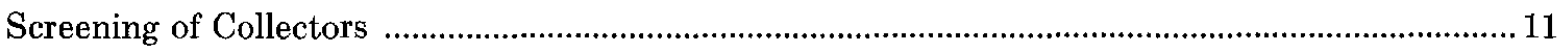

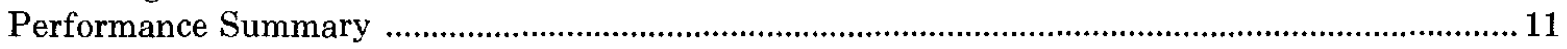

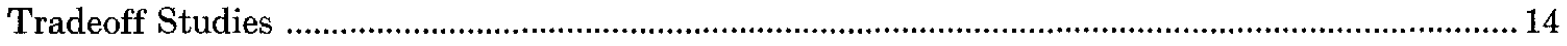

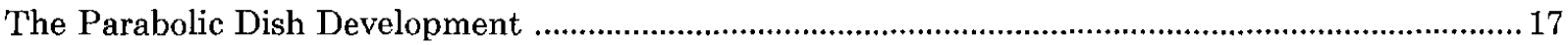

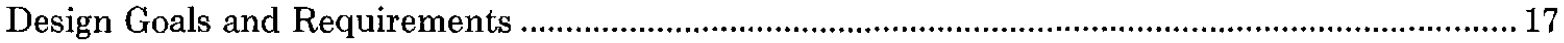

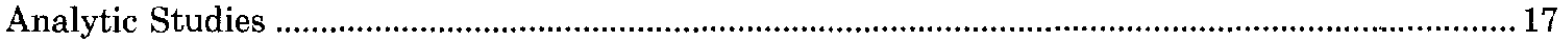

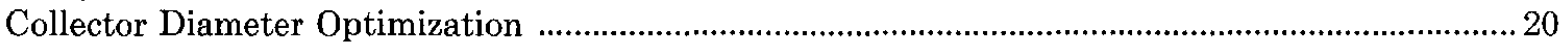

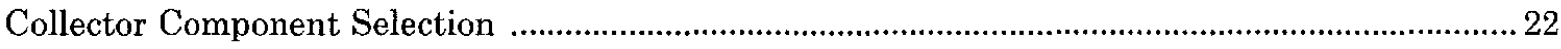

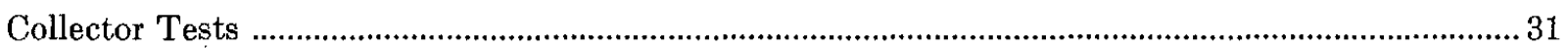

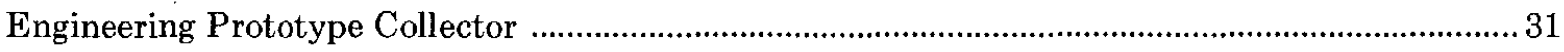

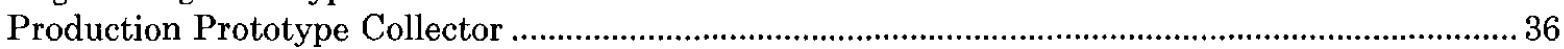

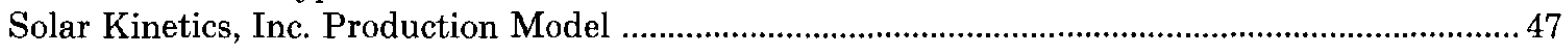

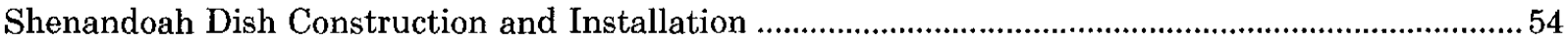

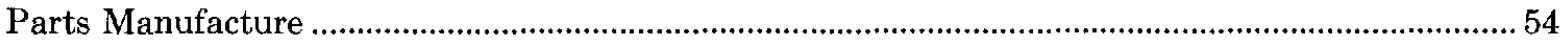

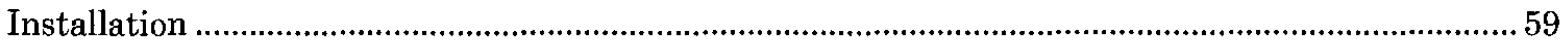

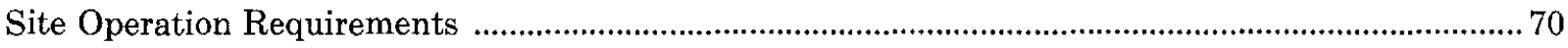

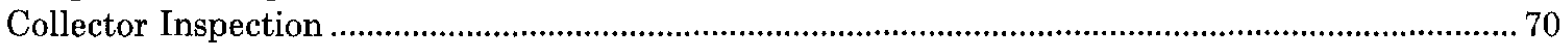

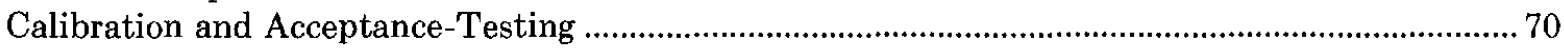

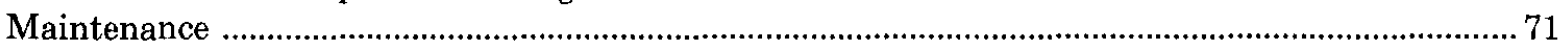

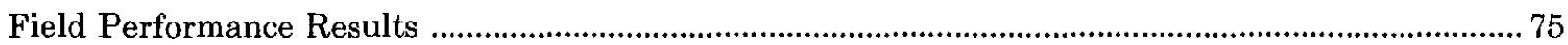

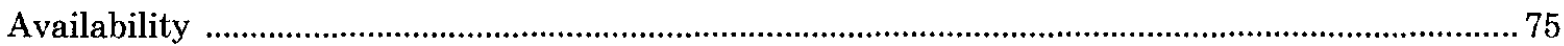

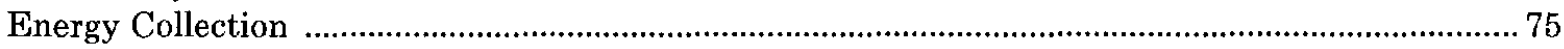

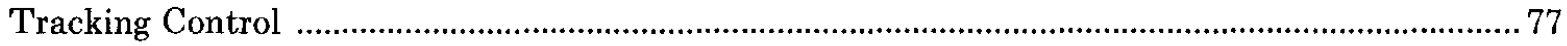

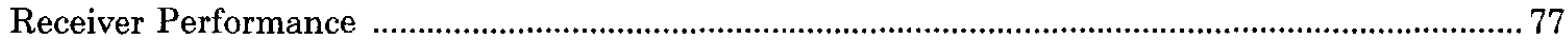

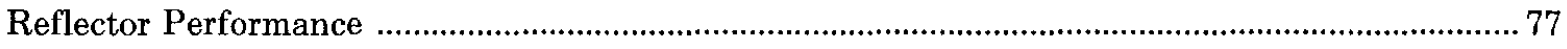

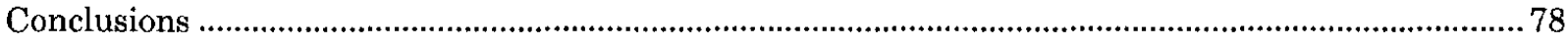

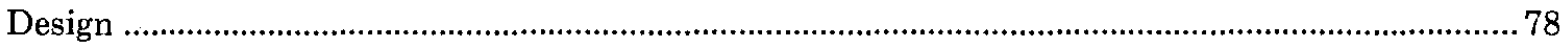

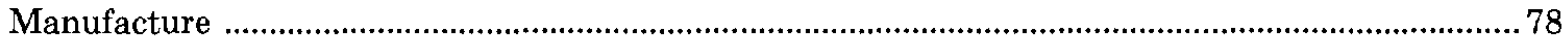

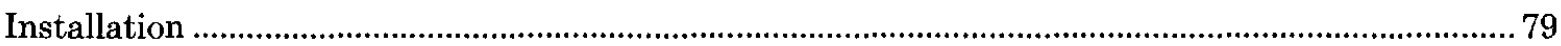

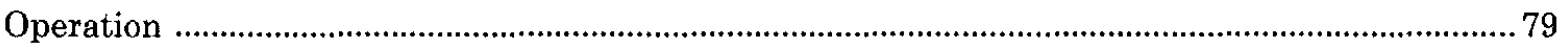

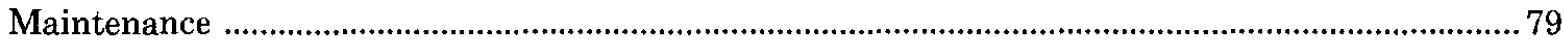

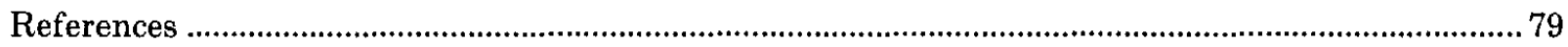

APPENDIX -D-2300 Installation Manual, Solar Kinetics, Inc. ....................................................... 81 


\section{Figures}

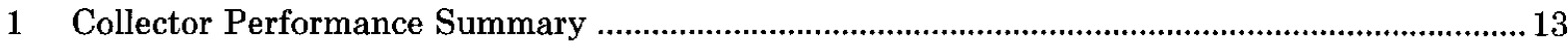

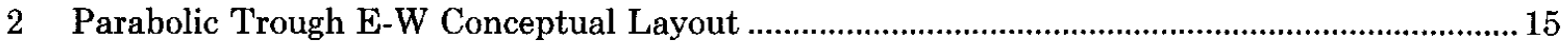

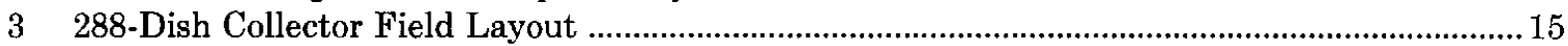

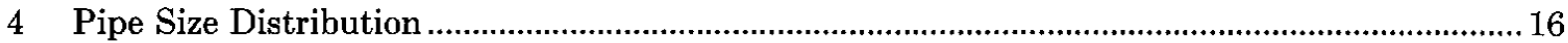

5 Nominal Collector Performance and Design Parameter ..............................................................19

6 Focal Length Optimization .............................................................................................

7 Reflector Surface Parameter Sensitivity Analysis .......................................................................... 19

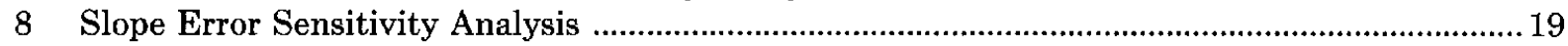

9 Concentration Ratio Sensitivity Analysis …………………………………………………........ 20

10 Tracking Bias Error Sensitivity Analysis ………………………………………………...... 20

11 Variation of Steady State Heat Loss to Collector Diameter and Piping Radius ........................20

12 Composite Steady State Heat and Pumping Power Losses vs Tubing Size .................................2 21

13 Daily Average Total Field Energy Parameter vs Collector Diameter ............................................. 21

14 Optimization Results_Collector Diameter vs Cost/Btu Delivered ................................................... 21

15 Collector Efficiency vs Diameter for Various Insolation Levels ...................................................2 21

16 Total Collector Weight and Cost for Constant Structure Stiffness .............................................22

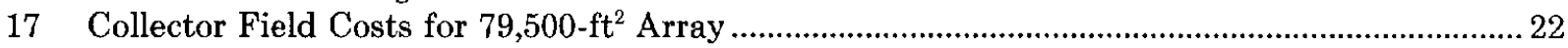

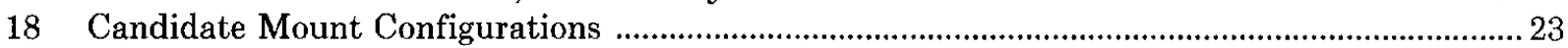

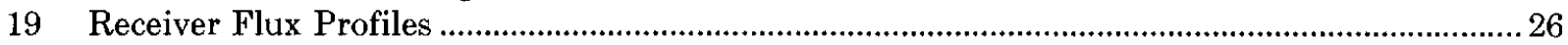

$20 \quad$ Integrated Receiver Flux Profiles ………………………………………………………….... 26

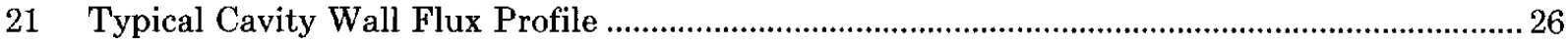

22 Receiver (a) Design Flux Levels and (b) Film Coefficient Matching ……………………….........2 27

23 Receiver Tube Sizing/Pressure Drop Relationship ...................................................................... 28

24 Relationship Between Coil Diameter and Pressure Drop for (a) Single Coil and

(b) Parallel Twin Coil .................................................................................................................. 28

25 Tracking Error Sensitivity ........................................................................................................ 30

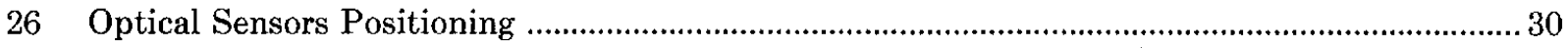

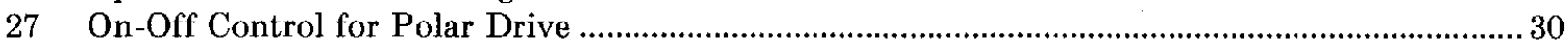

28 Engineering Prototype Collector - (a) Front View, (b) Side View ……………………………....... 32

$29 \quad$ EPC Receiver-Coil Assembly .................................................................................................... 34

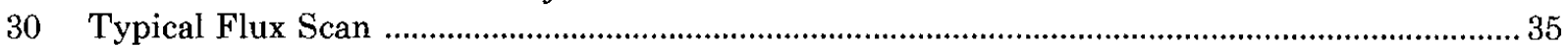

$31 \quad$ Flux Profile Test Results ...................................................................................................

$32 \quad$ GE Parabolic Dish Receiver Thermal Loss ............................................................................... 35

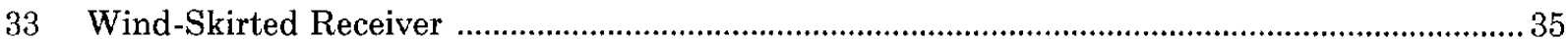

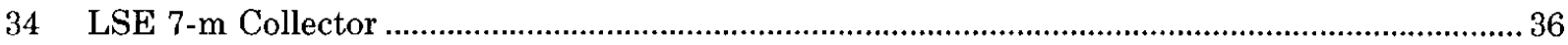

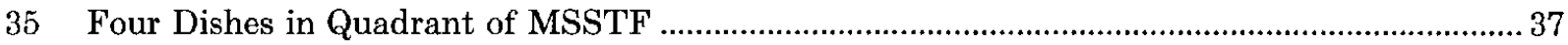

36 Foamed Quartz and Calcium Silicate Insulation Installed on Field Piping ................................ 38

37 Receiver. Thermal Loss vs Elevation Angle-Test Results at Average Cavity

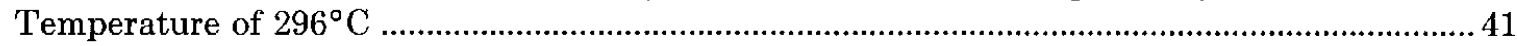

38 Receiver Thermal Loss vs Elevation Angle-Prediction at Fluid Outlet $399^{\circ} \mathrm{C}$.......................... 41

$39 \quad$ Receiver Coil Temperature .................................................................................................. 41

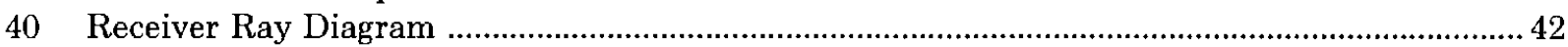

41 Tube Temperature - (a) November 5 (b) November 12 …………………………………....... 42

42 Double-Wound Coil ............................................................................................................. 43

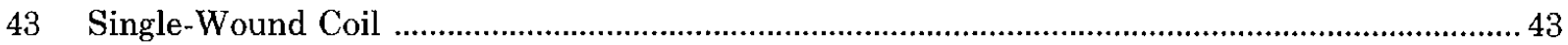

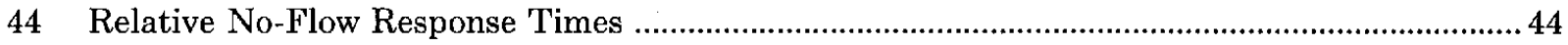

45 Receiver - (a) Aperture Plate, (b) Predicted Temperatures With Quartz Cloth .........................45

46 Shenandoah Prototype Collector ............................................................................................... 49

$47 \quad$ Focused Solar Image in Receiver …………………………………………………………..... 52

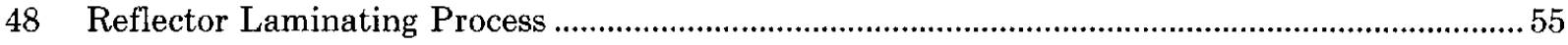

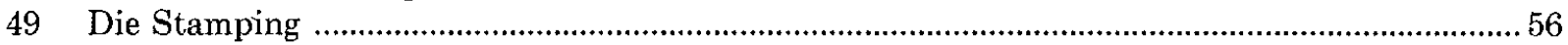




\section{Figures (cont)}

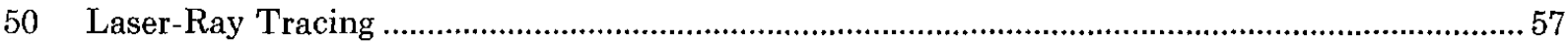

51 Slope Error Plot From Laser-Ray Tracing .................................................................................. 58

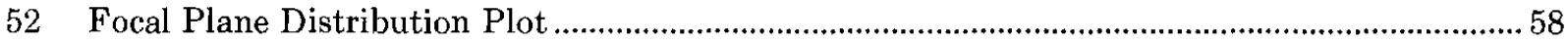

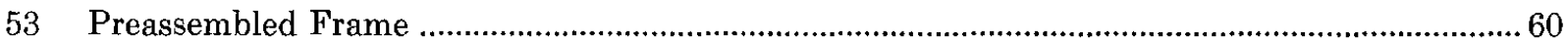

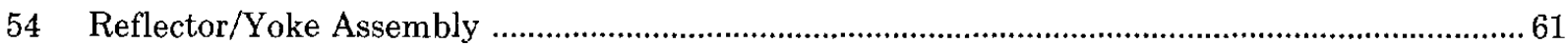

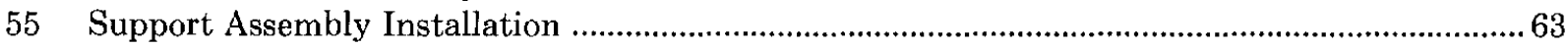

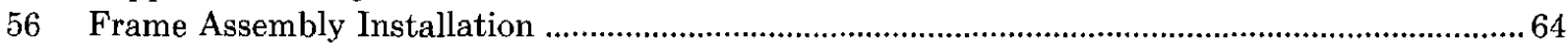

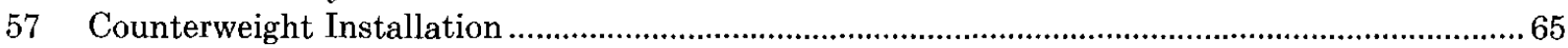

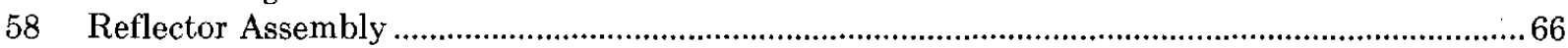

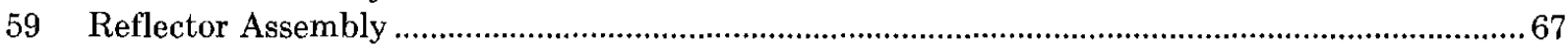

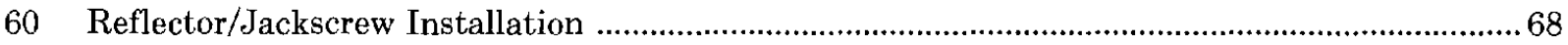

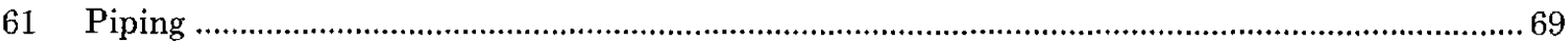

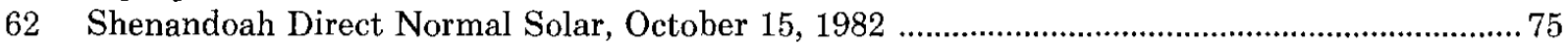

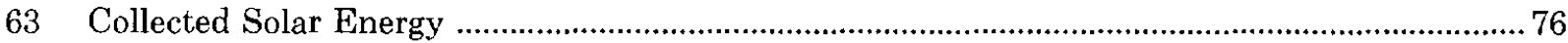

\section{Tables}

1 Typical Collector Performance Analysis Assumptions ................................................................. 11

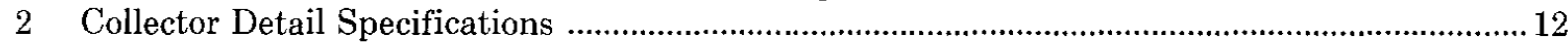

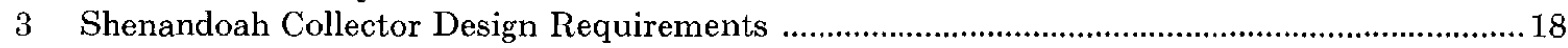

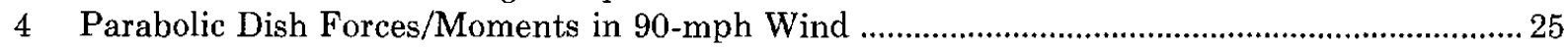

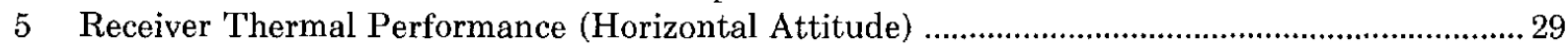

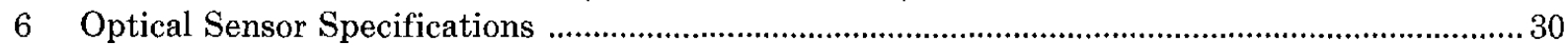

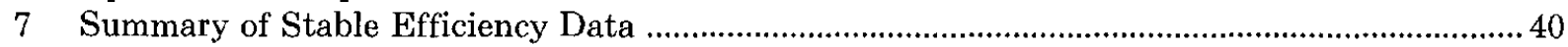

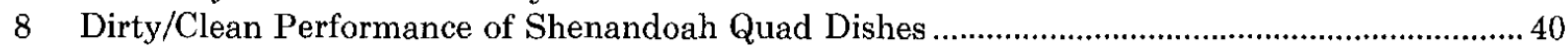

9 Shenandoah Operation-October 15, 1982 Summary …............................................................ 76 


\section{The Shenandoah Parabolic Dish Solar Collector}

\section{Introduction}

The objectives of the Shenandoah, Georgia, Solar Total Energy System (STES) (initially called the Large Scale Experiment) were to design, construct, test, evaluate, and operate an STES to obtain experience with large-scale hardware systems for future applications; to obtain meaningful cost and performance data of an STES; to develop the interface responsibilities of an STES with the user and with the utility; and to obtain information for dissemination relative to an STES. The General Electric Company was contracted to conduct the conceptual and preliminary design of the STES in 1977.

A wide range of potentially applicable subsystems and system candidates were considered for supplying the electric, process steam, and heating and cooling energy needs of the user, a knitwear clothing manufacturer. Ten different solar collectors were evaluated by GE for operation under Shenandoah solar conditions before the distributed collection/central generation configuration was finally selected.

Because of the moderate insolation levels predicted for the 5-acre Shenandoah STES, a collector that would maximize energy collection was needed. The parabolic dish was selected as the collector offering the most promise for providing the needs of this STES. 


\section{Solar Collectors}

\section{Collector Candidates}

Collector types can be divided into three general categories:

- Stationary reflector designs

Cusp and compound parabolic configurations

Fixed mirror with distributed focus

Fixed segmented mirror with moving receiver

- Single-axis tracking designs

Parabolic linear troughs

Segmented linear array tracking system

- Two-axis tracking designs

Paraboloids

Linear Fresnel lens configurations

Central receivers

Each of these was examined as a candidate during the conceptual design studies of the Shenandoah STES.

\section{Stationary Reflector Designs}

Cusp and Compound Parabolic Collectors. Collectors of these designs maximize the radiant energy entering the optical system within a specified field of view. Although they have relatively large reflector areas for a given concentration ratio, the multiple reflections of the radiation before absorption in the receiver gives rise to losses. However, if the system is coupled with low loss absorbers, such as evacuated tubes, their efficiencies and collection rates are comparable to some trough systems.

The primary advantage of these designs lies in the lower capital and maintenance cost of a nontracking system. A disadvantage is the need for a cover to prevent foreign material from collecting in the stationary reflectors.

Fixed Mirror Distributed Focus Collectors. The Spherical Crosbyton bowl is representative of this class of collectors. Incoming solar rays are focused to a single line parallel to the rays and passing through the center of curvature of the reflector. The energy distribution along the receiver, which is placed at the center of curvature, is a function of the solar position. The bowl is tilted to maximize collector performance. Energy collection rates and efficiencies are comparable to those of other collector types.
Fixed Segmented Mirror, Moving Receiver Collector. The concrete General Atomic collector typifies this class of solar collector. The energy reflected from mirror segments on a reference circle is concentrated on a moving receiver pivoted about the geometric center of the circle. For a given optical accuracy, the long focal length of this collector increases the beam spreading at the focus, and thus the losses are increased as a result of the larger receiver intercept area required over a shorter focal length system.

\section{Single-Axis Tracking Designs}

Parabolic Linear Troughs. This is the most highly developed of the solar collector designs and represents the historic approach to solar energy collection. Both reflector and receiver rotate to maximize energy collection during the day. Maximum operating temperatures for a trough are presently restricted by receiver absorber temperature limitations. Because of their highly developed state, troughs are used as a basis for comparing other solar systems.

Segmented Linear Array Tracking System. The SLATS (an acronym applied by the Sheldhal Company to their collector) has curved reflector segments that are rotated to focus on a fixed receiver. The long focal length gives rise to beam spreading and to increased receiver losses due to the larger receiver diameter required to intercept the beam. Also, the segmented mirror sections are subject to blocking and shadowing, which result in additional losses.

\section{Two-Axis Tracking Designs}

Paraboloids. Paraboloids, the so-called dish collectors, focus the reflected energy into a small area and are referred to as "point-focus" concentrators, in contrast to the previously discussed "line-focus" types. Not all dish collectors are point-focusing, however. When receivers are mounted on a central stem, the reflected image conforms to the torroidal aperture of the receiver. These dish collectors have relatively low thermal losses, resulting in high efficiencies. The high concentration ratios possible with these collectors also permit operating temperatures above those of trough collectors. The cavity-type receivers allow the use of 
nonselective absorber materials $(\alpha=\epsilon)$ that are less temperature limited than selective materials.

Linear Fresnel Lens. Unlike other collectors, which concentrate reflected radiation, these collectors focus the incoming radiation onto a receiver. Both point-focusing and line-focusing Fresnel lenses are available.

Small Scale Central Receiver. The small scale central receiver uses the same size heliostats as used by the units developed for central power station applications, but it uses a smaller receiver. The heliostats and their control system represent the major cost item for this system.

\section{Screening of Collectors}

The process of selecting possible candidates for the Shenandoah STES followed a screening procedure consisting of

- Compiling the latest information on all of the collector types

- Evaluating this information for completeness and suitability

- Determining collector performance under operating conditions

- Choosing candidate types based on an overall assessment of the performance, cost, availability, and risk

- Performance analysis using the assumptions in Table 1.

\section{Performance Summary}

Based on the assumptions listed in Table 1, the collector types in Table 2 were analyzed. The analysis results are summarized in Figure 1. These results were for a single unit and did not include the effect of shadowing, parasitic losses, or pipefield losses. Further studies were confined to the two leading candidates, the dish, and the trough parabolas.

The high concentration ratio coupled with 2 -axis tracking gives the dish collector an overwhelming performance advantage. The losses from a collector are a function of the concentration ratio, the cosine of the incidence angle, and the insolation when other collector factors such as absorptivity, reflectivity, etc, are held constant. The cosine function over the range of significant insolation can vary by a factor of 2.5 . Thermal losses for dishes at high concentration ratios are roughly constant and about $1 / 10$ as large as for linear absorber collectors. And, even in the presence of relatively low direct normal insolation levels, the dish collector efficiency is a rather constant high value. Linear absorbers show a rather dramatic falling off in efficiency at low insolation levels.

The fixed apertures of stationary reflector collector designs can be optimized only for particular periods of the year, resulting in much variability of output in addition to losses due to cosine, edge loss, and shadowing effects. The dish collector was also found to provide almost twice the collection area for a given site size as that provided by a trough collector.

The knitwear plant that was to receive the energy from the solar system was initially considered for twoshift operation. Thus, the baseline criterion involved sizing the field to supply the electrical load for a full 16 hours. This procedure was not possible with a trough field because of the size limitation of the available site. The studies also indicated that even though the pipefield for a dish field is significantly larger (by a factor of 3) and has significantly larger losses than a trough field located on the same size site, the dish field would still deliver significantly greater energy (by a factor of 2 to 3$)$.

\section{Table 1. Typical Collector Performance Analysis Assumptions}

- Average insolation conditions are ASHRAE

- Liu \& Jordan Method is used to separate direct and diffuse on hourly basis

- Absorber loss can be represented by an average loss coefficient

- Average wind conditions are $4.5 \mathrm{~m} / \mathrm{s}(10 \mathrm{mph})$ for tube-in-tube absorbers

- Average wind on the glass face of an isolated absorber is $1.8 \mathrm{~m} / \mathrm{s}(4 \mathrm{mph})$

- Ambient air temperature $=18.3^{\circ} \mathrm{C}\left(65^{\circ} \mathrm{F}\right)$

- There is no shading or blocking by nearby objects

- Black chrome absorptivity $=0.94$

- Black chrome emissivity=0.20@ $315^{\circ} \mathrm{C}\left(600^{\circ} \mathrm{F}\right)$; $0.13 @ 190^{\circ} \mathrm{C}\left(375^{\circ} \mathrm{F}\right)$

- Plastic tape reflectivity $=0.85$

- Second surface glass reflectivity $=0.90$

- Pyrex glass transmission $=0.90$

- End losses are negligible 


\begin{tabular}{|c|c|c|c|c|c|c|c|c|c|c|c|c|c|c|c|}
\hline \multirow{3}{*}{ Table 2. Col } & \multirow[b]{3}{*}{$\begin{array}{c}\text { Track- } \\
\text { ing } \\
\text { Axes } \\
\end{array}$} & \multirow{2}{*}{\multicolumn{4}{|c|}{ Collector }} & \multicolumn{4}{|c|}{ Receiver } & \multirow{2}{*}{\multicolumn{5}{|c|}{ Collector }} & \multirow{3}{*}{$\begin{array}{c}\text { Collec- } \\
\text { tor Loss } \\
@ 600^{\circ} \mathrm{F} \\
\text { Btu/ft }{ }^{2} / \mathrm{h}\end{array}$} \\
\hline & & & & & & \multirow{2}{*}{$\begin{array}{c}\text { Abs } \\
\text { Dia/ } \\
\text { Width } \\
\text { (M) }\end{array}$} & \multirow[b]{2}{*}{$\begin{array}{l}\text { Absorb- } \\
\text { tivity }\end{array}$} & \multirow[b]{2}{*}{$\begin{array}{c}\text { Emmis- } \\
\text { sivity }\end{array}$} & \multirow[b]{2}{*}{$\begin{array}{c}\text { Glass } \\
\text { Tube } \\
\text { Dia } \\
(\mathrm{m}) \\
\end{array}$} & & & & & & \\
\hline & & $\begin{array}{l}\text { Aperture } \\
\text { Width } \\
(\mathrm{m})\end{array}$ & $\begin{array}{l}\text { Module } \\
\text { Length } \\
\text { (m) }\end{array}$ & $\begin{array}{c}\text { Rim } \\
\text { Angle } \\
\left({ }^{\circ}\right)\end{array}$ & $\mathbf{F} / \#$ & & & & & $\begin{array}{c}\text { Trans- } \\
\text { mission }\end{array}$ & $\begin{array}{c}\text { Reflect- } \\
\text { ivity }\end{array}$ & $\begin{array}{c}\text { Surface } \\
\text { Accuracy } \\
\text { (rad) }\end{array}$ & $\begin{array}{c}\text { Touching } \\
\text { Accuracy } \\
\left({ }^{\circ}\right)\end{array}$ & $\begin{array}{c}\text { Reflec- } \\
\text { tor } \\
\text { Material }\end{array}$ & \\
\hline \multicolumn{16}{|l|}{ Parabolic } \\
\hline Trough \#1 & 1 & 2.70 & 6.1 & 74 & .33 & .08 & .94 & .20 & & .90 & .85 & $3 \mathrm{E}-3$ & .1 & FEK-163 & 23.7 \\
\hline Parabolic & & & & & & & & .20 & .05 & .90 & .85 & $2 \mathrm{E}-3$ & .1 & FEK-163 & 51.8 \\
\hline Trough \#2 & 1 & 1.80 & 3.0 & 90 & .25 & .03 & .94 & .20 & .06 & .90 & .85 & $1.3 \mathrm{E}-3$ & .1 & FEK-163 & 56.6 \\
\hline Parabolic & & & & & & & & .20 & .04 & .90 & .9 & $4 \mathrm{E}-3$ & .1 & Glass & 58.1 \\
\hline Trough \#3 & 1 & 1.10 & 6.1 & 90 & .25 & .03 & .94 & .95 & $\mathrm{NA}$ & $\mathrm{NA}$ & .9 & $4 \mathrm{E}-3$ & .1 & Glass & 06.5 \\
\hline Parabolic & & & & & & & & .20 & & .90 & .87 & $4 \mathrm{E}-3$ & .1 & Glass & 32.1 \\
\hline Trough \#4 & 1 & 0.60 & 3.0 & 110 & .17 & .01 & .94 & .20 & & .90 & .85 & $4 \mathrm{E}-3$ & .1 & Glass & 45.9 \\
\hline Parabolic Dish & 2 & 6.70 & NA & 42 & .45 & NA & .90 & .20 & & .90 & .90 & $4 \mathrm{E}-3$ & .1 & Glass & 21.8 \\
\hline Fixed Mirror \#1 & 1 & 2.10 & 3.8 & 32 & $\mathrm{NA}$ & .05 & .94 & .20 & & .75 & NA & $\mathrm{NA}$ & .1 & Acrylic & 69.4 \\
\hline Fixed Mirror \#2 & 1 & 2.00 & 6.1 & 32 & NA & .08 & .94 & & & & & & & & \\
\hline Fixed Abs & 1 & 3.04 & 6.1 & 13 & 2.20 & .08 & .94 & & & & & & & & \\
\hline Fresnel Lens & 2 & 0.912 & 3.6 & 26 & 1.00 & .04 & .94 & & & & & & & & \\
\hline
\end{tabular}


D.N. INSOLATION

PARABOLIC DISH

PARABOLIC TROUGH \#2

PARABOLIC TROUGH $\# 1$

FIXED MIRROR *1

FIXED MIRROR *2

FIXED ABS

FRESNEL LENS

PARABOLIC TROUGH \#2

PARABOLIC TROUGH \#3

PARABOLIC TROUGH $* 4$

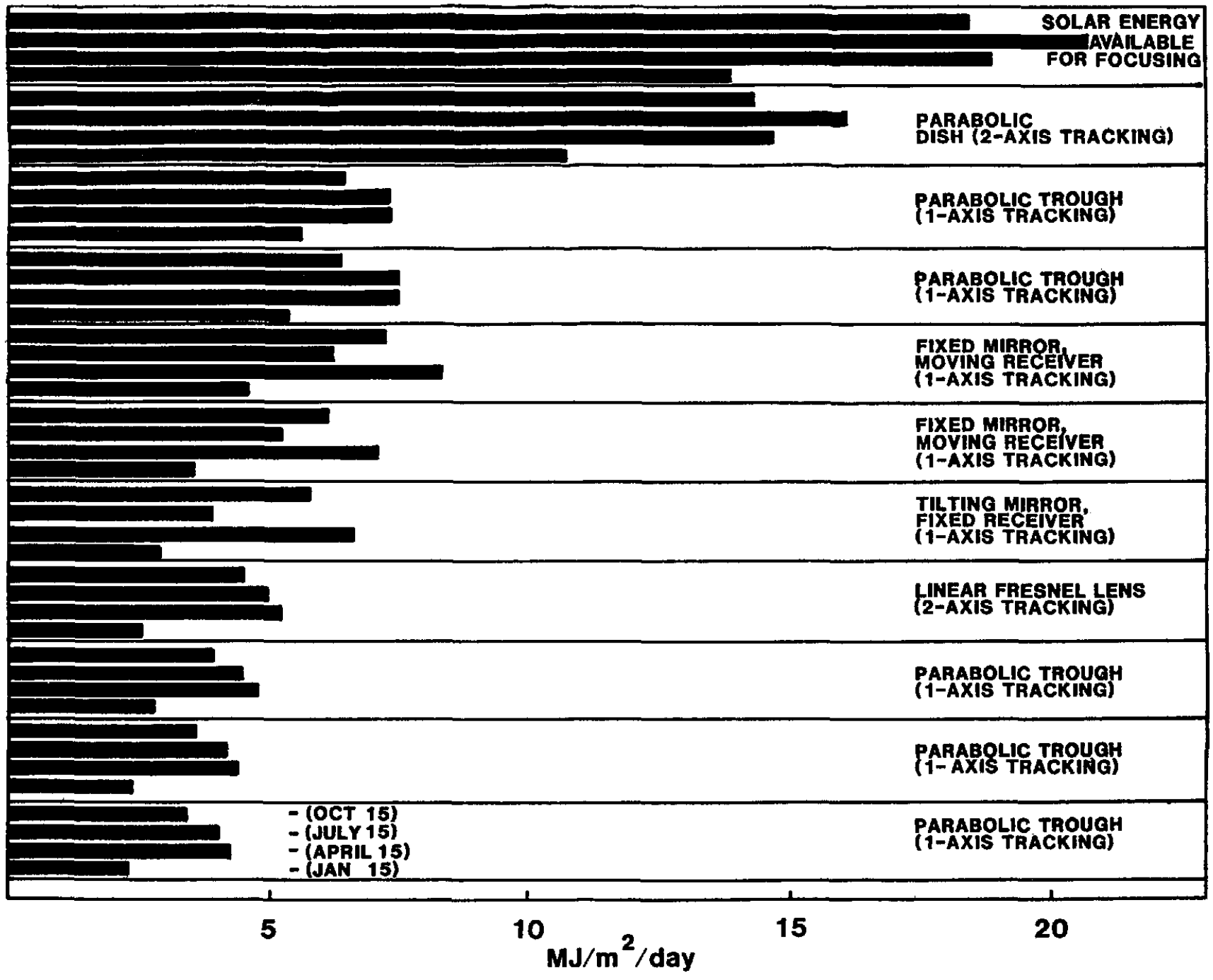

Figure 1. Collector Performance Summary 


\section{Tradeoff Studies}

\section{Shadowing}

Shadowing and blocking studies were performed on collector fields composed of troughs and of dishes. These studies confirmed the intuitive assumption that increased shadowing resulting from increased packing factors would affect an E-W oriented trough field rather uniformly over a year but the cosine factor would cause a N-S oriented trough field to suffer almost all of its attenuation in the winter months. Also, practical factors such as maintenance access space dictate maximizing trough widths to achieve maximum output from a given sized field. ${ }^{1,2}$

Parabolic dish shadowing studies were conducted using techniques developed by Sandia Laboratories. ${ }^{3}$ Both diamond shaped and rectangular shaped array geometries were studied. A diamond pattern does not suffer as severe a penalty in shadowing with changes in $x / y$ ratios, which permits denser packing and greater output for a given sized field, than with a rectangular arrangement of dishes. For the same packing factor (but with various $\mathrm{x}$ dimension to $\mathrm{y}$ dimension ratios-N-S/E-W), an $\mathrm{x} / \mathrm{y}$ ratio of approximately 0.7 gave optimum results for both rectangular and diamond array patterns. The yearly output for dishes and troughs increases with increased packing factors, but the energy gain for each additional collector becomes less.

\section{Orientation of Troughs}

Because a N-S orientation contributes only a small amount of energy to the annual total during the winter and because the objective of the STES is to provide the relatively constant energy requirements of the application throughout the year, comparisons of the trough performance against the dish were made using the E-W orientation of the troughs, even though on an annual basis the N-S orientation would yield about $12 \%$ more energy.

\section{Receiver Losses}

Comparative studies of trough receivers with and without wind effects for unevacuated glass shrouds show a decrease of $30 \%$ in collected energy if winds of $10 \mathrm{mph}(4.4 \mathrm{~m} / \mathrm{s})$ are assumed to be blowing across the shroud. Thus, trough collectors with evacuated tubes are needed to maintain reasonable collection efficiencies for the Shenandoah STES application where local climatological data indicate average annual wind speeds of $4 \mathrm{~m} / \mathrm{s}$ with wind $96 \%$ of the time.

\section{Pipefield and Collector Array}

Restricted land areas may require packing densities that will cause mirror-to-mirror shadowing in order to provide the specified percentage of the load requirements of the application. The collector field must be laid out so that the net collected energy (heat collected minus the parasitic power requirements minus the field pipe losses) is maximized. Analysis of the trough and dish systems showed that net performance is optimized when there is a net temperature change of $70^{\circ} \mathrm{C}\left(125^{\circ} \mathrm{F}\right)$. For troughs $9 \mathrm{ft}$ wide with a receiver diameter of $1.5 \mathrm{in}$. and a maximum fluid flow rate of $10 \mathrm{gpm}$, performance optimization leads to a row length of $300 \mathrm{ft}$ (Figure 2). For a dish system with a receiver having a 3/4-in. tubing of 7 turns, the row optimization was 4 dishes in a row (Figure 3 ). With the above optimization results, spacing was determined that would maximize collected energy at minimum cost. For troughs, this spacing turned out to be $14 \mathrm{ft}$. For dishes, a diamond pattern $28 \mathrm{ft}(\mathrm{N}-\mathrm{S})$ by $42 \mathrm{ft}$ (E-W) minimized shading while maximizing packing density. The piping length for the optimized collector spacings for a trough field $\left(8,222 \mathrm{~m}^{2}\right)$ was found to be $1,183 \mathrm{~m}$. For the dish field $\left(10,087 \mathrm{~m}^{2}\right)$ the total piping length was $3,443 \mathrm{~m}$ (Figure 4). The accompanying pipefield thermal losses for a $600^{\circ} \mathrm{F}$ operating system was $0.75 \times 10^{6} \mathrm{Btu} / \mathrm{hr}\left(0.22 \mathrm{MW}_{\mathrm{th}}\right)$ for the dish and 0.3 $\times 10^{6} \mathrm{Btu} / \mathrm{hr}\left(0.09 \mathrm{MW}_{\mathrm{th}}\right)$ for the trough field. 


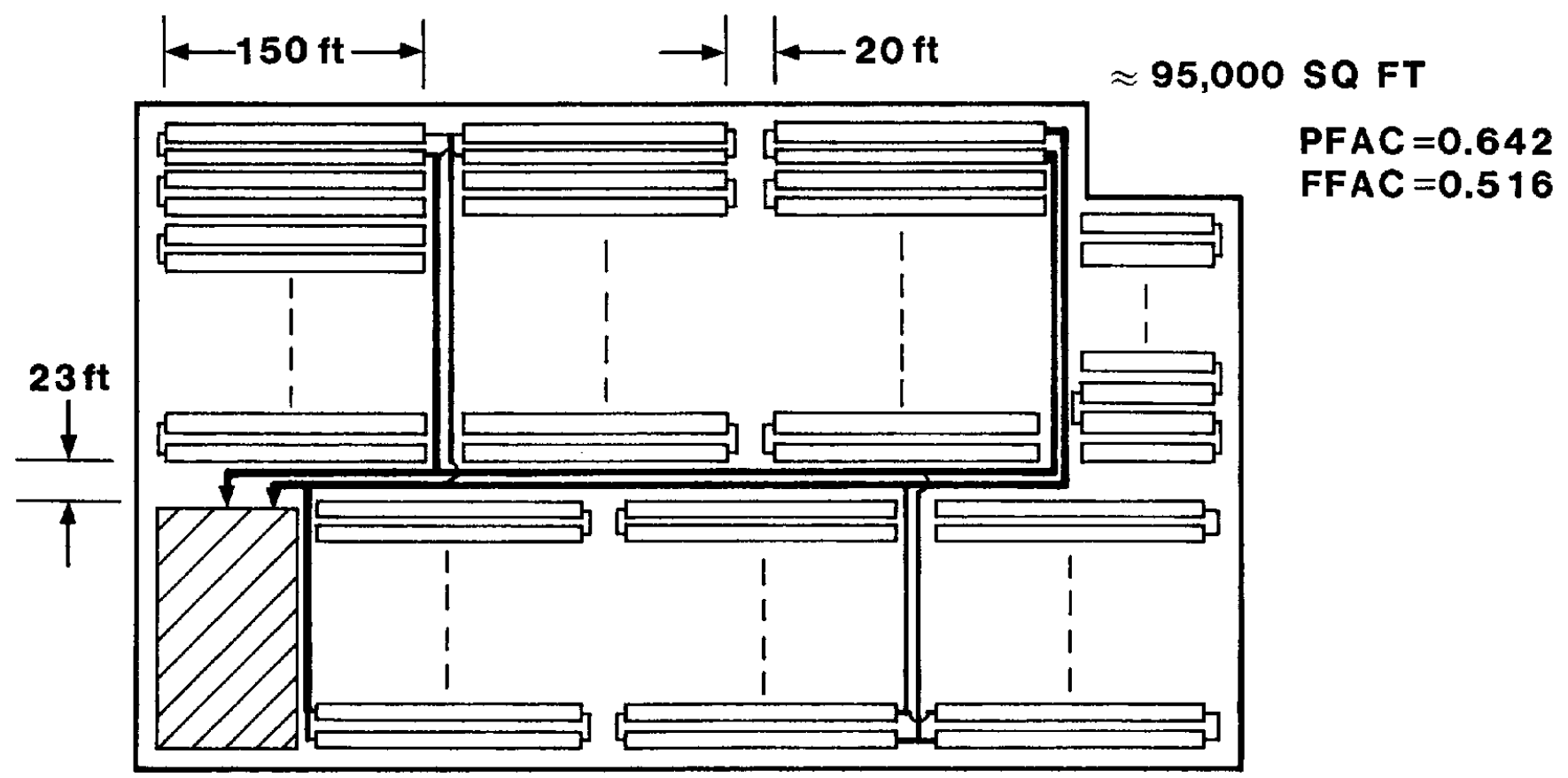

Figure 2. Parabolic Trough E-W Conceptual Layout

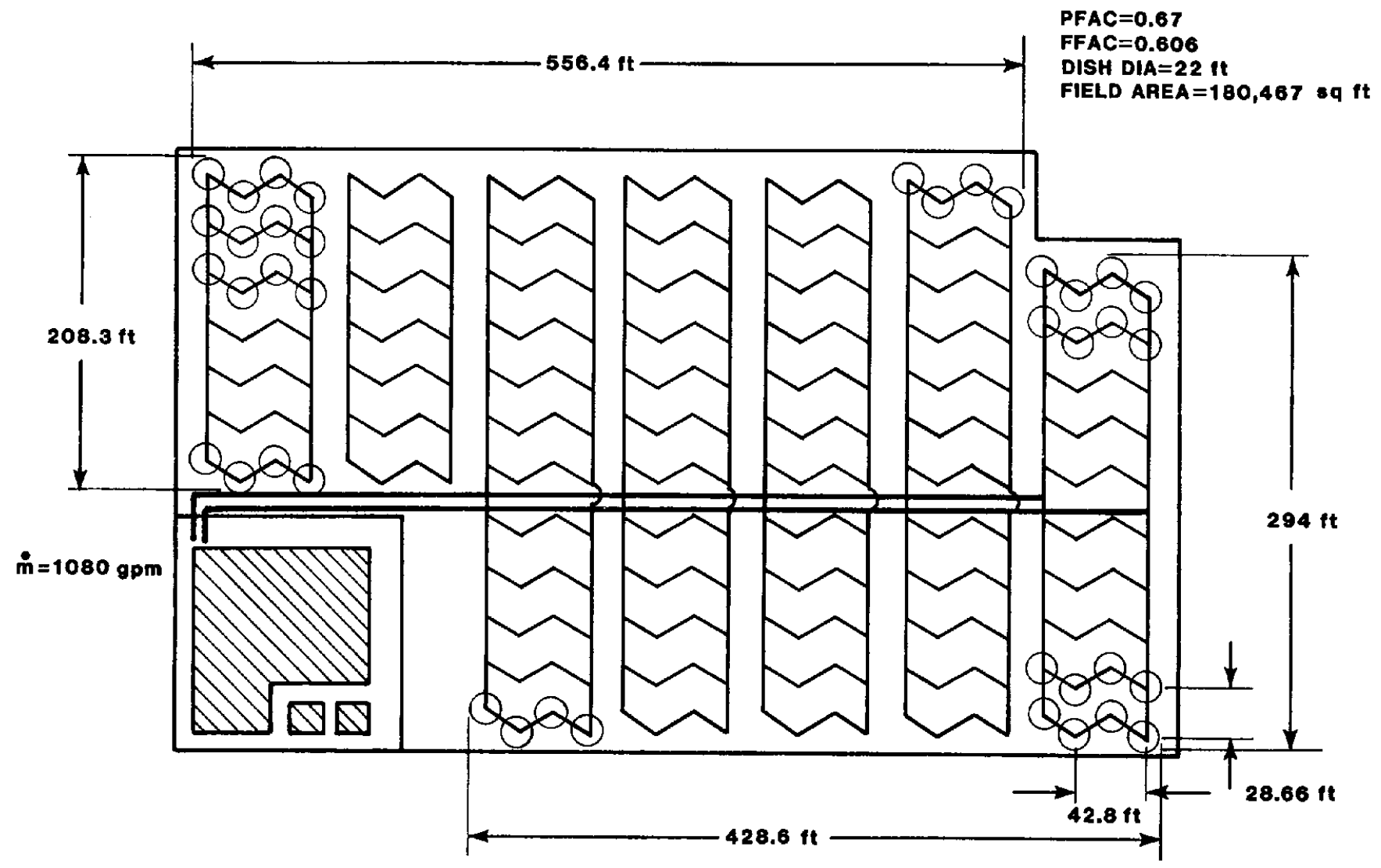

Figure 3. 288-Dish Collector Field Layout 


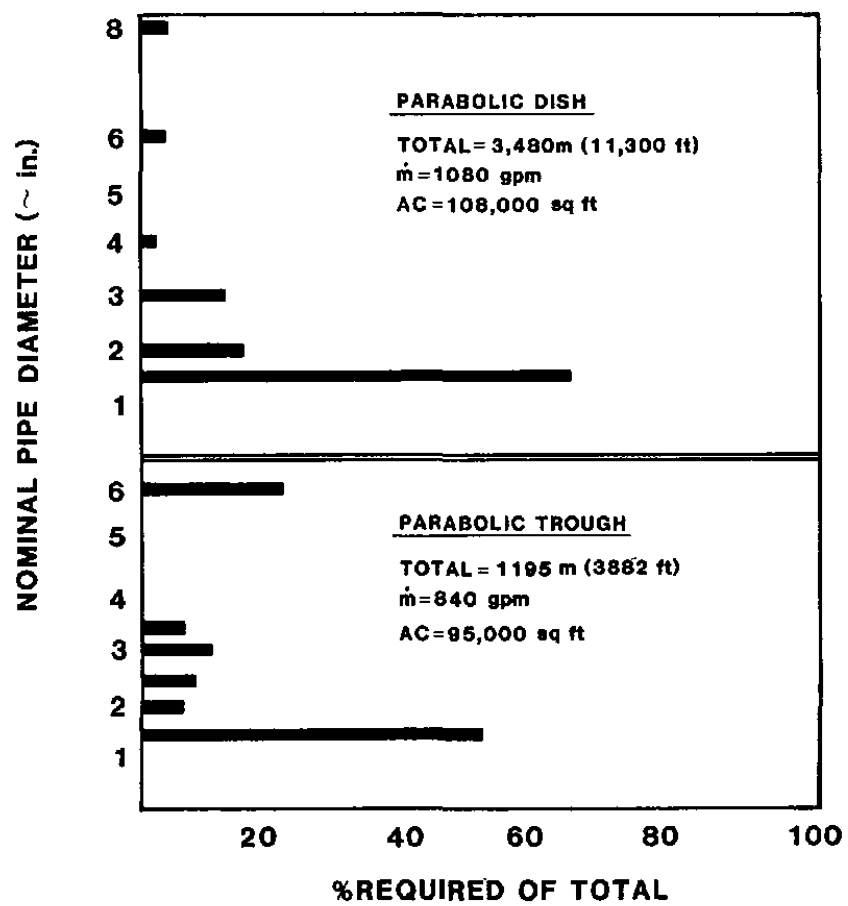

Figure 4. Pipe Size Distribution 


\section{The Parabolic Dish Development}

\section{Design Goals and Requirements}

From comparative studies of the capabilities of the various collectors, the two-axis tracking parabolic dish was selected as the collector most likely to meet application requirements.

The collector is the most critical element of a solar system, and it dictates the overall cost and performance of the system. Its development was therefore based on the following three basic principles.

1. Low fabrication costs

2. Capacity for meeting performance requirements

3. Capability of being developed, fabricated, and installed within the schedule established for the Shenandoah STES

Design development followed an iterative screening process based on a reference collector configuration that embodied the selected component concepts and overall configuration of a dish collector. From design decisions based on the three principles above, the collector system and field requirements were determined (Table 3).

\section{Analytic Studies}

The major collector design requirements were established from optical and thermal models incorporated into a collector system analysis model. The key variables in describing collector performance were

- f/D (focal length to dish diameter ratio)

- Surface reflectivity (hemispherical and specular reflectance)

- Slope error (deviation from a true paraboloid)

- Tracking error (offset of the image at the receiver)

- Concentration ratio (dish to receiver aperture ratio)

For this analysis, the following simplifying assumptions were made:

- The source, slope, and specular error distributions were assumed to be normally distributed.

- Tracking error was treated as a bias error rather than a random error.

- Convection losses from the receiver were based on a $10-\mathrm{mph}$ wind with the receiver elevation midway between noon and the horizon.
Figure 5 indicates the nominal values of the collector parameters derived from the trade-off studies, and the design and off-design performance characteristics of the collector using these nominal values. Refinements in the preliminary design effort following the optimization analysis led to parameter values that are slightly different from those shown in the figure.

\section{Focal Length/Dish Diameter Ratio}

The first variable selected was the f/D ratio. For each $\mathrm{f} / \mathrm{D}$ ratio an optimum concentration ratio was determined that balanced the receiver aperture size in terms of greater acceptance against greater heat loss. This study indicated 0.5 to be an optimum $\mathrm{f} / \mathrm{D}$ ratio (Figure 6).

\section{Surface Reflectivity}

Figure 7 shows the sensitivity of the total reflectivity and specular reflectance relative to the energy collected. As expected, total reflectivity has a profound influence on the performance, whereas performance has only a weak sensitivity to specularity below $\sim 8 \mathrm{mrad}$ due to the moderate concentration ratio specified for this dish. To achieve a collector efficiency of $67 \%$, the studies indicated that a total reflectivity of 0.88 was needed. Lower reflectivity concentrators would result in a comparable lower efficiency collector. For these studies, the reflectivity was stipulated to be 0.88 and the specularity was established at $8 \mathrm{mrad}$ rms.

\section{Slope Error}

Because surface slope errors less than $0.5^{\circ}$ did not affect performance to any large extent, $0.5^{\circ}$ was specified as the required slope error. Construction techniques and manufacturing tolerances are two collector fabrication elements influenced by the slope error. The slope error sensitivity relative to collected energy is shown in Figure 8.

\section{Concentration Ratio}

The sensitivity of concentration ratio on the collected energy is shown in Figure 9. Both parameters were normalized for this analysis. The concentration ratio determines the diameter of the receiver aperture 
and thus the overall size of the receiver. A concentration ratio of $\sim 250$ maximized the output. In other words, the size of receiver opening was such that the ratio of energy entering the receiver to the energy lost from the receiver was maximized.

\section{Tracking Error}

Tracking bias error-the position of the receiver aperture centerline relative to the center of the reflected solar flux distribution at the focal plane- was the final major design parameter specified. The bias error is an accumulation of mechanical offsets caused by alignment tolerances, tracking sensor accuracy, position indicator accuracy, and the mechanical stiffness of the collector. Figure 10 shows how the tracking error influences the energy collected. For the aperture size determined from the concentration ratio study, an offset $>0.25^{\circ}$ caused a significant amount of energy to miss the receiver. Therefore, a bias error of $0.25^{\circ}$ was specified as a collector design requirement.

\section{Table 3. Shenandoah Collector Design Requirements}

\begin{tabular}{|c|c|c|}
\hline Item & Design Requirement & \\
\hline Type: & Concentrating, 2-axis tracking, parabolic dish & \\
\hline Coolant Fluid: & Syltherm 800 & \\
\hline Output: & $1.09 \times 10^{8} \mathrm{Btu} / \mathrm{yr}$ & \\
\hline Operating Conditions: & $\begin{array}{l}\text { - Ambient temperature range } \\
\text { Fluid } \Delta \mathrm{T} \\
\text { - Max working fluid bulk temperature } \\
\text { - Wind loads } \\
\text { - Tracking range: } \\
\text { Polar axis } \\
\text { Declination axis } \\
\text { - Insolation Levels }\end{array}$ & $\begin{array}{l}17^{\circ} \mathrm{F}-95^{\circ} \mathrm{F} \\
250^{\circ} \mathrm{F} \\
750^{\circ} \mathrm{F} \\
30 \mathrm{mph} \\
\\
\sim 180^{\circ}\left( \pm 90^{\circ}\right) \\
\sim 105^{\circ}\left( \pm 5^{\circ} \text { to }-90^{\circ}\right) \\
\text { Design }-200 \mathrm{Btu} / \mathrm{ft}^{2} / \mathrm{h} \\
\text { Max }-300 \mathrm{Btu} / \mathrm{ft}^{2} / \mathrm{h} \\
\text { Min }-50-75 \mathrm{Btu} / \mathrm{ft}^{2} / \mathrm{h}\end{array}$ \\
\hline $\begin{array}{l}\text { Nonoperating } \\
\text { Survival Conditions: }\end{array}$ & $\begin{array}{l}\text { - Ambient temperature range } \\
\text { - Wind loads } \\
\text { - Hail impact } \\
\text { - Lightning strike }\end{array}$ & $\begin{array}{l}-3^{\circ} \mathrm{F} \text { to } 104^{\circ} \mathrm{F} \\
90 \mathrm{mph} \\
0.6 \mathrm{in} \text {. dia } \\
100 \mathrm{kA} \text { peak current } \\
1 \mu \mathrm{s} \text { rise time }\end{array}$ \\
\hline $\begin{array}{l}\text { Maintenance } \\
\text { Routine: }\end{array}$ & $\begin{array}{l}\text { - Reflective surface washable } \\
\text { - Receiver cleanable without removal } \\
\text { - Control calibration }\end{array}$ & Design provisions \\
\hline Unscheduled: & $\begin{array}{l}\text { - Disk petals replaceable } \\
\text { - Receiver replaceable } \\
\text { - Receiver/dish alignment } \\
\text { - Controls removable }\end{array}$ & Design provisions \\
\hline Hazard Shutdown: & $\begin{array}{l}\text { - Defocus time } \\
\text { - Over temperature } \\
\text { - Loss of fluid flow } \\
\text { - Power loss } \\
\text { - Environmental }\end{array}$ & $\begin{array}{l}2 \% / \mathrm{s} \text { minimum } \\
\text { Automatic } \\
\text { Automatic } \\
\text { Standby power } \\
\text { Manual override }\end{array}$ \\
\hline
\end{tabular}




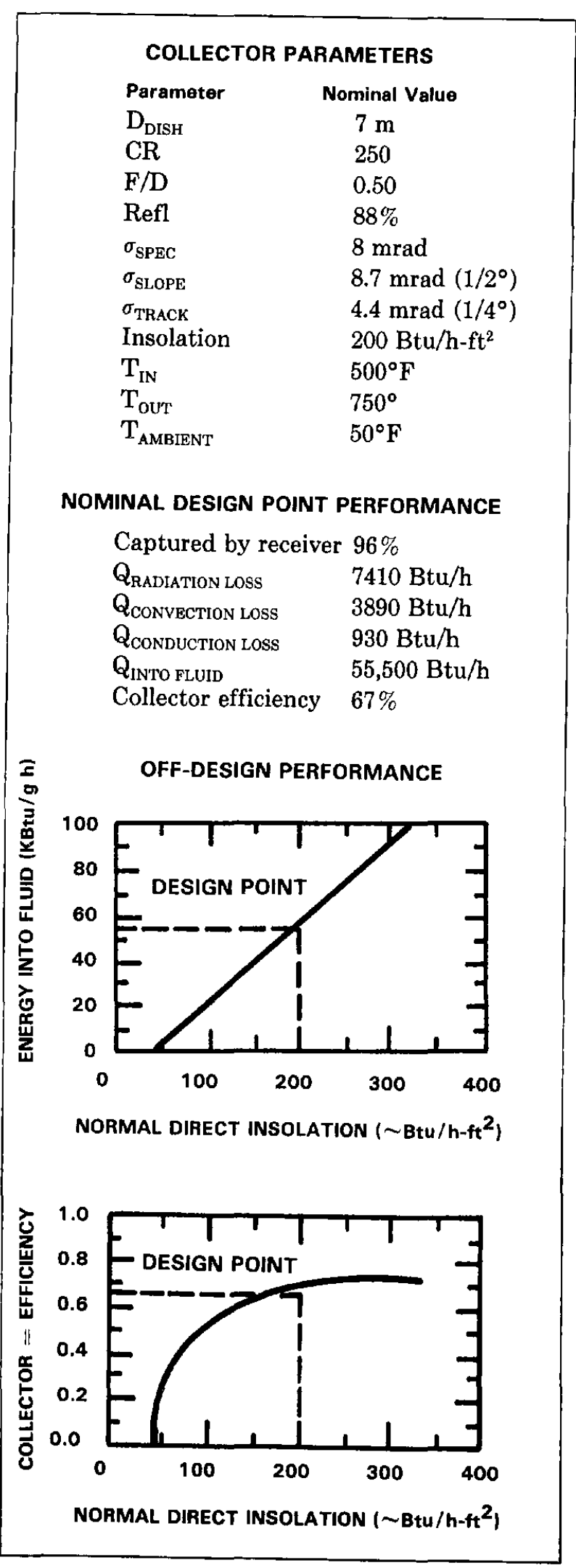

Figure 5. Nominal Collector Performance and Design Parameter

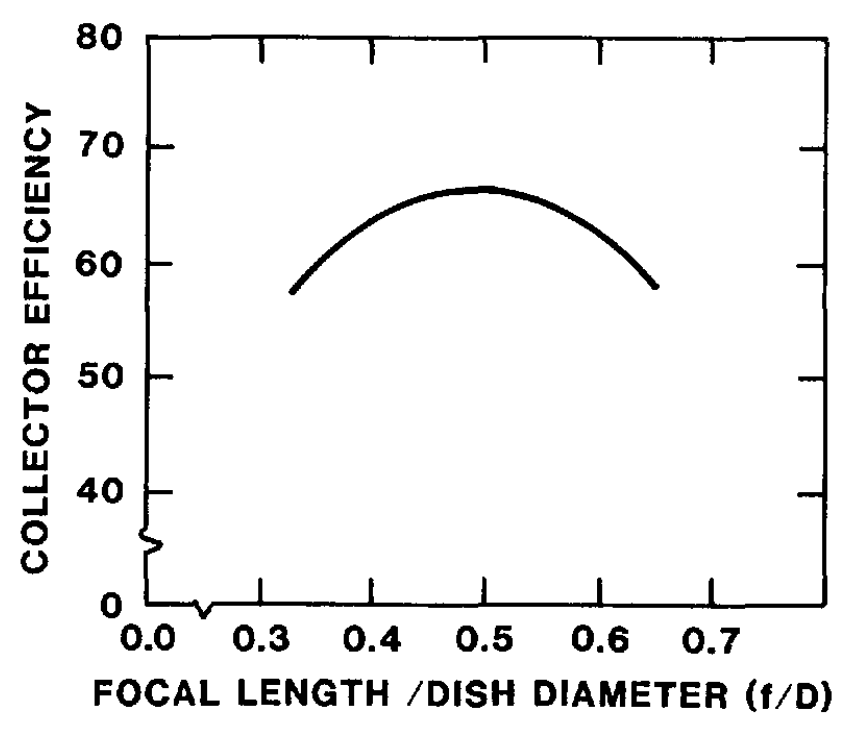

Figure 6. Focal Length Optimization

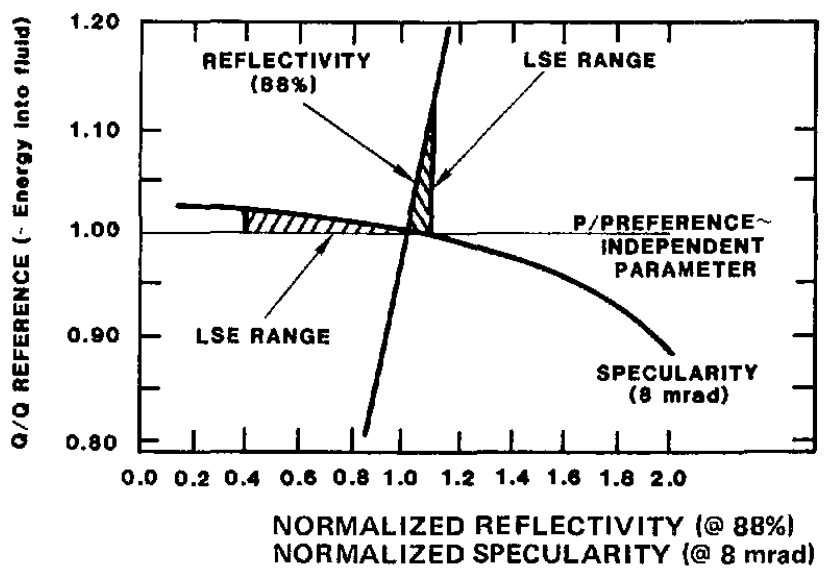

Figure 7. Reflector Surface Parameter Sensitivity Analysis

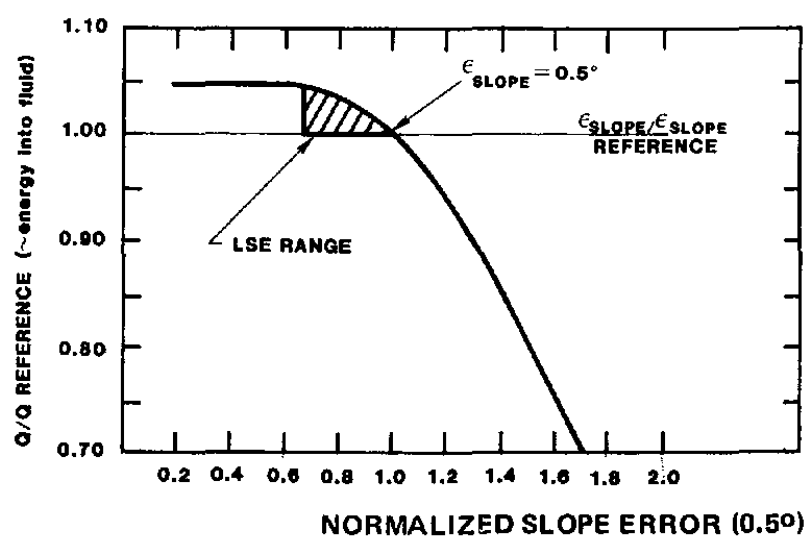

Figure 8. Slope Error Sensitivity Analysis 


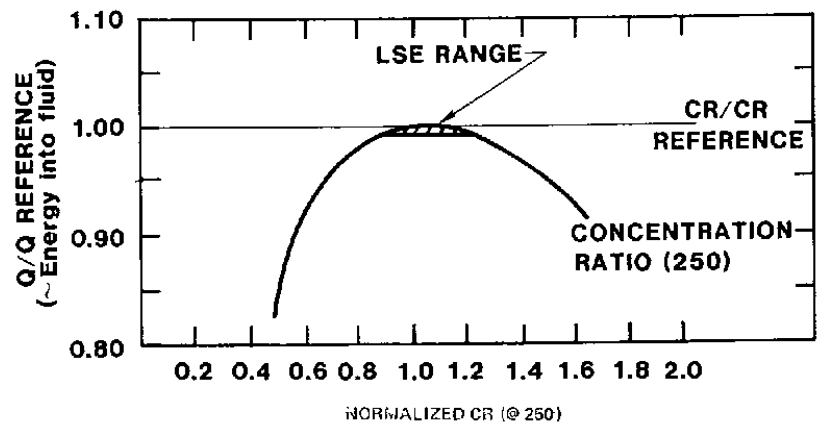

Figure 9. Concentration Ratio Sensitivity Analysis

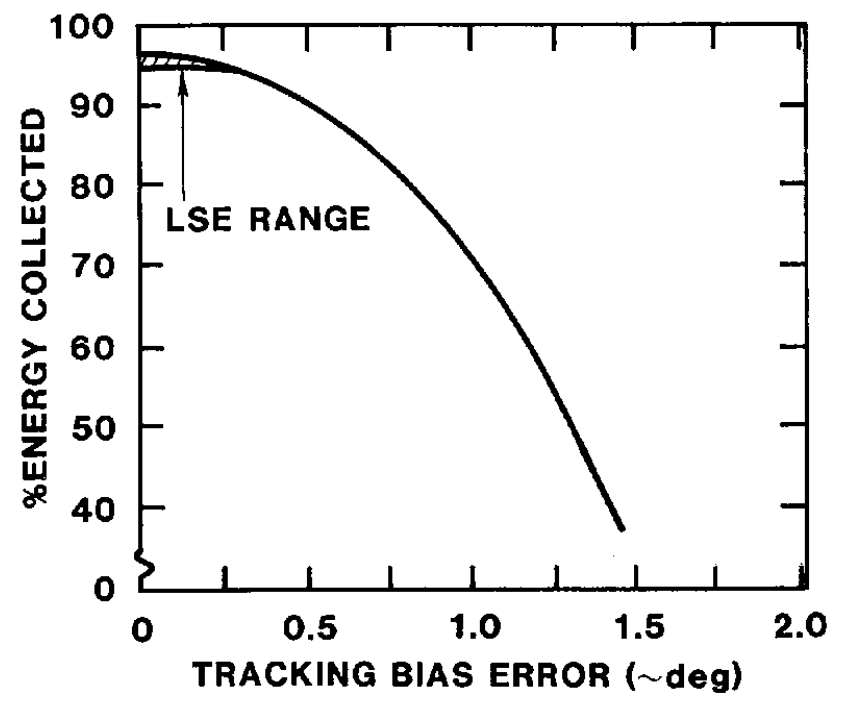

Figure 10. Tracking Bias Error Sensitivity Analysis

\section{Collector Diameter Optimization}

The diameter of the dish is the design parameter having the major effect on the field cost and performance of the collector. The basis for selection of the diameter was the energy delivered per day and the cost of the total collector field. The pipefield costs for the range of collector diameters examined did not affect costs and were an order of magnitude lower than collector costs. However, reducing pipefield losses had a dramatic effect on the energy collected and a significant effect on the collector diameter. This relationship is shown in Figure 11. Two alternatives were examined for reducing these losses. The first approach involved increasing the insulation thickness, which quickly lead to very large amounts to achieve any significnt heat loss reductions. The second approach was to reduce the pipe diameters and to nest the small up and down piping that connects to the collector receivers. Lower losses achieved, however, were at the expense of requiring greater pumping power. The relationship between pipe diameter and heat loss, including the pumping power increase treated as a thermal loss, is shown in Figure 12. The electrical pumping power was converted to thermal units using $33 \%$ conversion efficiency. The parametric data from the various pipefield studies were used to obtain data that show how the total collector-field energy parameters vary with the collector diameter (Figure 13). These data were then used to determine the cost per unit of energy delivered for various dish diameters (Figure 14).

Receiver performance largely determines collector performance, and the variation of collector performance relative to insolation is shown in Figure 15.

Structural analysis of the collector dish and mounts under wind and gravity loadings yielded the weight diameter relationship shown in Figure 16. For high production volumes, reflector and mount costs can be related to weight, and most important, the diameter increases proportionately to the collector weight, which results in a higher collector cost. The relationship between the estimated costs of the entire collector field and collector diameter (Figure 17) shows that the collector cost dominates the overall field costs.

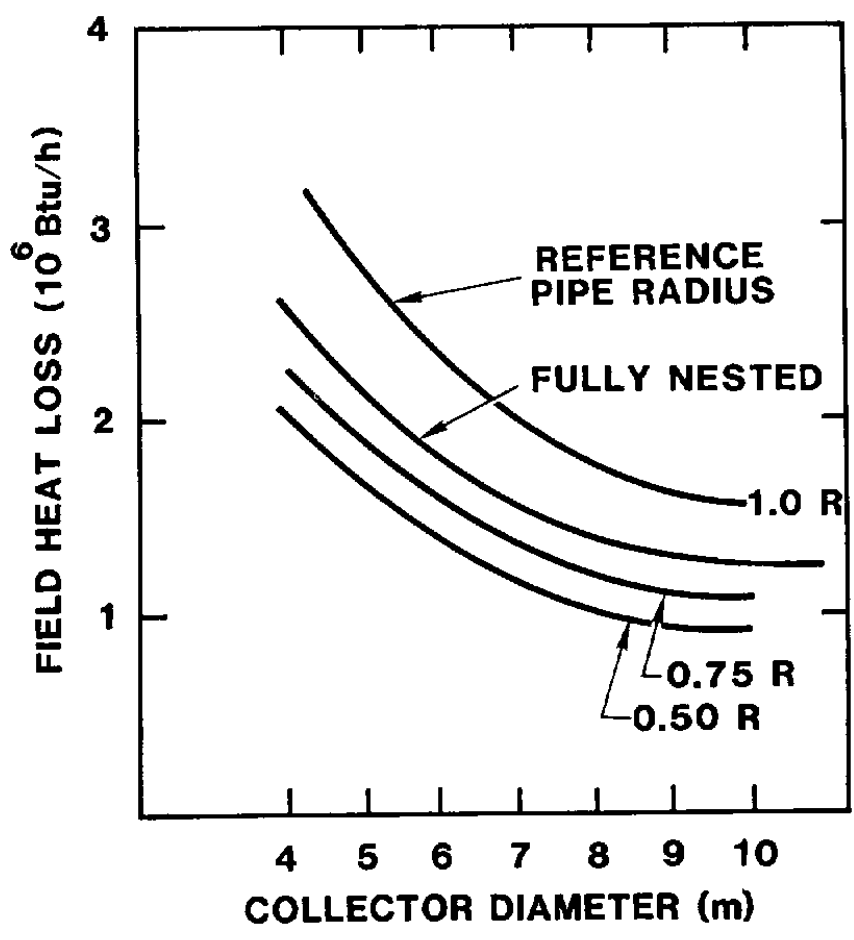

Figure 11. Variation of Steady State Heat Loss to Collector Diameter and Piping Radius 


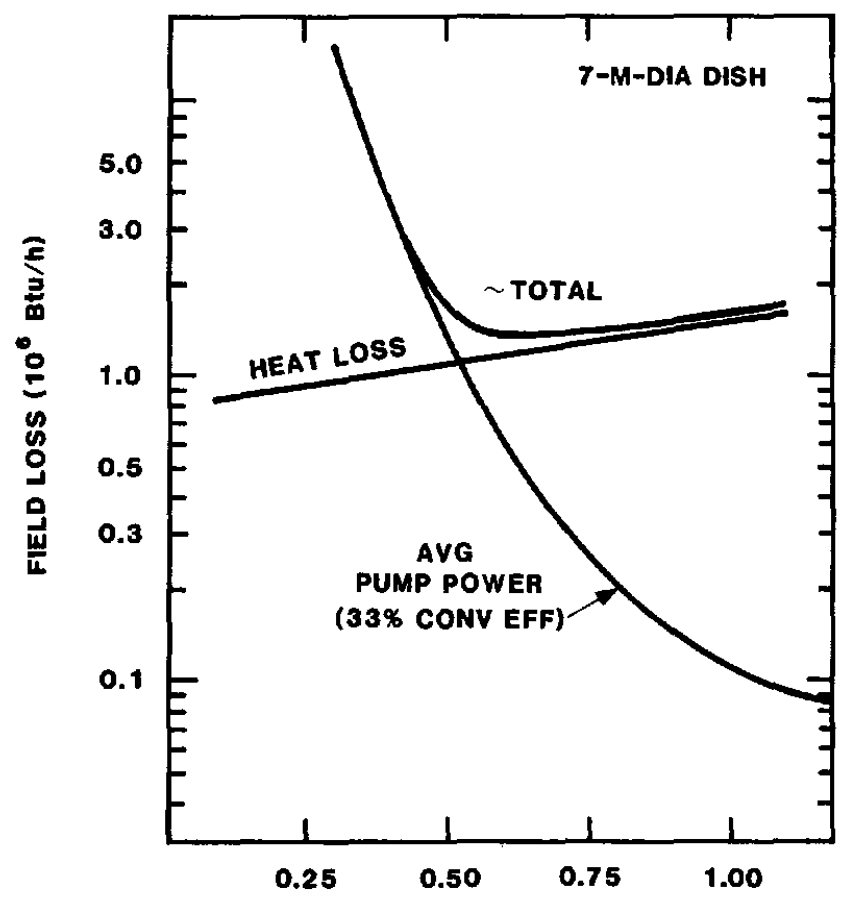

TUEING RADIUS REDUCTION FRACTION

Figure 12. Composite Steady State Heat and Pumping Power Losses vs Tubing Size

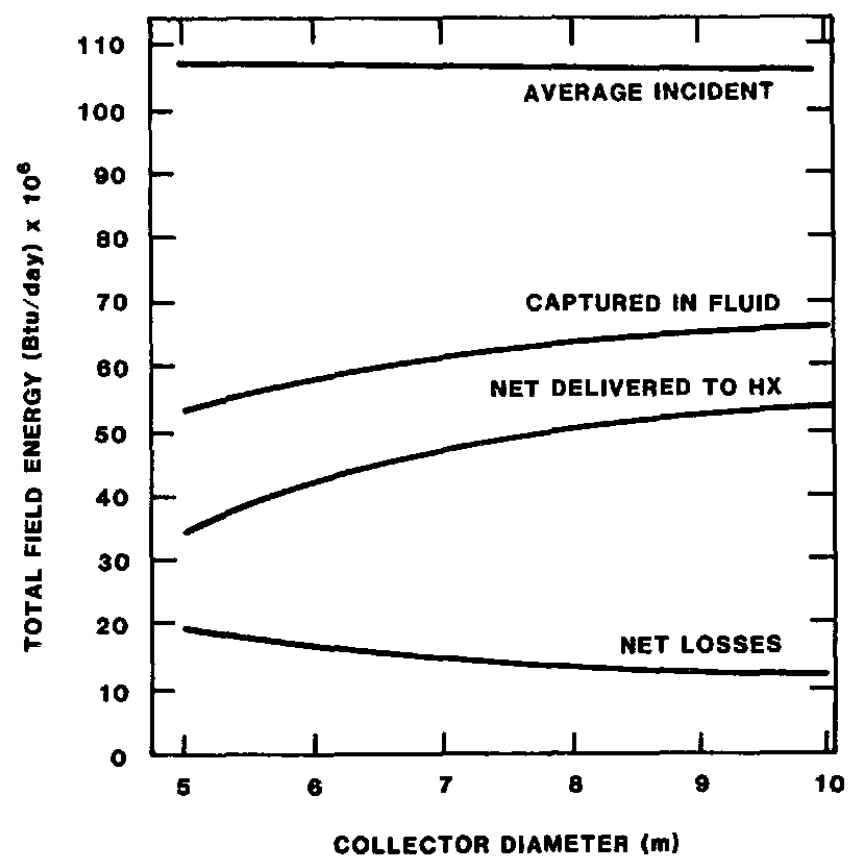

Figure 13. Daily Average Total Field Energy Parameter vs Collector Diameter

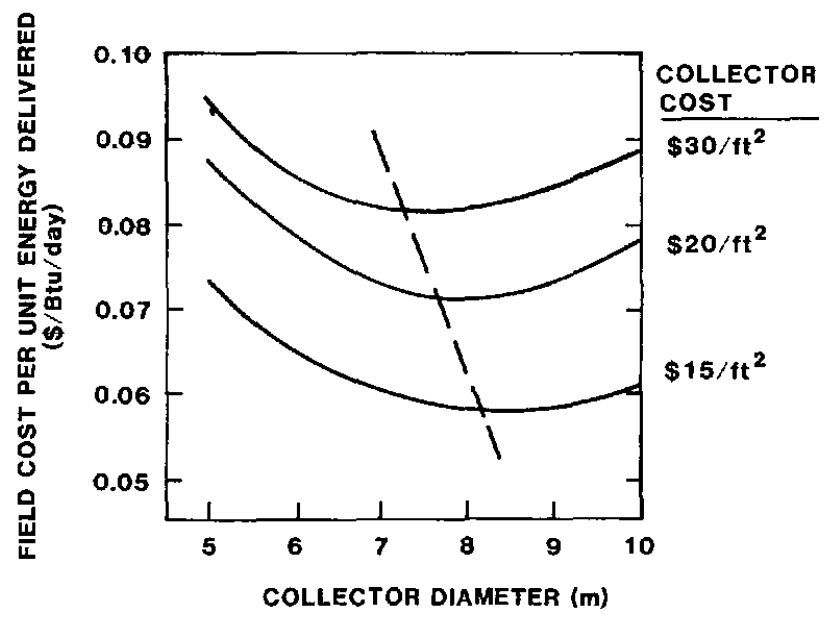

Figure 14. Optimization Results-Collector Diameter vs Cost/Btu Delivered

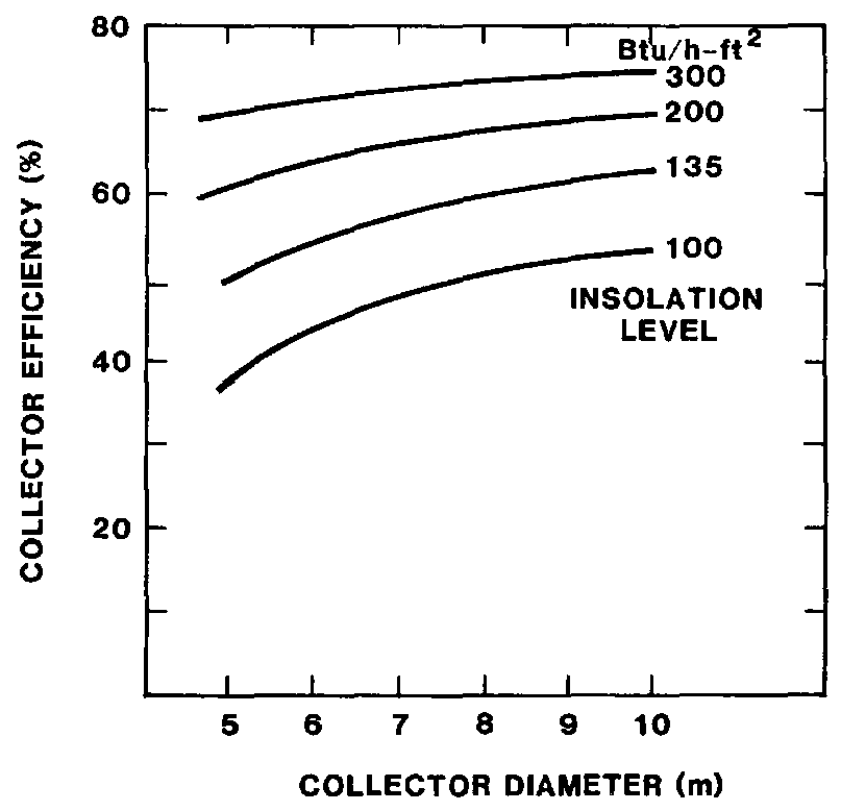

Figure 15. Collector Efficiency vs Diameter for Various Insolation Levels 


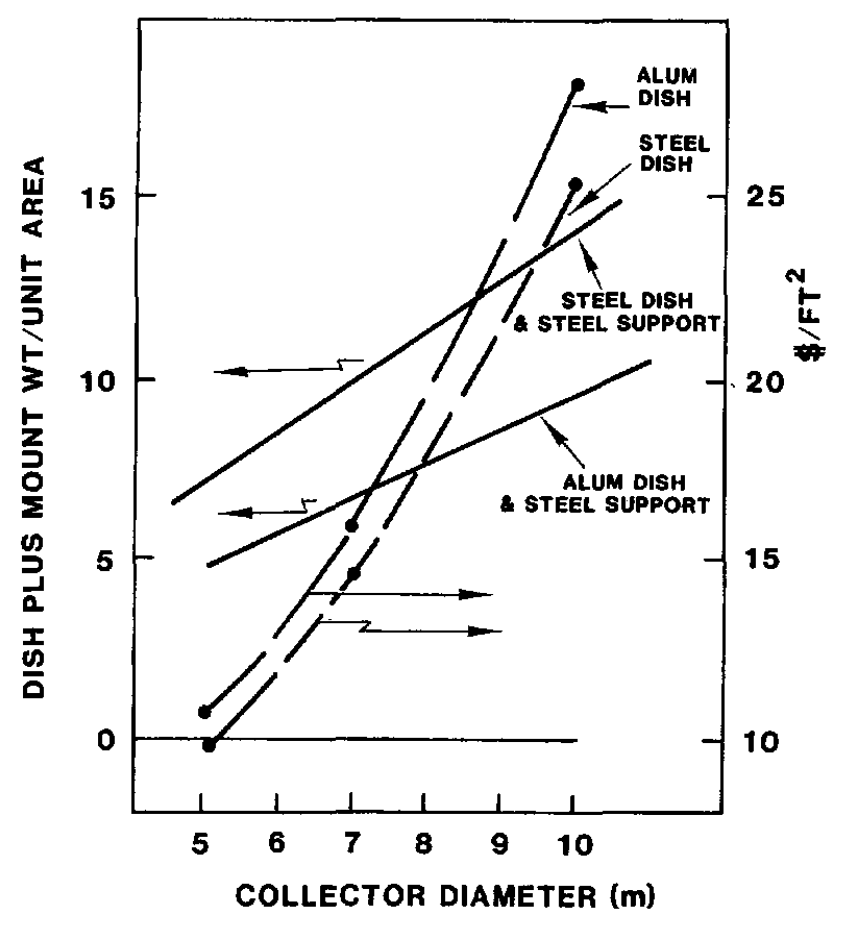

Figure 16. Total Collector Weight and Cost for Constant Structure Stiffness

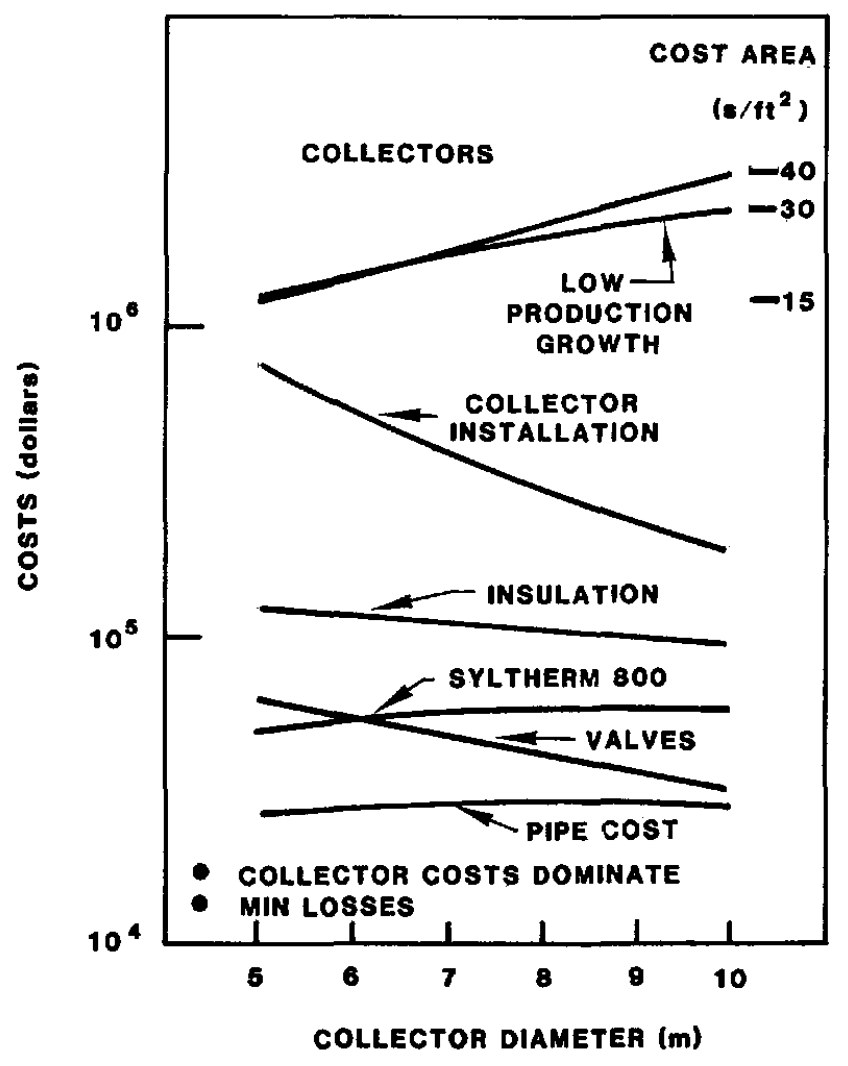

Figure 17. Collector Field Costs for 79,500-ft ${ }^{2}$ Array

\section{Collector Component Selection}

From the basic collector parameters established by the sensitivity analyses of the key collector variables, component requirements were established.

\section{Reflector}

For a system requirement of an operating temperature of $750^{\circ} \mathrm{F}$ (based on receiver concepts that were evaluated) the design requirement for a slope error of $0.5^{\circ} \mathrm{rms}$ did not preclude any of the fabrication techniques currently available. However, material options were quickly restricted to a choice between steel and aluminum because the Shenandoah schedule did not permit the pursuit of plastic or composite options for a reflector. In addition, the structural procedures followed for radio telescopes were not considered because the $0.5^{\circ}$ slope error did not warrant the cost associated with such highly accurate approaches. Fabrication was limited to sheetforming techniques using either steel or aluminum. Stainless steel was eliminated from consideration because its cost and weight would have added to structural demands on the collector. Because structural steel, although cheaper than aluminum, would require special processing to develop a reasonably reflective surface and because the cost of developing and implementing such a process would eliminate any cost savings that might be gained from its use, aluminum was selected as the reflector material.

of the sheet-forming techniques studied, the choices for the reflectors were narrowed to die stamping or stretch forming. Die stamping was chosen for its low cost ( 0.10 to $0.20 / \mathrm{ft}^{2}$ over material costs) when large quantities of reflector sections (such as for the Shenandoah STES) was being considered. Also, laserray tracing of available die-stamped parabolic radio antenna sections showed the presently available process was producing slope errors of $0.6^{\circ}$ to $0.7^{\circ} \mathrm{rms}$, closely approaching the $0.5^{\circ}$ required.

Reflector section support structures on the front and rear were considered. Because of lack of experience with the possible effects of front-side supports and potential scheduling problems, rear rib sections were adopted to provide the needed support.

For the reflecting surface, initial considerations focused on enhancing the aluminum surface itself. Laboratory tests indicated chemical and mechanical polishing of a strain-hardened magnesium alloyed aluminum would provide the reflectivity needed to achieve desired collector efficiencies. The original candidates for the proposed coating were silicone RTV and Alglas. The proprietary nature of Alglas precluded its use. As an alternative, anodizing of the 
aluminum surface was considered. Anodized samples indicated that enough surface reflectivity could be achieved to produce the efficiency needed. However, field tests for the two reflectors did not bear out the optimistic results of the laboratory. The RTV coating collected dust, insects, and other airborne materials that decreased the reflectivity and were difficult to remove. The special cleaning compounds and vigorous surface scrubbing required to remove the debris resulted in surface deterioration that prevented the achievement of original reflective levels by a few points. The time required to clean the anodized surfaces and the frequency of the cleanings made the use of an RTV-coated relfector prohibitively costly. Also, anodized surface reflectivity showed progressive degradation with exposure time- when tested in a freshly washed condition, the original level of $\sim 0.86$ (the maximum level achievable with the RTV coating) was found to have degraded to $\sim 0.6$ after a few months of exposure.

These results prompted investigations in the use of FEK-244, a reflective film produced by $3 \mathrm{M}$, which was, and still is, being used on parabolic trough collectors. Although $3 \mathrm{M}$ manually applied the film to a 5-m communications antenna to convert it to a solar collector for use by General Electric as a test concentrator, they did not recommend the procedure on a production basis because of the lack of historical information on the behavior of film on a compound curved surface; in addition, the labor involved in manually applying the film to the aluminum "petal" sections would have made the process expensive. The procedure developed for the Shenandoah collectors involved laminating the film to a flat aluminum substrate that was less costly than the magnesium alloy originally proposed, cutting the film for stress relief where the aluminum-film laminate was bent to provide rigidity, shearing the laminate to shape, and then die stamping the laminate into a parabolically contoured petal. Early-production petals were temperature cycled in a high-humidity chamber to obtain effects of temperature-humidity on the laminate. The FEK was found to "tunnel" after only a few cycles. (Tunneling is the formation of ridges at the edge of the film due to its expansion in a high temperature-high humidity environment.) Limiting the size of the film sections eliminated the tunneling. Therefore, the Shenandoah collectors have six film sections on each of the 21 petals that make up the reflector for a collector.

\section{Mount and Drive}

Three different mount and drive approaches were investigated to provide a 2 -axis tracking capability for the collector. These are shown in the sketches of Figure 18. The first is an adaptation of a pedestal-type tracking antenna that provides high slue rates and high pointing accuracy. The second is a modified approach (a drive mechanism is added) of a synchronous satellite antenna that uses low-cost structural members. The third is a cradle that uses a gear drive to rotate the shaft on which a reflector is suspended.
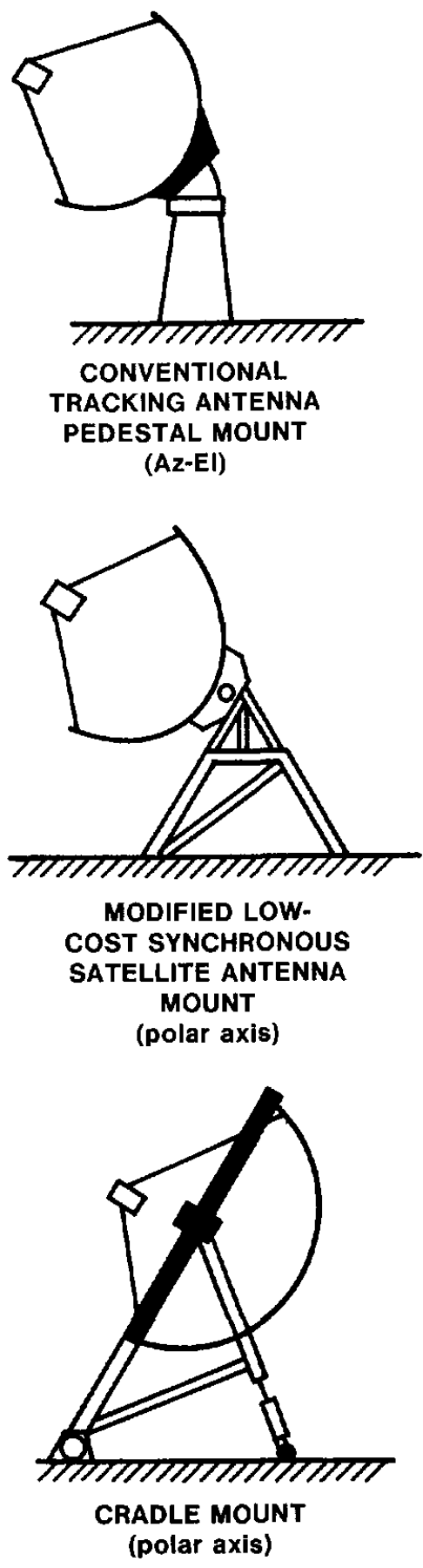

Figure 18. Candidate Mount Configurations 
The modified synchronous antenna approach was selected because the other two were not cost effective for the accuracy and tracking rates required or because they presented structural design challenges for overcoming bending movements and interference problems and appeared to offer no cost advantages over the selected approach.

The tracking drive selected was a linear drive using standard electrically operated jackscrew actuators. Trade-off studies indicated that gear drives and hydraulic systems were more expensive, and the hydraulic system did not have the required stiffness. The major drawback with jackscrews was the limitation in travel. However, by using them in tandem, the required polar rotation was achieved. The jackscrew was sized at 10 tons to withstand $60 \mathrm{mph}$ wind loadings while fully extended and $90 \mathrm{mph}$ wind loadings when retracted.

The stationary collector base frame assembly is a tripod mount bolted to a horizontal, triangular $\mathrm{H}$-beam frame that ties the three concrete foundation posts together. The posts are $5 \mathrm{ft}$ above grade to provide ground clearance of the reflector. To this rigid-base frame, a yoke structure is attached to provide polar rotation about an axis mounted on the frame assembly at the polar angle corresponding to the latitude angle of the site. Declination axis rotation is provided by pivoting the reflector assembly about an axis located on the yoke. When the collector is in the "stow" position $-90^{\circ}$ polar, $-23.5^{\circ}$ declination, which is toward the south and east) the reflector axis is almost $15^{\circ}$ below the horizon. In this position, the reflector surface is protected from hail damage.

Table 4 gives the drag, lift, and torque data for a 7 -m-dia dish collector subjected to a $40-\mathrm{m} / \mathrm{s}(90-\mathrm{mph})$ wind. During operation, winds of $13 \mathrm{~m} / \mathrm{s}(30 \mathrm{mph})$ must be survived. Structural deflections must be held to $0.125^{\circ}$ to meet the $0.25^{\circ}$ tracking error allowable for energy capture in the receiver. To meet this requirement, the collector structure must be relatively stiff.

The collector reflector is counterbalanced by a counterweight to keep the tracking drive motor size as small as possible. A $910-\mathrm{kg}$ (2000-lb) concrete casting is used for this purpose. The tracking motor that drives the reflector assembly is $1 / 10 \mathrm{hp}$. The ac motor was selected on the basis of torque (140 in.-lb), speed ( $40 \mathrm{rpm}$ to obtain a minimum $0.1 \%$ ), and service life $(4000 \mathrm{hr}$ over $20 \mathrm{yr}$ ) requirements. The low power requirement permits the use of relays rather than magnetic starters for control purposes.

The use of two jackscrew assemblies in tandem to drive the reflector through the full range of polar rotation also permits both drive motors to operate at the same time to double the rotational speed to $0.2^{\circ} \%$ from the normal tracking speed of $0.1 \% \mathrm{~s}$. Accelerated movement of the collector is needed when emergency stowing is required because of imminent storms or when receiver aperture plate heating must be reduced while the collector is coming into or out of focus.

\section{Receiver}

Of the many configurations analyzed, the cavitytype receiver was selected for the Shenandoah dish collector because it provided lower radiative losses and reduced convective losses over the other designs. Even though it was larger and more expensive, the performance-to-cost ratio was the highest of any design studied. Figure 19 shows the flux profiles for various $f / D$ ratios assuming a total error of $1^{\circ}$. The $1^{\circ}$ error would arise from manufacturing tolerances, specularity of the reflector, deflection of the structure, and control system errors. Generally, lower errors result in higher concentration ratios, smaller permissible receiver apertures, and attendant lower losses, but the higher concentrated flux level causes increasing difficulties related to fluid protection from high temperatures. A $1^{\circ}$ error leads to reasonable receiver sizes and performance and is consistent with accuracies obtainable from low-cost, stamped-petal dish construction.

Figure 20 shows the capture percentages for $\mathrm{f} / \mathrm{D}$ ratios between 0.4 and 0.7 as a function of the concentration ratio (ratio of dish area to receiver aperture area).

The distribution of the flux intensity along the receiver coil for a cavity receiver is shown in Figure 21.

The piping considerations for the receiver led to an investigation of a Cassegrainian secondary reflector configuration that would allow the receiver to be placed at the vertex of the parabolic reflector. This configuration would result in a simpler piping routing and reduced structural stiffness requirements on the collector because the secondary reflector would weigh much less than a receiver. But the loss in energy due to the additional reflection and larger convective losses due to the upward facing receiver cavity mouth (or, if covered with a transparent material, the larger transmission loss) outweighed the reduction in piping loss with the Cassegrainian configuration.

The requirements established for the collector that directly influence the receiver design are

1 . The dish slope error $\left(0.5^{\circ} \mathrm{rms}\right)$, which determines the flux levels impinging on the receiver coil

2 . The concentration ratio $(\sim 250)$, which determines the energy intensity and aperture size

3. The pressure drop (5 psi) and differential temperature between the film and bulk fluid $\left(100^{\circ} \mathrm{F}\right)$, which determines the coil configuration and tube sizing 
Table 4. Parabolic Dish Forces/Moments in 90-mph Wind

Wind Force on solid surface paraboloid reflector based on JPL wind tunnel tests. (Program revised $2 / 2 / 77$.)

Model Number

Reflector Diameter

Reflector f/D Ratio

Vertex Axial Offset

Vertex Radial Offset

Pivot Axis to Ref Plane

Ambient Temperature

Wind Velocity

Dynamic Pressure
GE Solar Pedestal

$22.97 \mathrm{ft}$

0.5

$.0 \mathrm{ft}$

$.0 \mathrm{ft}$

$.0 \mathrm{ft}$

$68^{\circ}$

$90 \mathrm{mph}$

$20.4 \mathrm{lb} / \mathrm{sq} \mathrm{ft}$

\begin{tabular}{|c|c|c|c|}
\hline $\mathrm{O}$ & $\mathrm{T}$ & D & $\mathrm{L}$ \\
\hline $\begin{array}{c}\text { Reflector Axis } \\
\text { From Wind } \\
\left({ }^{\circ}\right)\end{array}$ & $\begin{array}{c}\text { Torque About } \\
\text { Pivot Axis } \\
\text { (lb-ft) }\end{array}$ & $\begin{array}{c}\text { Drag } \\
\text { (lb) }\end{array}$ & $\begin{array}{l}\text { Lift/Side } \\
\text { Force } \\
\text { (lb) }\end{array}$ \\
\hline 0 & 0 & 12664 & 0 \\
\hline 10 & -2230 & 12411 & -2111 \\
\hline 20 & -4945 & 11486 & -4390 \\
\hline 30 & -6981 & 10730 & -6585 \\
\hline 40 & -9696 & 9361 & -8443 \\
\hline 50 & -12314 & 8089 & -10384 \\
\hline 60 & -24090 & 6060 & -12073 \\
\hline 70 & -7692 & 4047 & -10131 \\
\hline 80 & 12196 & 2133 & -4643 \\
\hline 90 & 20136 & 1492 & 0 \\
\hline 100 & 19533 & 2080 & 3208 \\
\hline 110 & 17916 & 1980 & 422 \\
\hline 120 & 19080 & 2421 & 422 \\
\hline 130 & 18660 & 3264 & 1351 \\
\hline 140 & 15040 & 4779 & 2026 \\
\hline 150 & 11161 & 6020 & 2111 \\
\hline 160 & 8834 & 7340 & 1773 \\
\hline 170 & 5667 & 8817 & 1098 \\
\hline \multirow[t]{3}{*}{180} & 0 & 9118 & 0 \\
\hline & & & \\
\hline & D & & \\
\hline ropulsion I & & & \\
\hline
\end{tabular}




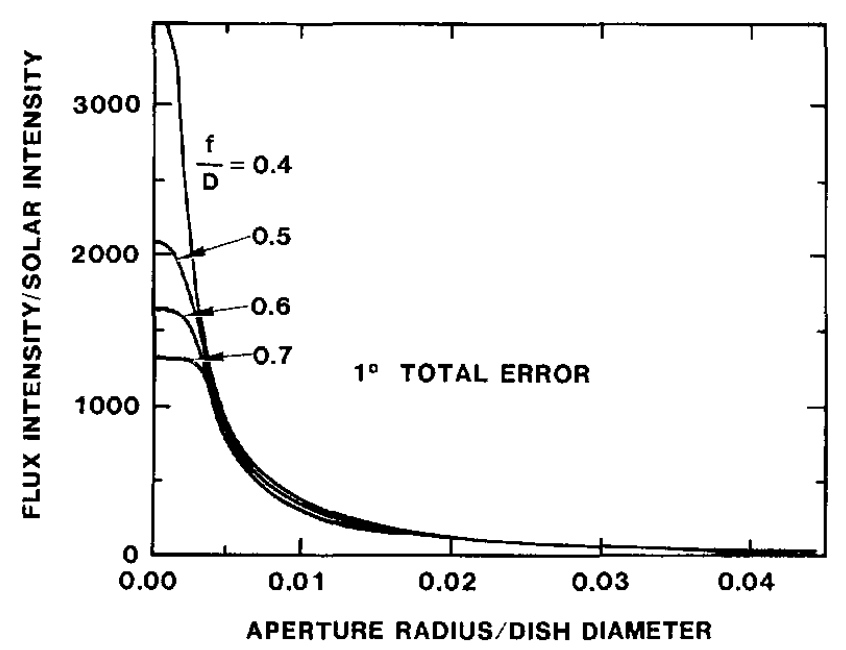

Figure 19. Receiver Flux Profiles

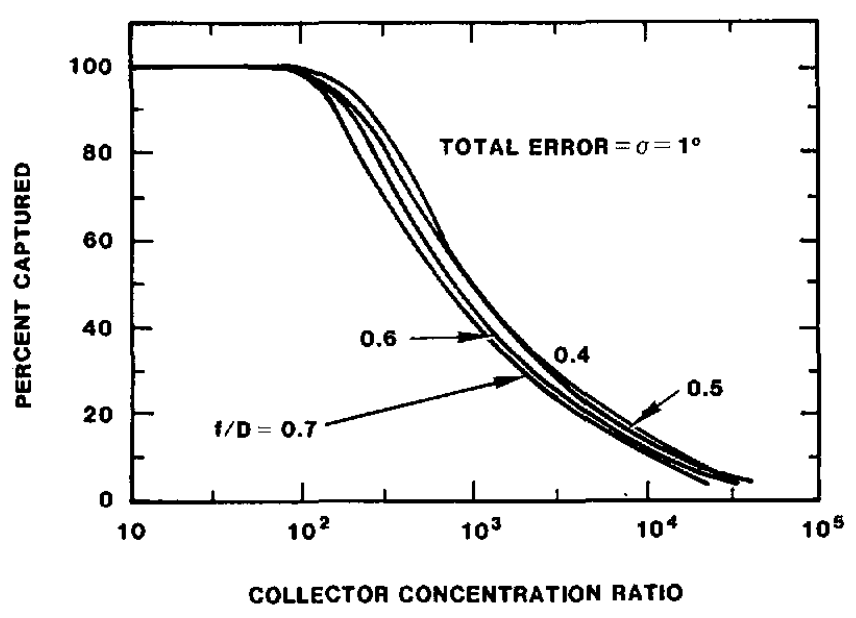

Figure 20. Integrated Receiver Flux Profiles

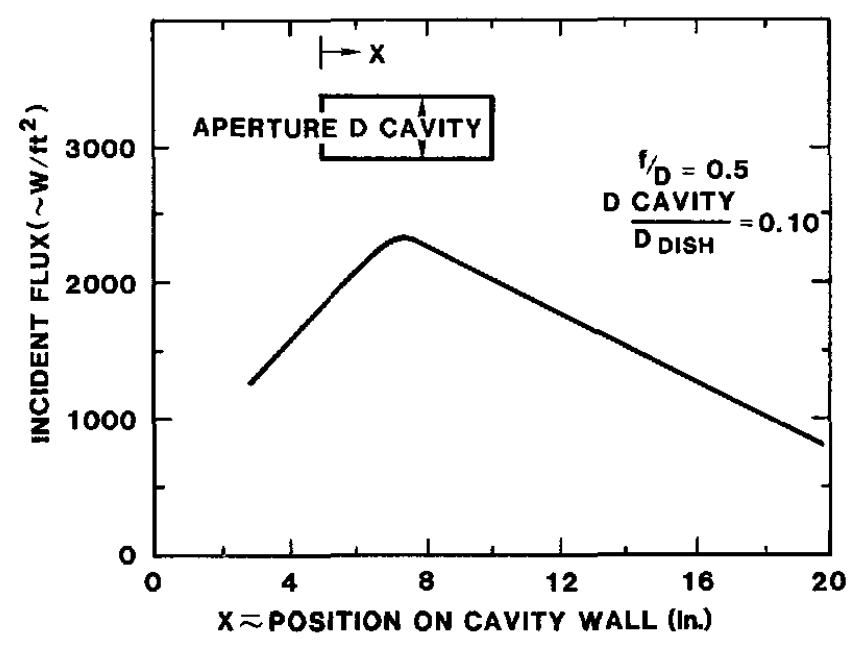

Figure 21. Typical Cavity Wall Flux Profile
Figure 22(a) shows the relationship between the peak flux impinging on the cavity wall and the receiver coil diameter. Figure 22(b) shows the relationship which exists between the receiver coil diameter, the tubing diameter, and the film coefficient for a differential temperature of $100^{\circ} \mathrm{F}$ between the wall and . fluid.

Figure 23 shows the relationship between the tube diameter, the coil diameter, and the pressure drop.

Figures 24(a) and 24(b) show the relationship between the coil diameter and the pressure drop for a single coil and for a parallel twin coil. As indicated, the diameter required for a single-pass receiver coil is much larger than for a twin-pass. The initial receiver design was based on a twin-coil configuration to minimize the overall receiver size, but test results dictated the use of the single-pass design. Tests of the twin-coil receiver produced anomalous results indicating a difficulty in establishing equal flow in the two tubes, leading to unequal fluid conditions in the two paths. Some results indicated conditions associated with laminar fluid flow, and others indicated fluid boiling.

The coil material was originally designated to be low-carbon steel. However, the possible embrittlement of carbon steels from prolonged exposure to elevated temperatures prejudiced its use, and stainless tubing was specified. The coil was finalized at a length of $210 \mathrm{ft}$ of 0.5 -in. outside diameter tubing with a wall thickness of 0.035 in. Pyromark ${ }^{\circledast}$ paint was used to enhance the absorptivity of the receiver coil $(\alpha=$ 0.90). Thermal losses for the receiver for temperatures between $700^{\circ}$ and $775^{\circ}$ are shown in Table 5. 


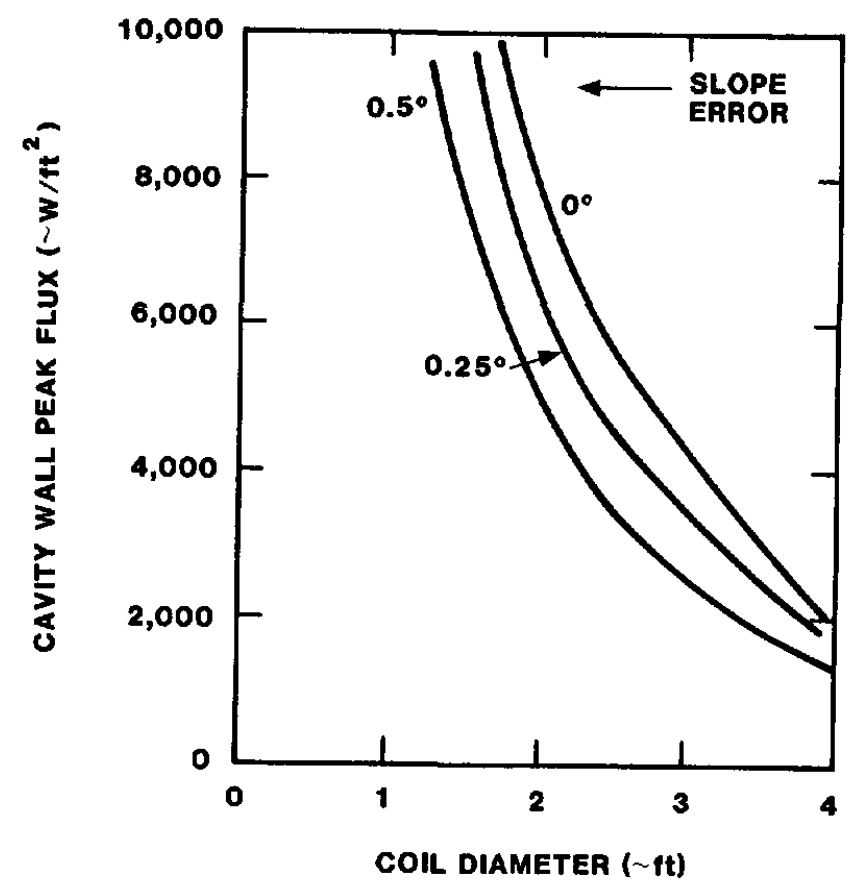

(a) FLUX LEVELS
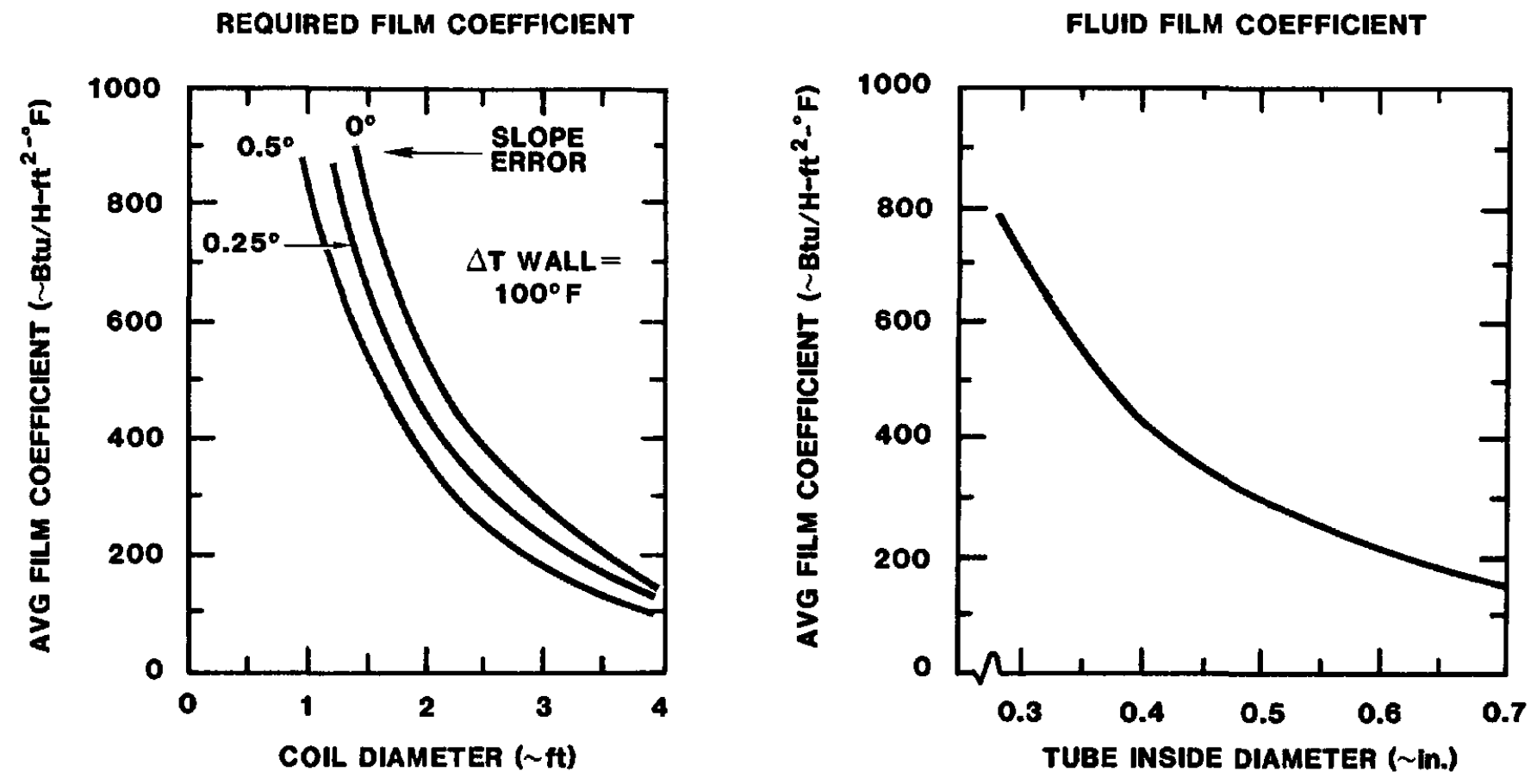

(b) FILM COEFFICIENT MATCHING

Figure 22. Receiver (a) Design Flux Levels and (b) Film Coefficient Matching 

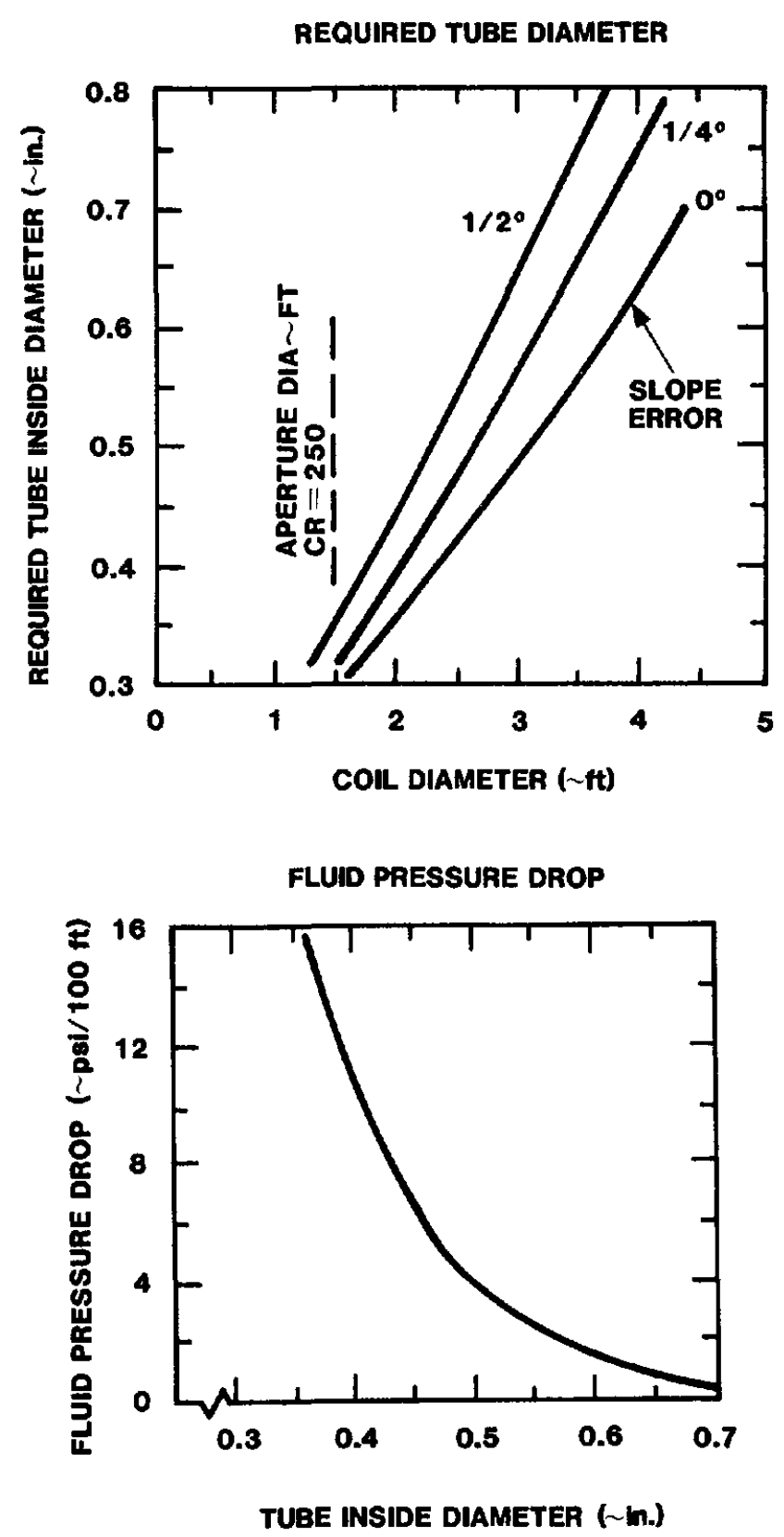

Figure 23. Receiver Tube Sizing/Pressure Drop Relationship

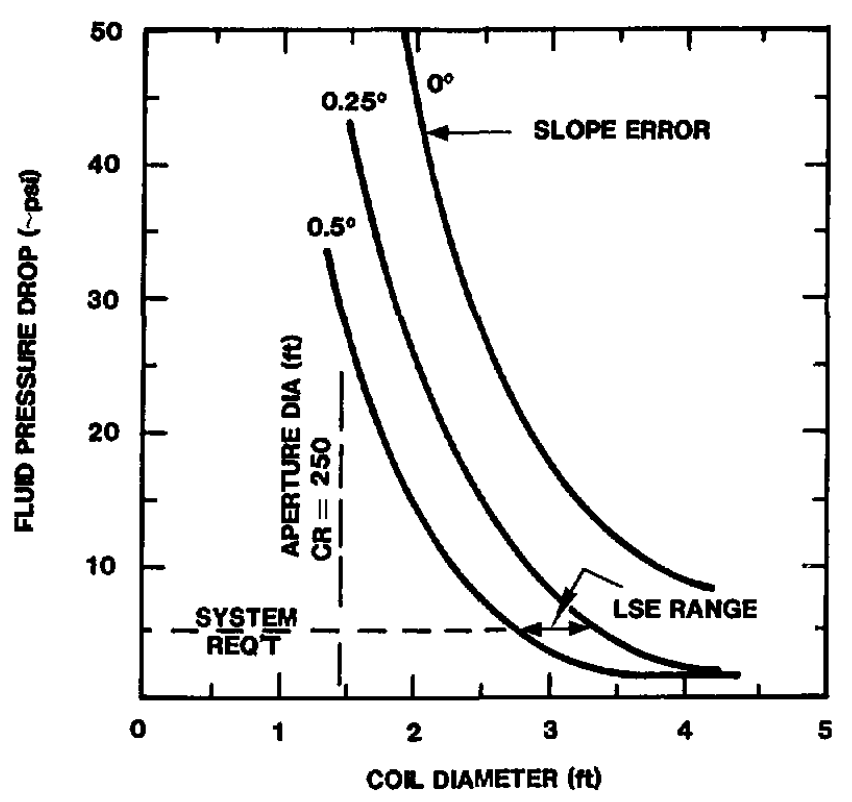

a. Single Coil

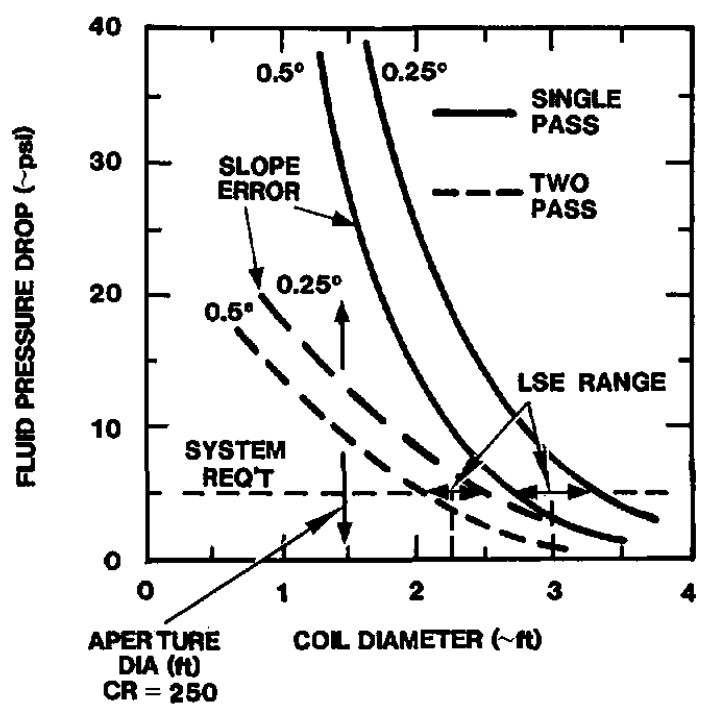

b. Parallel Twin Coil

Figure 24. Relationship Between Coil Diameter and

Pressure Drop for (a) Single Coil and (b) Parallel Twin Coil 


\section{Table 5. Receiver Thermal Performance (Horizontal Attitude)}

\begin{tabular}{|c|c|c|c|c|}
\hline \multirow[b]{2}{*}{$\begin{array}{l}\text { Outlet } \\
\text { Temp } \\
\left({ }^{\circ} \mathrm{F}\right)\end{array}$} & \multicolumn{3}{|c|}{ Thermal Losses } & \multirow[b]{2}{*}{$\begin{array}{c}\text { Total } \\
Q_{\text {loss }} \\
(\mathrm{Btu} / \mathrm{h})\end{array}$} \\
\hline & $\begin{array}{c}\mathrm{Q}_{\mathrm{rad}} \\
(\mathrm{Btu} / \mathrm{h})\end{array}$ & $\begin{array}{c}\mathrm{Q}_{\text {conv }} \\
(\mathrm{Btu} / \mathrm{h})\end{array}$ & $\begin{array}{c}\mathrm{Q}_{\text {cond }} \\
(\mathrm{Btu} / \mathrm{h})\end{array}$ & \\
\hline 775 & 8199 & 4104 & 963 & 13266 \\
\hline 750 & 7410 & 3933 & 926 & 12269 \\
\hline 725 & 6676 & 3762 & 889 & 11727 \\
\hline 700 & 5995 & 3591 & 853 & 10439 \\
\hline
\end{tabular}

\section{Collector Control}

Tracking system options considered were

- Closed loop tracking

- Open loop computer drive

- Hybrid (a combination of closed loop and open loop)

The open loop system requires precise fiducial alignment and position indications beyond those that can be achieved from low-cost production methods. The closed loop system was judged to be far more compatible with the collector for providing the required tracking accuracies. However, the need to provide initialization for the closed loop tracker as well as cloud cover tracking, emergency shutdown, and other control functions made the hybrid system a logical selection for the collector control system.

The Shenandoah hybrid tracking system combines computer tracking with optical sensors to provide a precisely focused collector. The computer drives the collector to a calculated position based on a programmed ephemeris sun position algorithm. Tracking is then transferred to the optical system when the reflected solar image on the receiver is approximately $1^{\circ}$ off-axis. The optical tracker then positions the collector for the receiver to accept the maximum reflected energy. The closed loop tracker maintains the position accuracy to within $6 \mathrm{mrad}$ $\left(\sim 0.25^{\circ}\right)$.

The advantage of such a tracking system over a computer-only or a clock-drive tracking system is that the mechanical stiffness and precise position and orientation of the collector is not critical to tracking accuracy.
The effect of random tracking errors on the collector efficiency is shown in Figure 25. Its effect when held to around $0.25^{\circ}$ is found to be relatively small compared with the effect of a $0.5^{\circ}$ collector-slope error.

The operating principle of the optical tracking system is illustrated in Figure 26. Four sensors located $90^{\circ}$ apart on the receiver aperture provide differential signals for the polar and declination controls. The fiber-optic specifications are given in Table 6.

The optical tracking system is aligned initially by manually bringing the receiver into focus by observing that the reflected solar image on the receiver is symmetrically positioned. The two polar and the two declination axis sensors are adjusted to make each sensor amplifier output voltage equal in magnitude. This adjustment is an iterative process that requires manually updating the collector to keep it in focus while the sensor amplifier outputs are equalized.

The computer tracking position indications are sensed by precision potentiometers that possess high linearity. Both polar and declination position potentiometers are set to provide a mid-position indication when the collector is rotated to its solar noon position at equinox. Then, using the sun position algorithm in the computer, the position indications are correlated with the time-of-day angular position of the collector as it tracks the sun by using the fiber-optic tracking system. When cloud cover obscures the sun, the computer tracking system positions the collector to reacquire the sun by updating its position based on the sun position algorithm in the computer. The on-off control operation during computer tracking is shown in Figure 27. 


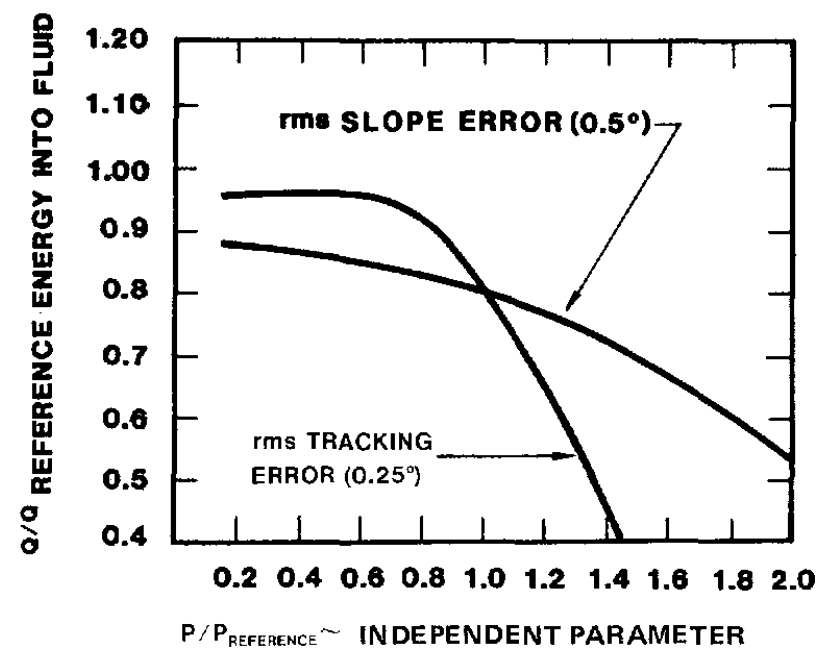

Figure 25. Tracking Error Sensitivity

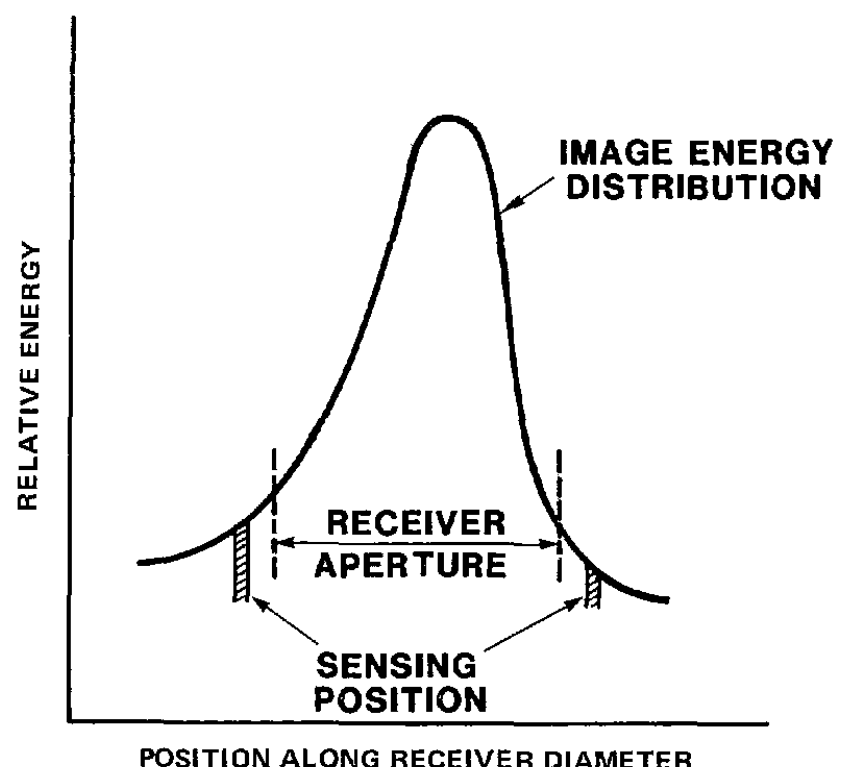

Figure 26. Optical Sensors Positioning

Figure 25. Tracking Error Sensitivity

\section{Table 6. Optical Sensor Specifications}

Fiber Bundle

No. of Fibers

- $\quad$ Glass

Size of Fiber

Size of Bundle

Assembly

Trans/ft

End Loss

Length

Temperature Limits
- $\quad 40$

$-\quad .033^{\prime \prime}$

- $\quad 3 / 16^{\prime \prime}$ dia

- $\quad 4$ each

-
$-\quad .96$

$-\quad 8 \%$

- $\quad 8^{\prime}$ 


\section{Collector Tests}

\section{Engineering Prototype Collector (EPC)}

A 5-m communications antenna manufactured by Scientific Atlanta was converted into a solar collector by adding reflective film (FEK-244), a cavity receiver that replaced the Cassegrainian reflector at the focal point, and a drive mechanism, and by integrating a closed loop tracking unit. The diameter of the reflective area was masked off to reduce it to obtain an f/D ratio of 0.5 , which had been selected as optimal for the Shenandoah dish.

This EPC (Figure 28) was tested at Sandia's Collector Module Test Facility to

- Measure and characterize the performance of a parabolic dish collector

- Verify and update the analytical and design tools used to design the Shenandoah dish

- Determine the mechanical operation and the control operation of a 2-axis tracking antenna using hardware representative of that specified for Shenandoah

The receiver was constructed from stainless steel tubing, 7/16 in. in diameter by $86 \mathrm{ft}$. in length, which was coated with an absorptive oxide to increase the absorptivity to 0.9 . The receiver wall and aperture plate were covered with a porcelain coating to enhance the surface reflectivity. A ceramic insulation blanket was used to reduce thermal losses. The receiver was highly instrumented with thermocouples to provide the desired thermal data. The coil assembly is shown in Figure 29.

The EPC incorporated a hydraulic actuator as part of its support system to permit rapid defocusing of the collector. The opening of a valve, upon command, would allow the dish to quickly defocus by $10^{\circ}$. Any loss of flow or over-temperature signal would trip the defocusing valve.

Collector tracking was controlled by computer, sun sensor, or timer. Collector position was determined from potentiometers mounted on the azimuth and elevation axes. Manual override of the automatic control systems was provided to permit driving the collector to any desired elevation and azimuth position.
A hydrocarbon heat transfer fluid, T-66, was used in these tests to obtain an outlet temperature of $600^{\circ} \mathrm{F}$. Although this was less than the $750^{\circ} \mathrm{F}$ operating temperature designated for the Shenandoah STES, it was felt that $600^{\circ} \mathrm{F}$ would provide an adequate temperature for diagnostic purposes.

Before testing was started, a solar flux profile was obtained to determine the flux distribution at the focal plane. Both N-S and E-W profiles were obtained (Figure 30). Figure 31 shows the integrated flux that would be intercepted by the 12 -in. aperture of the receiver. The $83 \%$ intercept factor is lower than that predicted for a reflective surface slope error of $0.5^{\circ}$, indicating that this communications dish antenna had a slope error $>0.5^{\circ}$. This error was confirmed later when laser-ray tracing of the reflector surface indicated a slope error approaching $0.7^{\circ}$. Also contributing to the lower intercept factor was the displacement of the receiver aperture location from the focal plane predicted by the $\mathrm{f} / \mathrm{D}$ value of 0.5 . It was found that the focal plane should have been approximately 2 in. closer to the vertex of the dish.

Tests were conducted to determine the thermal losses from the receiver. Heated T-66 fluid was circulated through the coil, and the flow rate and exit temperatures were measured for various T-66 inlet temperatures. Measured losses were greater than predicted. Thermocouple data indicated convection losses were higher than the performance model predictions. The results are shown in Figure 32. Note the effect of covering the aperture, which indicates the contribution of the convective loss component to the total. A wind skirt was added to the collector to reduce its effect on convective losses. The wind-skirted receiver is shown in Figure 33.

During the test period, the EPC collector sustained damage when travel limit switches were compromised to permit overtravel of the collector to a position that would allow in situ laser-ray tracing of the reflector. Unfortunately, testing was interrupted because of damage to portions of the collector. The sun-tracker had been removed and left lying on the ground, but power to the collector had not been disengaged at the end of the day. Because the collector was set to operate in the automatic tracking mode, the 
next morning it responded to the sun-tracker signals, causing the jackscrews to be driven off the threads and the reflector structure to pivot on the mount and strike the ground. Four petal sections, a jackscrew, and motor and structural welds were damaged.
Repairs were effected and testing was resumed in 2 weeks.

The results of the testing of the EPC were incorporated into the succeeding collector design.

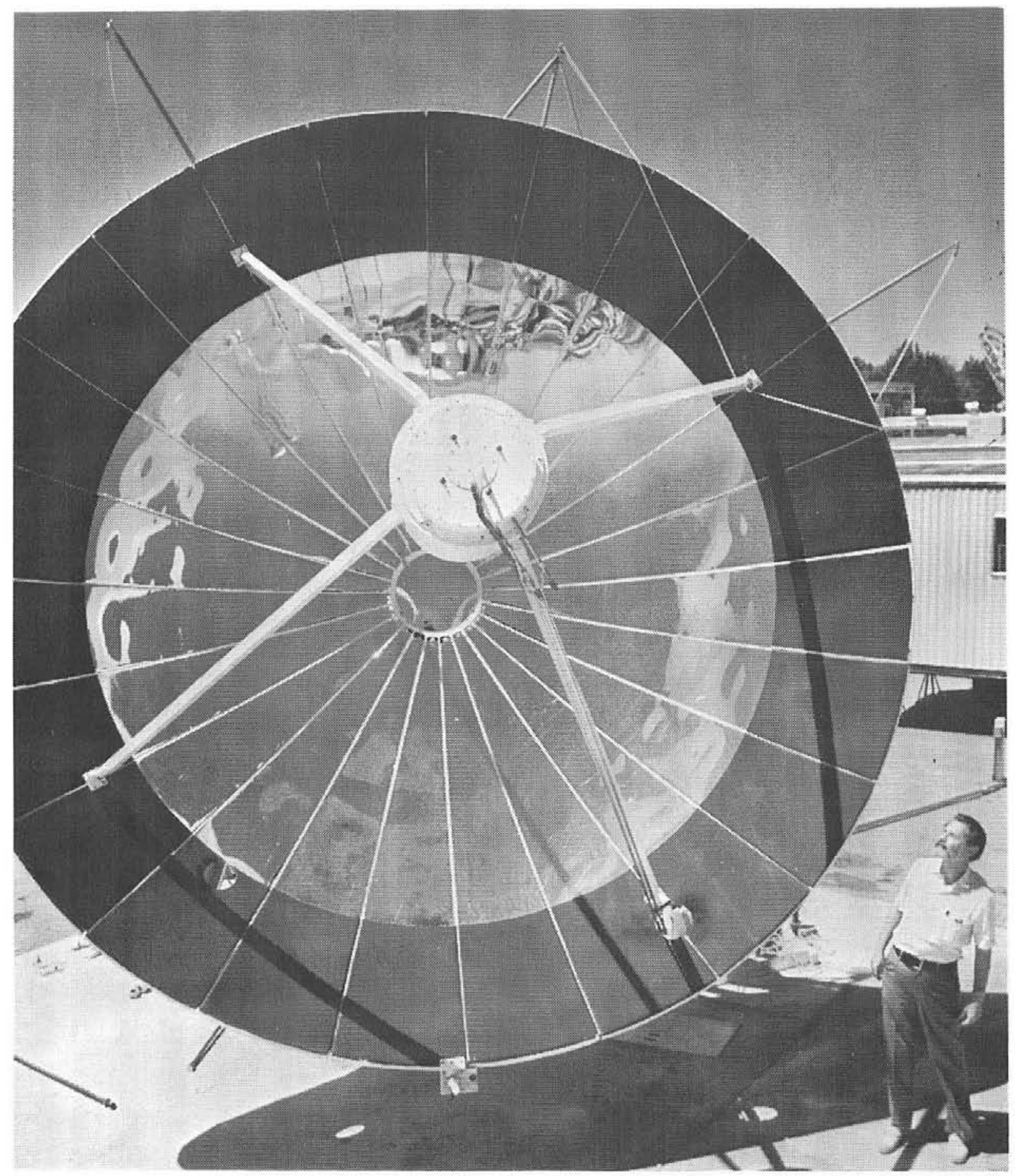

(a)

Figure 28. Engineering Prototype Collector-(a) Front View and (b) Side View 


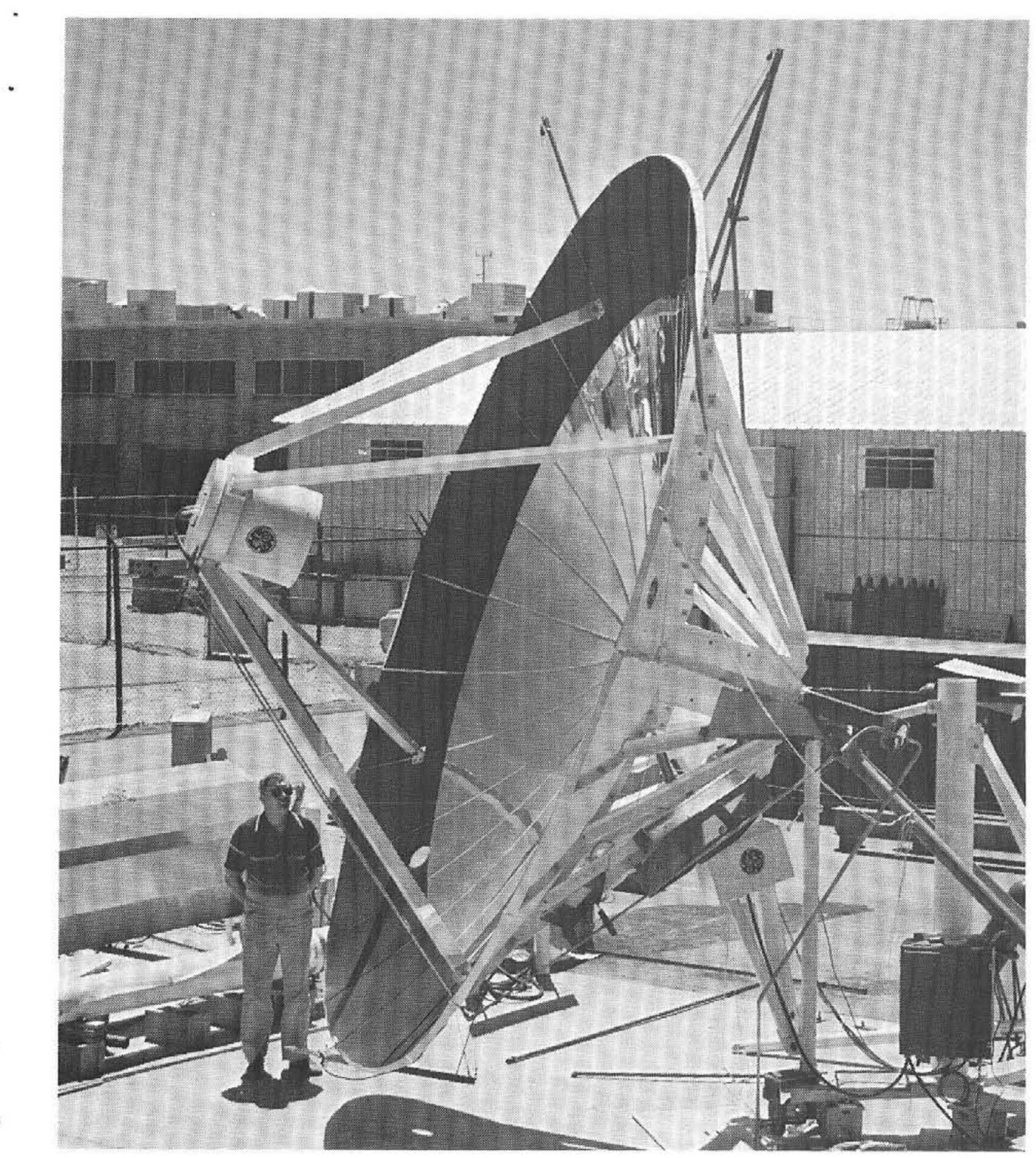

(b)

Figure 28. Continued 


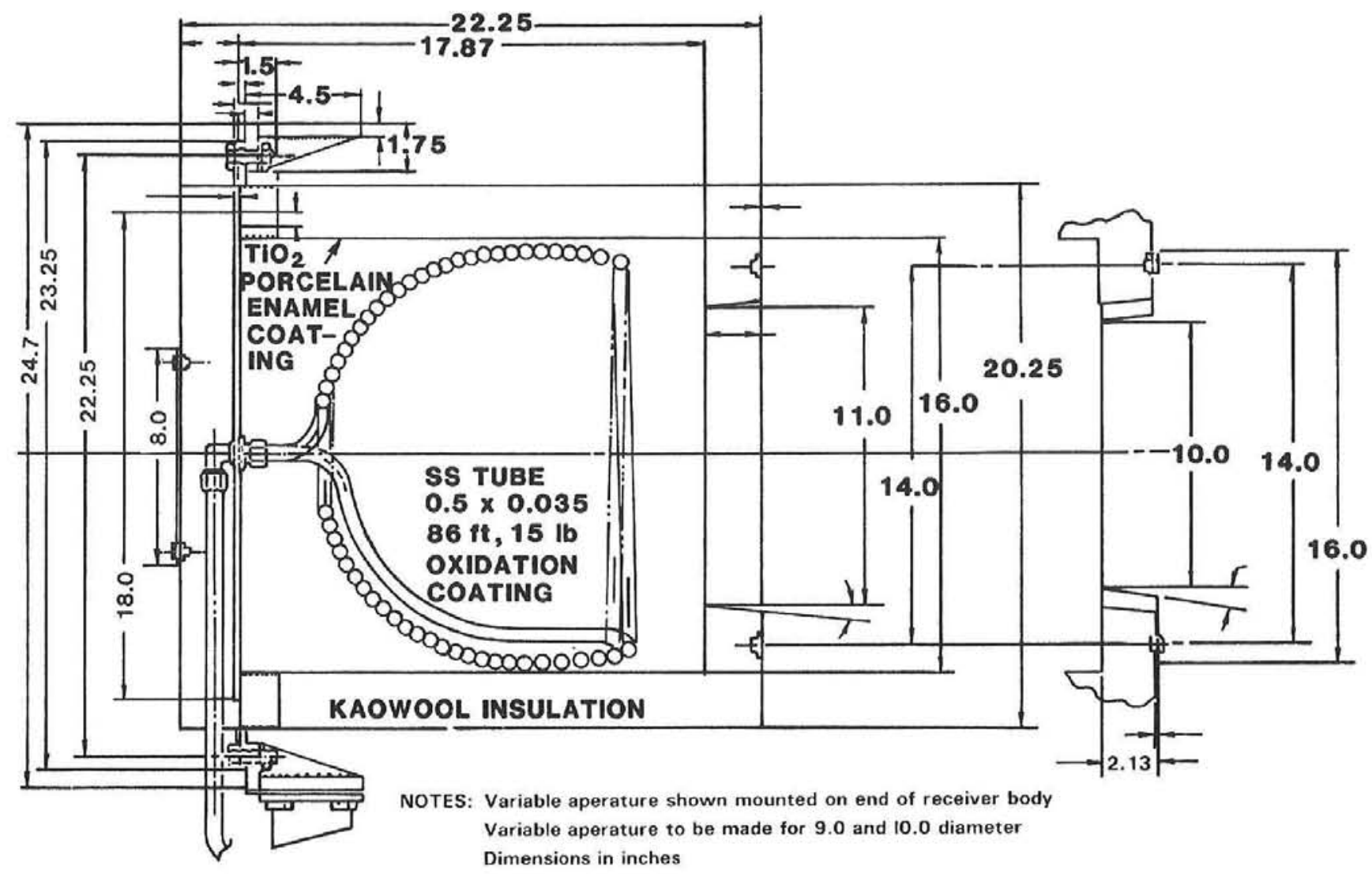

Figure 29. EPC Receiver-Coil Assembly 


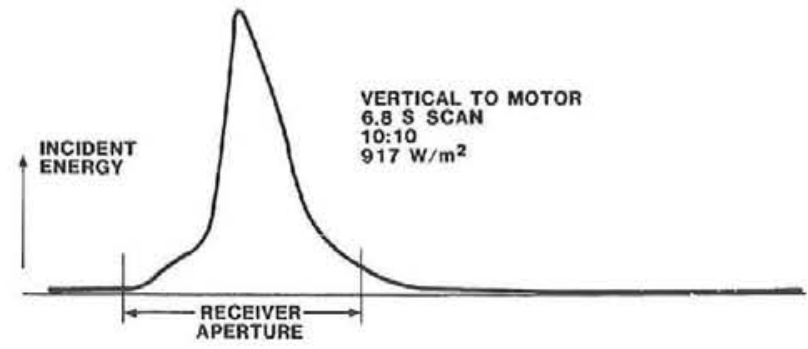

Figure 30. Typical Flux Scan
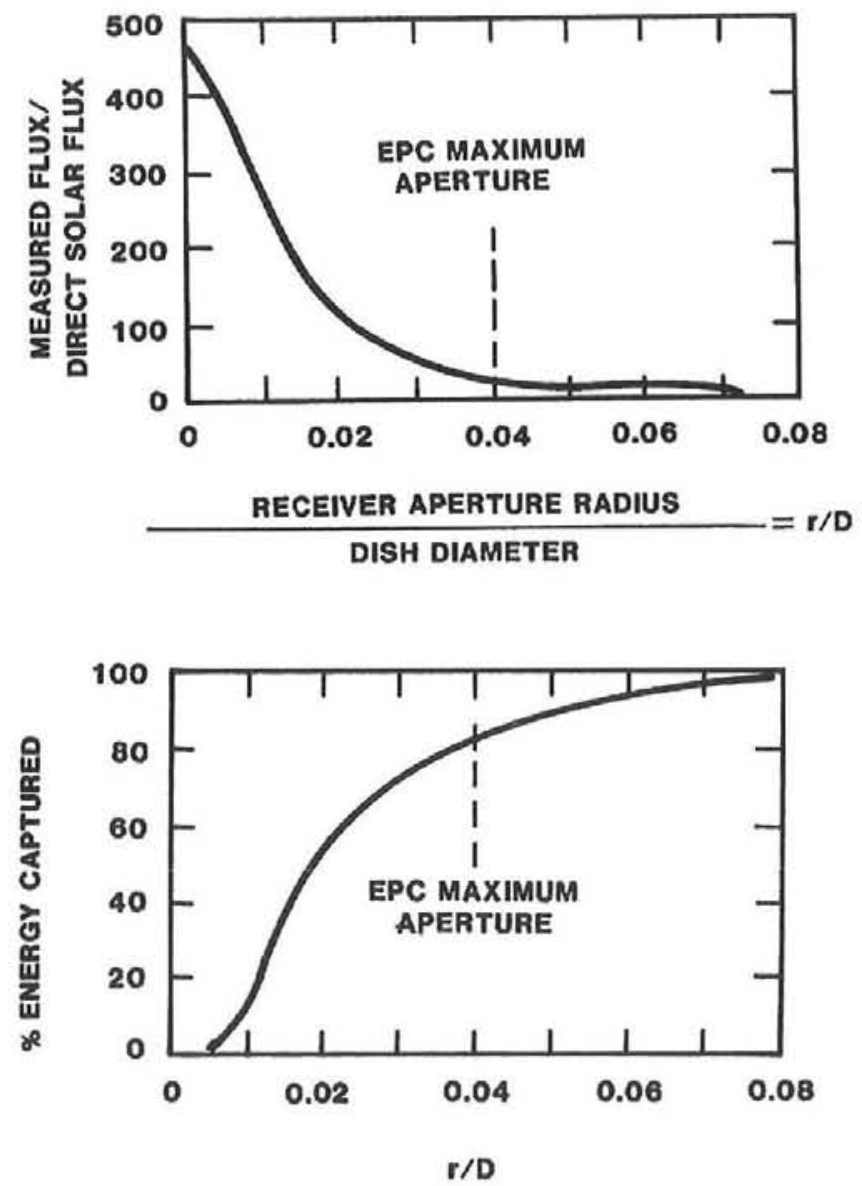

Figure 31. Flux Profile Test Results

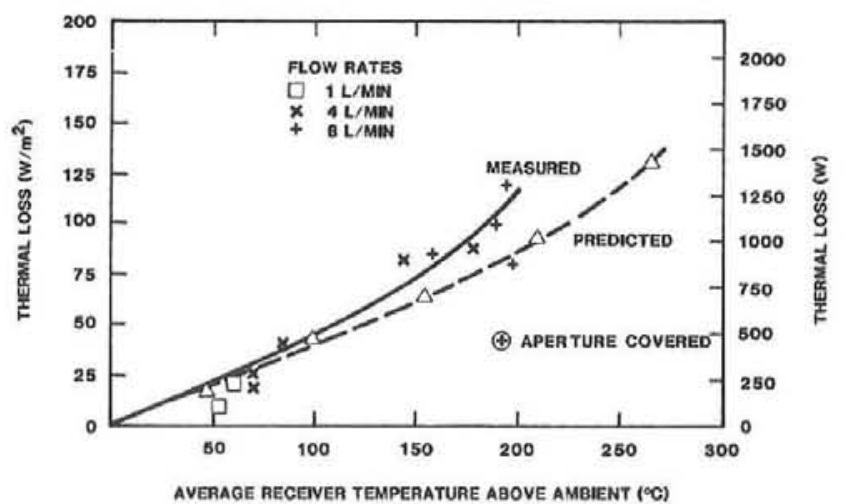

Figure 32. GE Parabolic Dish Receiver Thermal Loss

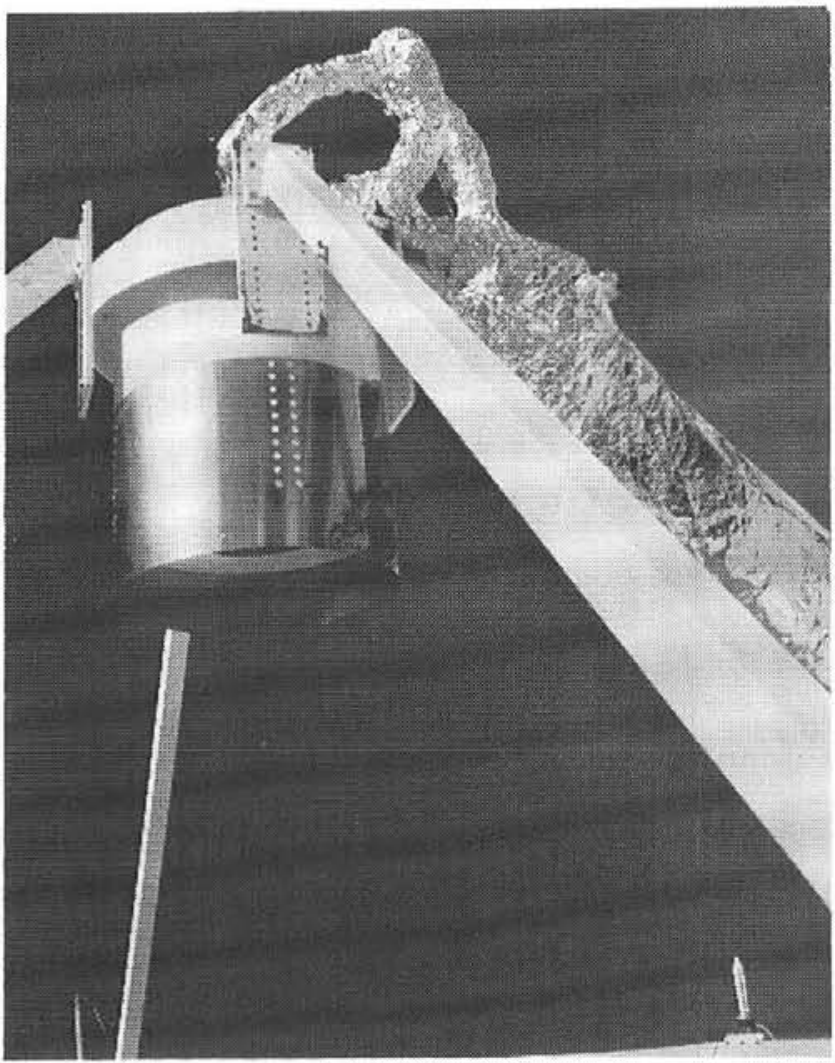

Figure 33. Wind-Skirted Receiver 


\section{Production Prototype Collector}

\section{Test-System Description}

Four 7-m prototypes of the Shenandoah collectors were designed, fabricated, installed, and tested by GE in a quadrant of Sandia's Mid-Temperature Solar Subsystem Test Facility (MSSTF). ${ }^{4}$ The four collectors were installed in the diamond-shaped geometric pattern that was to be implemented at Shenandoah. The installation and operation simulated proposed Shenandoah conditions. These tests were conducted to provide confirmation of the collector-pipe field design and to finalize the operating plans for the system. A prototype collector is shown in Figure 34. The annulus section of the reflector is a consequence of having to limit fabrication of the petal to a press that could accommodate only an 8-ft stamping die. The annulus is an aluminum section formed by spinning. The final Shenandoah configuration will have $10-\mathrm{ft}$ petals that will eliminate the annulus. Figure 35 shows the four dishes in the quadrant of the MSSTF. The four collectors were originally to have RTV670 coated, polished 5657 alumimum alloy reflectors. However, cleaning studies prompted consideration of alternative surfaces, and an anodized surface and an FEK-244 film surface were later substituted for the south and west RTV-coated collectors, respectively.

The test field was configured to dissipate the thermal energy generated by the four collectors in a cold Therminol 66 fluid loop through a heat exchanger. With all four collectors operating and insolation at $300 \mathrm{Btu} / \mathrm{ft}^{2} / \mathrm{h}$, a heat load of almost 400000 $\mathrm{Btu} / \mathrm{h}$ would have to be dissipated. The heat transfer fluid (HTF) used in the collector field was Syltherm ${ }^{\circledR}$. 800 , a Dow-Corning silicone compound, which is the only known liquid HTF permitting system operation at $750^{\circ} \mathrm{F}$ and is liquid at low temperature.

The collectors were operated with an inlet fluid temperature of $500^{\circ} \mathrm{F}$ and an outlet temperature of $750^{\circ} \mathrm{F}$. Previously, it had been proposed that the maximum temperature change across a Shenandoah collector be limited to $125^{\circ} \mathrm{F}$. However, the different temperature levels for each of two collectors operating in series had material, production, and control ramifications that made the singular operation of identical individual collectors the preferred approach for the Shenandoah system. Thus, the full temperature differential of $250^{\circ} \mathrm{F}$ is developed across each receiver.

The field piping was insulated with several different materials to evaluate their relative capacity for conserving the thermal energy generated by the collec- tors. Glass fiber, foamed quartz, and calcium silicate were used to insulate different sections of the pipefield plumbing. The temperature differences along the pipe were obtained from temperature readings of buried thermocouples at steady state operating conditions. The foamed quartz and calcium silicate insulation installed on the field piping are shown in Figure 36. Glass fiber insulation was used on the branch lines leading from the main manifold to each collector.

The collectors were mounted on reinforced concrete columns that provided $\sim 18$ in. of ground clearance below the reflector when the collectors were in their stow position. This mounting arrangement will be implemented at Shenandoah to prevent windblown material from collecting at the base. Debris collection is a potential hazard that could cause abrasion of the relector surface or a fire that might result from the solar caustic. The polar/declination mount and the jackscrew drive allow rotation of the collector beyond the horizontal to a downward-looking attitude in the stow position, providing hail protection and reduction of dew formation on the surface.

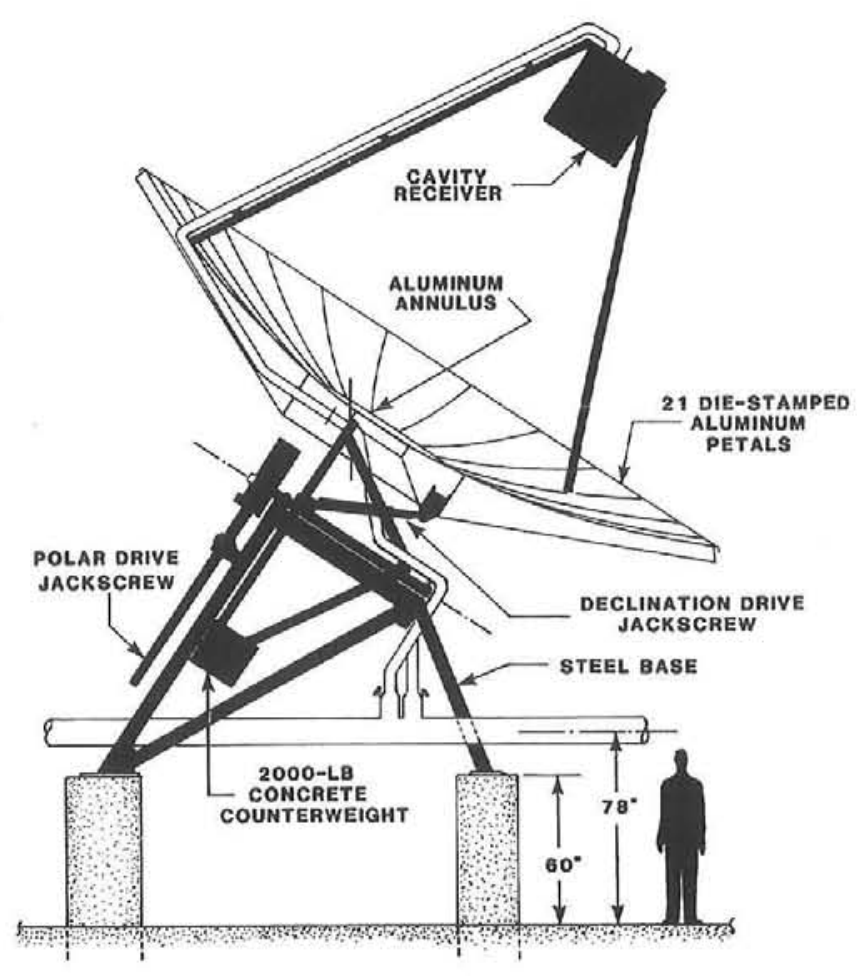

Figure 34. LSE 7-m Collector 


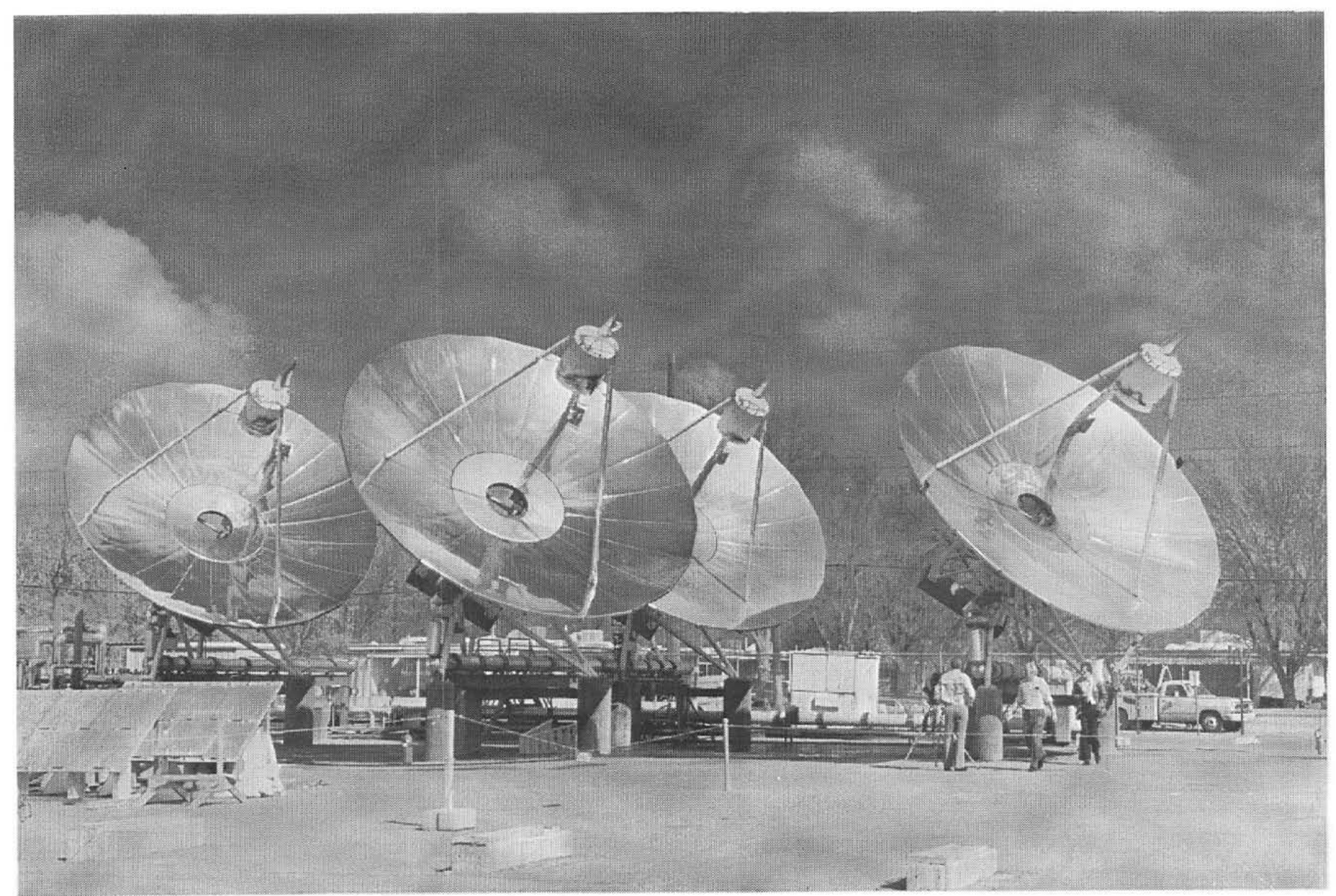

Figure 35. Four Dishes in Quadrant of MSSTF 


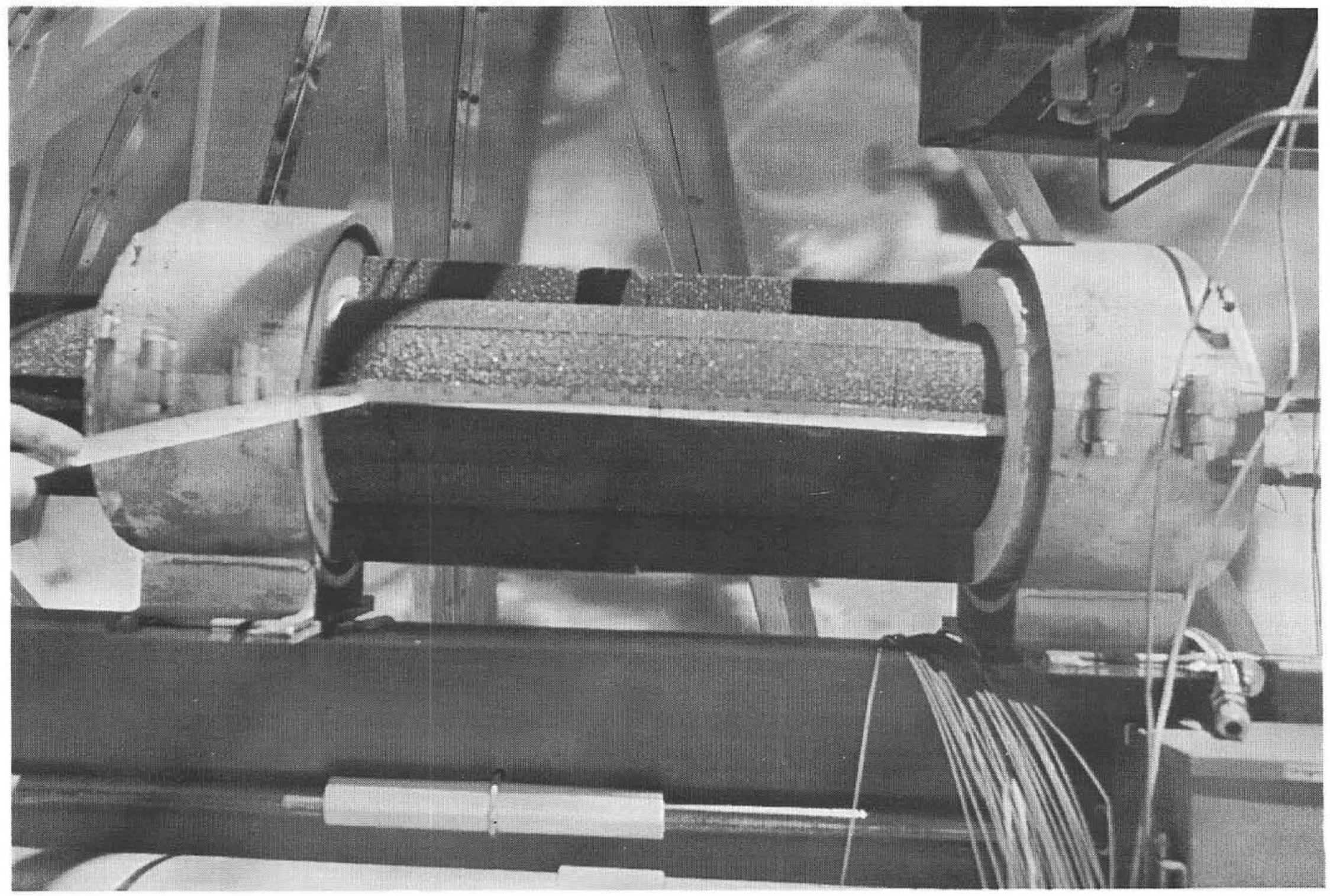

Figure 36. Foamed Quartz and Calcium Silicate Insulation Installed on Field Piping 
The quadrant was instrumented heavily to obtain temperature, pressure, flow, and power consumption information. Although data collection was the primary interest, selection of the different measuring devices that would best serve data collection requirements at Shenandoah was also the motivation for the heavy instrumentation. The data collection and control functions simulated operations for Shenandoah. Computer control of the collectors relied upon position indications from potentiometers located on the declination and polar axes of the collector. Positioning was augmented by a closed circuit fiber-optic tracking system that assumed control when the collector came within a degree of acquiring the sun. Glass rods on the receiver aperture signalled light intensity differences to a balancing circuit in the local collector control unit (CCU) to effect orientation changes which maximized solar energy transfer into the receiver. Safeguards were implemented to protect the receivers from overtemperature due to loss of fluid flow and/or loss of electrical power. Utility-power loss initiated operation of an auxiliary power generator for production of electricity to permit the collectors to be stowed.

Fluid flow rates through each collector were determined by the temperature indicated by immersion RTDs (resistance temperature devices) which monitored the temperature of the fluid exiting the receiver and by contact thermocouples at the point on the receiver coil where maximum heating was predicted to occur. For insolation levels between 75 and 300 $\mathrm{Btu} / \mathrm{ft}^{2} / \mathrm{h}$, attendant with collector operation, flow rates between 0.5 and slightly more than $2 \mathrm{gpm}$ were calculated to be required for controlling the temperature of the HTF to $750^{\circ} \mathrm{F}$. The quadrant field pump was sized to have a 10 -gpm delivery capability. Two pumps of different manufacture were operated to determine a possible candidate for Shenandoah.

An electric heater was inserted in the HTF flow path to thermally condition the Syltherm ${ }_{-} 800$ fluid, as recommended by Dow-Corning, prior to its exposure to solar heating. A nitrogen cover gas was maintained on the fluid during system operation to prevent oxidation of the fluid.

\section{Test Results}

Table 7 shows the results of early operational tests on the RTV-coated collectors. These data were obtained a few days after the surfaces had been cleaned. Reflectivity values for the RTV-coated surfaces were below 0.70 for the south dish and below 0.67 for the east dish when these operating data were obtained. The tendency toward further reduction in reflectivity with time was noted on these surfaces. The maximum efficiency values shown for the RTV and anodized surfaces in Table 8 were obtained after surface cleaning and is representative of a collector having an effective reflectance that is much less than predicted.

These results prompted a change in reflective surfaces on the collectors. The west dish surface was changed to an FEK-244 film and the east dish to an anodized surface. The anodized surface produced results comparable to the RTV-coated reflector. The west dish reflector with FEK-244-coated petals and annulus produced a peak efficiency of about $62 \%$. This value was obtained near equinox and will change with receiver elevation to a high of $63 \%$ at summer solstice $\left(78.5^{\circ}\right)$ and a low of $\sim 60.5 \%$ at winter solstice $\left(31.5^{\circ}\right)$ due to receiver convective loss changes. During the test period, the efficiency of the FEK-surfaced collector was calculated to be consistently about $5 \%$ to $15 \%$ higher than the anodized or RTV-coated collectors. Based on these results, for the Shenandoah application, the reflector surface was specified to be FEK-244.

Laser-ray tracing to determine slope errors of individual petals was not conducted on these $8 \mathrm{-ft}$ reflector sections due to press of time. However, the measured receiver intercept factor of $96 \%$ indicates slope errors were within specification requirements.

Thermal loss tests were also conducted as a function of the elevation angle of the receiver (attitude of the receiver aperture). With a constant inlet fluid flow rate and a constant inlet temperature of $565^{\circ} \mathrm{F}$ $\left(296^{\circ} \mathrm{C}\right)$, the elevation angle of the receiver was varied. The average wind speed (from the west) was $\sim 2.6$ $\mathrm{mph}(1.16 \mathrm{~m} / \mathrm{s})$ during these tests. The results are shown in Figure 37. These results extrapolated to maximum operating temperatures $\left(500^{\circ} \mathrm{F}\right.$ inlet, $750^{\circ} \mathrm{F}$ outlet) and average prevailing wind conditions for Shenandoah resulted in the thermal loss predictions shown in Figure 38.

During the course of testing, it was found that the thermocouples sensing the heating of the receiver coil were indicating a high temperature during the lower HTF flow rates that was not being reflected in an increased fluid temperature as indicated by the outlet immersion (RTD) resistance temperature device. This event is shown in the curves of Figure 39. Two theories were advanced to explain this phenomenon. 


\section{Table 7. Summary of Stable Efficiency Data}

\begin{tabular}{crlccc}
$\begin{array}{c}\text { Date } \\
\text { (CY 1979) }\end{array}$ & Times (Local) & Collector & $\begin{array}{c}\text { Avg } \\
\text { Insolation }\end{array}$ & $\begin{array}{c}\text { Avg } \\
\text { Efficiency }\end{array}$ & $\begin{array}{c}\text { Avg } \\
\text { Outlet }\left({ }^{\circ} \mathrm{F}\right)\end{array}$ \\
\hline $8 / 31$ & $9: 20-12: 15$ & South & 933 & $.53 \pm .02$ & 654 \\
$9 / 5$ & $11: 17-13: 57$ & South & 986.6 & $.56 \pm .02$ & 593.8 \\
$9 / 12$ & $9: 52-12: 17$ & South & 904.5 & $.54 \pm .02$ & 651.8 \\
$9 / 13$ & $9: 01-14: 07$ & East & 904.3 & $.50 \pm .02$ & 611 \\
$9 / 20$ & $9: 38-13: 10$ & East & & $.52 \pm .02$ & 710 \\
& & South & 943 & $.51 \pm 02$ & 714 \\
\hline \hline
\end{tabular}

\section{Table 8. Dirty/Clean Performance of Shenandoah Quad Dishes}

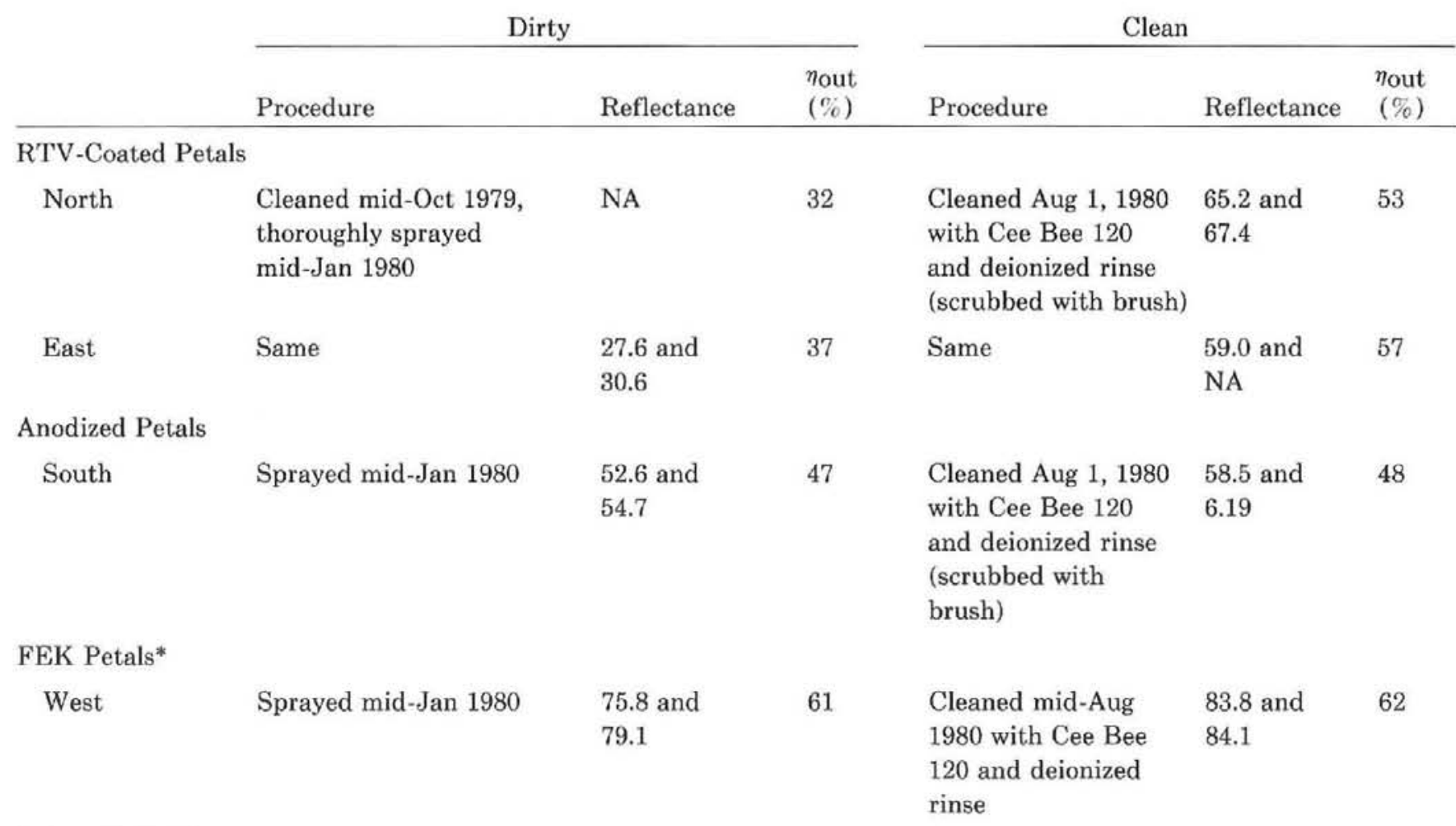

*First petal was installed October 1979. Second petal went through enviornmental chamber and was then installed May 1980. 
AVG SOUTH, EAST, \& WEST COLLECTORS

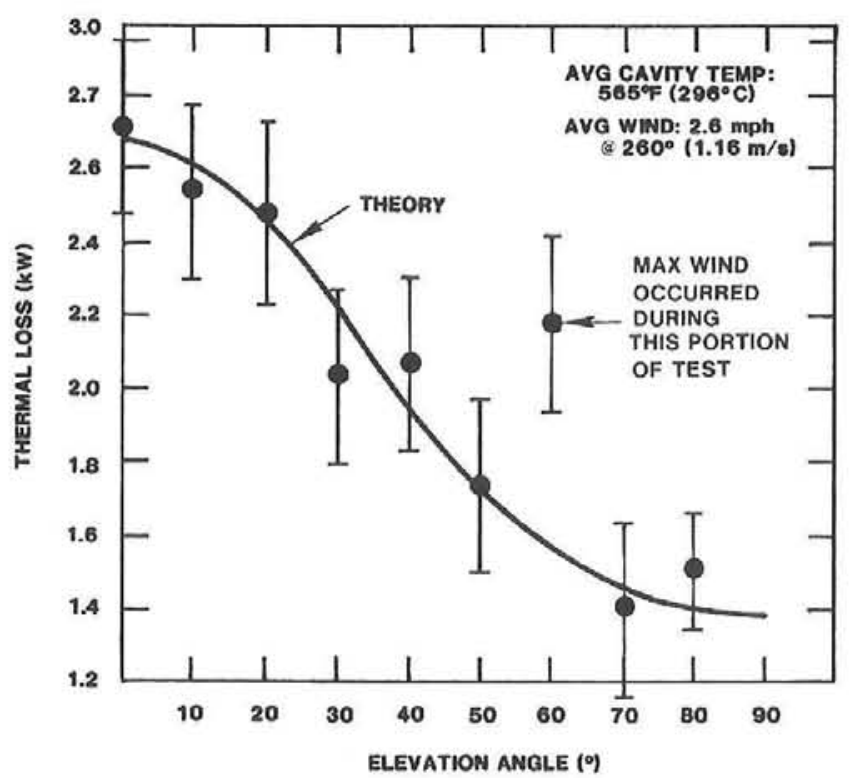

Figure 37. Receiver Thermal Loss vs Elevation AngleTest Results at Average Cavity Temperature of $296^{\circ} \mathrm{C}$

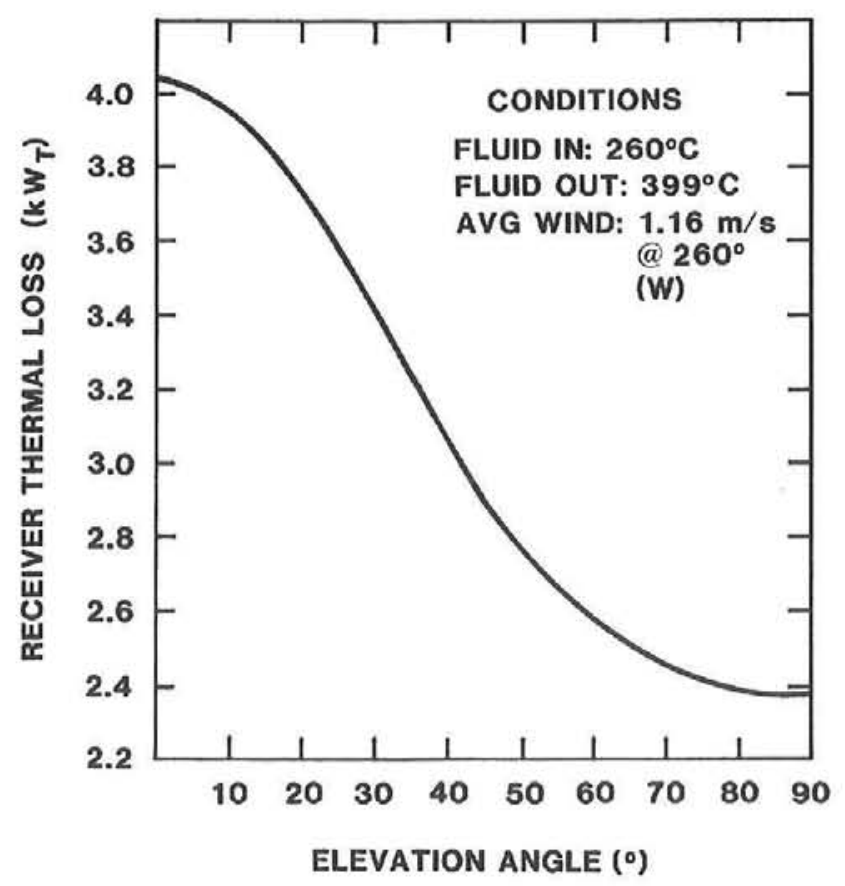

Figure 38. Receiver Thermal Loss vs Elevation AnglePrediction at Fluid Outlet $399^{\circ} \mathrm{C}$

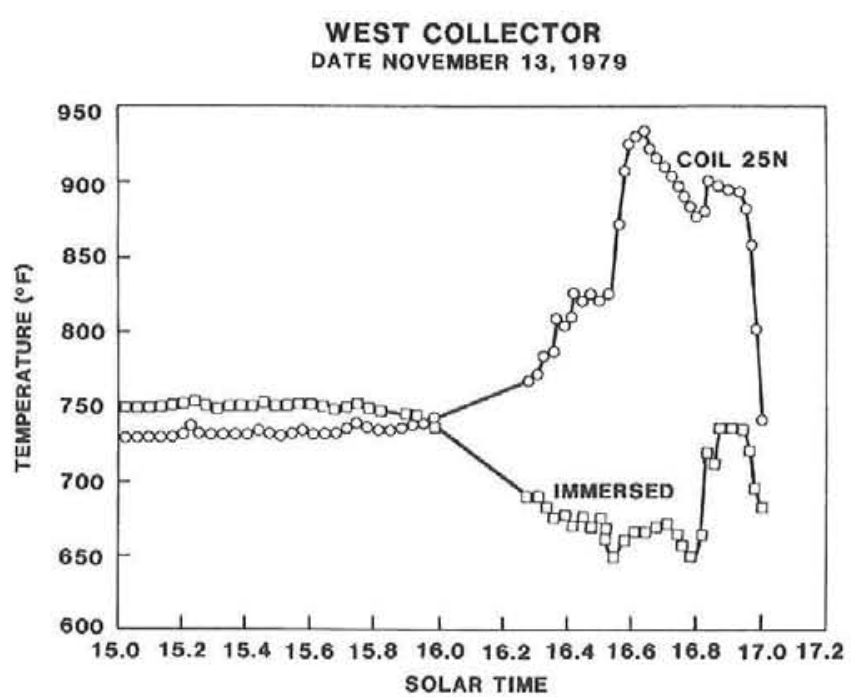

Figure 39. Receiver Coil Temperature

One contention was that the fluid was undergoing a transition from a turbulent state to a laminar state at the lower flow rates. This would create a reduced heat transfer condition so that the heat absorbed by the receiver coil was not being efficiently transferred to the fluid. Thus, the coil temperature would suddenly increase, but the decreased heat transfer would reduce the fluid temperature. The other theorized cause for the discrepancy in temperature indications between coil 25 and the immersion RTD was that as the insolation decreased (and flow rate was decreased accordingly) the reflected energy on the receiver coil also decreased, emphasizing nonuniformity of the flux distribution on the coil. The relative distribution of the rays in the receiver is shown in Figure 40. The coils above coil 25 and the outlet (which is at the top of the conical section) would then contribute little if any energy toward adding heat to the fluid. However, the slower moving fluid did not keep the coils "cooled" as much as during higher insolation conditions, which allowed the coils in the high flux regions to reach much higher temperatures. The fluid passing this region also absorbed greater heat, achieving higher temperatures than normal. But, as the fluid passed the upper cold coils, this heat was rapidly dissipated. The upper coils might be much below the $750^{\circ} \mathrm{F}$ operating level if no flux impinged on them, allowing the fluid to dissipate its heat rapidly and causing the temperature to fall even below $750^{\circ} \mathrm{F}$. 


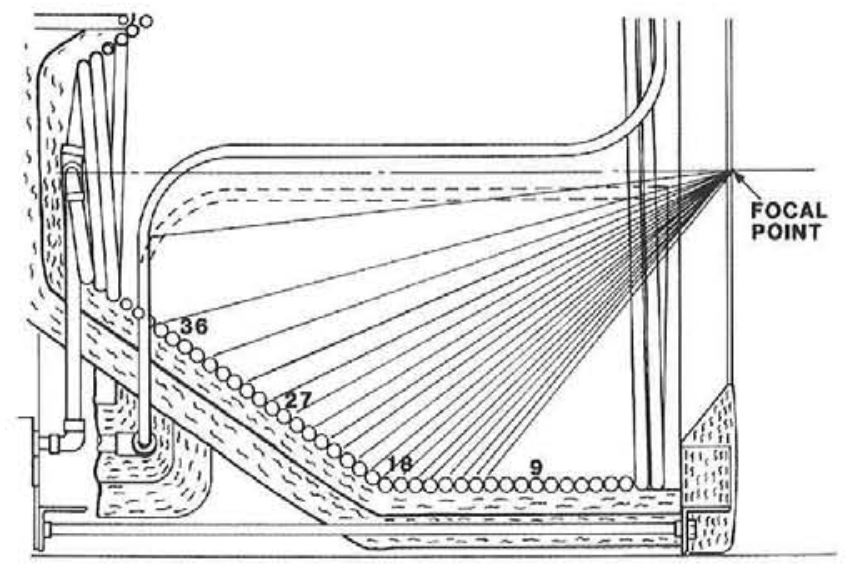

Note: Numbers refer to specific coils

Figure 40. Receiver Ray Diagram

The critical Reynolds number for flow transition is calculated to be $\sim 5500$ for the receiver coil parameters of the prototype collector. The indicated conditions of temperature, heating rate, and flow rate at the time of transition were used to determine an average heat transfer coefficient. The fluid temperature along the coil was then calculated using this coefficient. The plot of the fluid temperature with coil length provides a plausible explanation of the conditions that might have existed to produce the results obtained. Figures 41 (a) and $41(\mathrm{~b})$ show the proposed temperature curve of the fluid together with the measured temperature curve of the tube wall to predict the probable result of a flow transition occurrence.

A nonuniform flux distribution coupled with higher heat dissipation is also considered a plausible cause for the anomalous observations and is supported by the heat loss calculations for such a condition. The loss mechanism is hypothesized as being principally blackbody radiation from the unheated coils of the conic section to the aperture and to the cooler (assumed to be at $700^{\circ} \mathrm{F}$ ) sections of the coil. Calculations indicate the radiation loss to the aperture to be $\sim 3500 \mathrm{Btu} / \mathrm{h}$ and to the cooler sections of the coil to be $\sim 5600 \mathrm{Btu} / \mathrm{h}$. Coupled with a convection loss of $2000 \mathrm{Btu} / \mathrm{h}$ and conduction loss of $1000 \mathrm{Btu} / \mathrm{h}$, the total heat loss would be $12000 \mathrm{Btu} / \mathrm{h}$. The associated temperature drop over the length ${ }^{*}$ the unheated coils in the receiver would amount to $\sim 105^{\circ} \mathrm{F}$. This calculation compares favorably with a measured difference between coil 25 (hot coil) and the outlet immersion RTD of $\sim 120^{\circ} \mathrm{F}$.

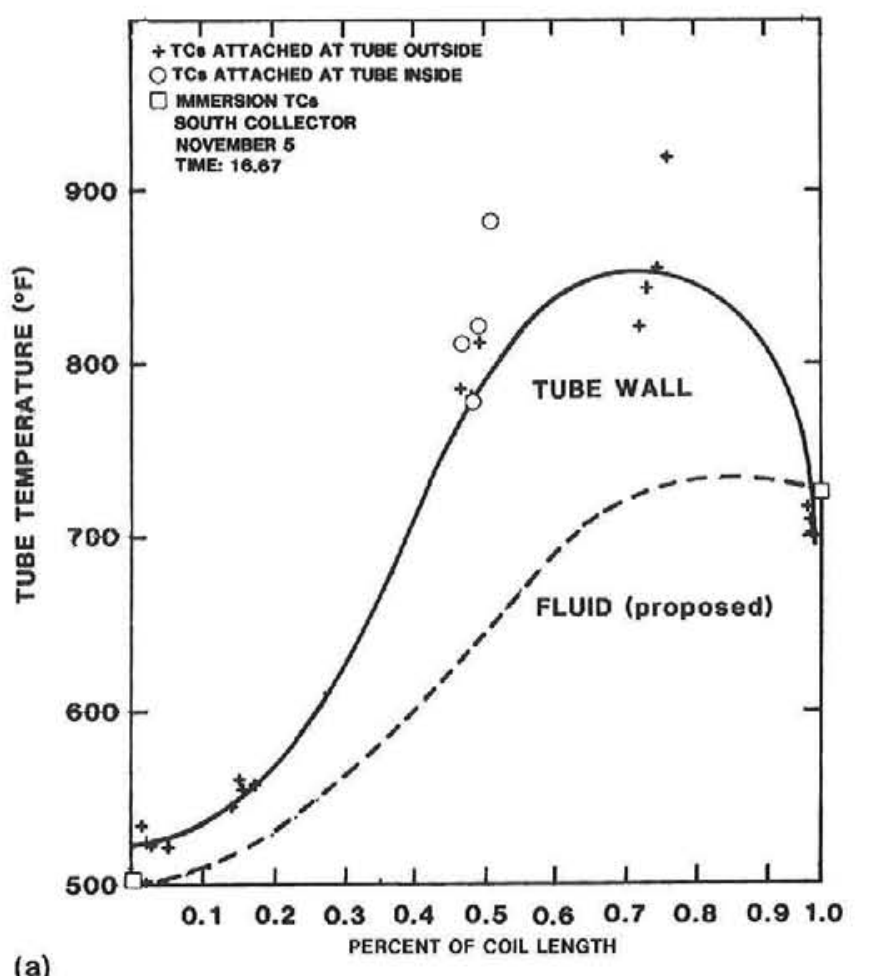

(a)

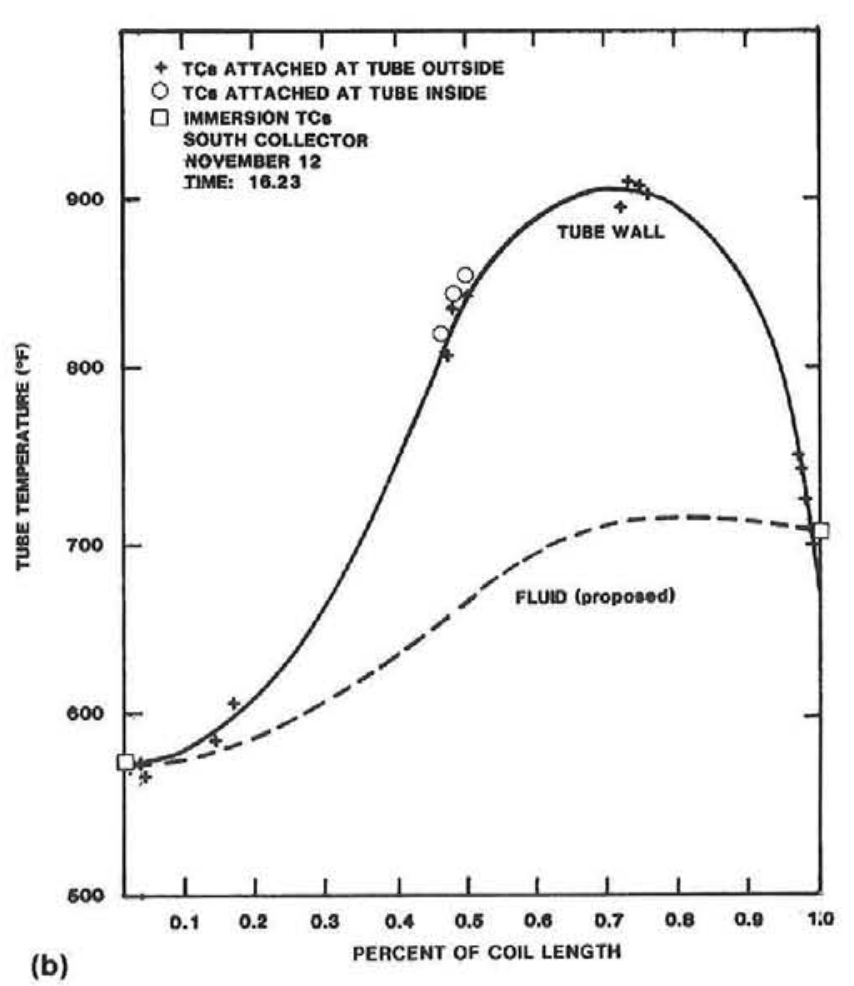

Figure 41. Tube Temperature-(a) November 5 (b) November 12 
If a direct measurement of the fluid temperature could have been made with an immersion RTD at the location that corresponded to the coil thermocouple reading, one could then ascertain whether flow transition was actually occurring. Time did not permit such a determination to be made. However, to prevent this phenomenon during low-solar-flux Shenandoah operations, the receiver coil was redesigned. The tube diameter was resized to limit the temperature difference between the tube wall and fluid to $<100^{\circ} \mathrm{F}$. Based on the heating rates and results from the west dish (FEK surface, which is the Shenandoah option) operation, a laminar heat transfer coefficient was calculated and a conservative laminar flow Reynolds number of 8200 was established to provide this limiting feature. With this laminar Reynolds number, the heat transfer (even at the low flow rates) will be sufficient to keep the temperature difference between the tube wall and fluid below $100^{\circ} \mathrm{F}$. A plot of how tube size affects the temperature difference and the pressure difference for a Reynolds number of 8200 is shown in Figure 42 for the double-coil receiver. Two 3/8-in.-dia coils would limit the wall/fluid temperature difference to $88^{\circ} \mathrm{F}$ and the pressure difference across the coil to $14 \mathrm{psi}$.

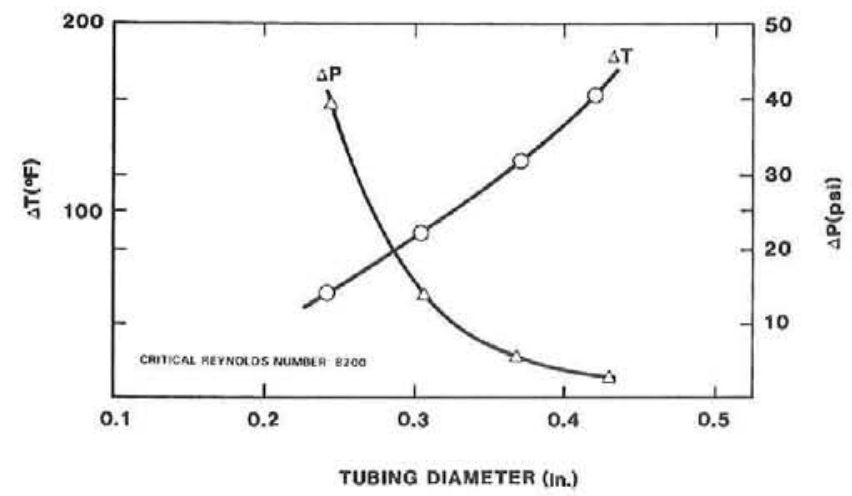

Figure 42. Double-Wound Coil

A single-coil receiver was also considered for the Shenandoah collector because of its mechanical simplicity. The design, based on the imposed restrictions, resulted in a $1 / 2$-in.-dia tube coil. The corresponding plot of the single-coil analysis is shown in Figure 43. The single-coil design was selected for implementation in the Shenandoah collector. A single-coil receiver was fabricated and tested in the west dish after GE concluded their formal testing at the MSSTF. At low flow rates, the receiver did not manifest the temperature anomaly observed on the earlier double-coil receiver, generating another theory for the anomalous behavior noted previously. It was speculated that the flow division in the double coils was not equal because of mechanical asymmetry or a constricted passage in one of the coils that caused fluid to boil in the coil at the lower flow rate. As a result, heat transfer would be reduced, but the coil temperature would increase and volumetric mass flow rates would be erroneously high. Calculations of efficiency under such conditions could lead to illogical efficiency numbers. The data did sometimes give rise to efficiency values greater than $100 \%$. These calculations were based on flow rates indicated in the output line. When flow meters were installed in the input line, flows were found to be consistently about $10 \%$ less, indicating that output flow probably included bubbles stemming from "boiling." Prior to this disclosure, collector efficiencies of $70 \%$ or more had been routinely calculated. "Boiling" was eventually identified as the result of a failure to properly condition the silicone fluid, which resulted in the breakup and evolution of cyclic vapors at elevated temperatures.

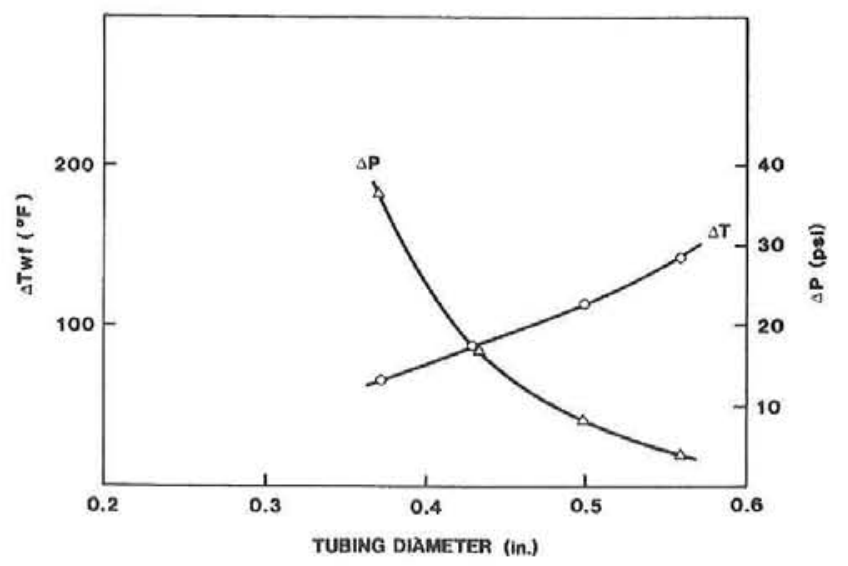

Figure 43. Single-Wound Coil

At the conclusion of operational testing of the collectors, a series of no-flow tests were conducted on the receiver. The purpose was to determine if the high temperature detector and its location were appropriate for providing an accurate and timely indication of a flow malfunction that would require immediate remedial action. After bringing the receiver into focus, the flow of the HTF was stopped for about 2 minutes while tracking was maintained. Thermocouples on the coils that received the highest flux responded rapidly and indicated the highest rate of rise of temperature. Thermocouples on shaded coils at the bottom or those at the top of the conic section had delayed responses, as did the immersion RTD at the outlet of the receiver coil. The latter responses are an indication of the heat conduction through the coil and HTF to the detectors. 
The relative response time of flow stoppage and temperature rise in the detectors is shown in Figures 44(a) and (b). As a result of these tests, the initial idea of using the immersion RTD at the outlet of the receiver coil as the over-temperature indicator was abandoned because of the observed delayed response. The time interval from flow stoppage to a high temperature indication would have allowed sufficient heating of the fluid to exceed the allowable film temperature and cause possible fluid degradation. For Shenandoah, an immersion RTD at the coil receiving maximum flux was implemented to provide the flow-stoppage overtemperature indication.

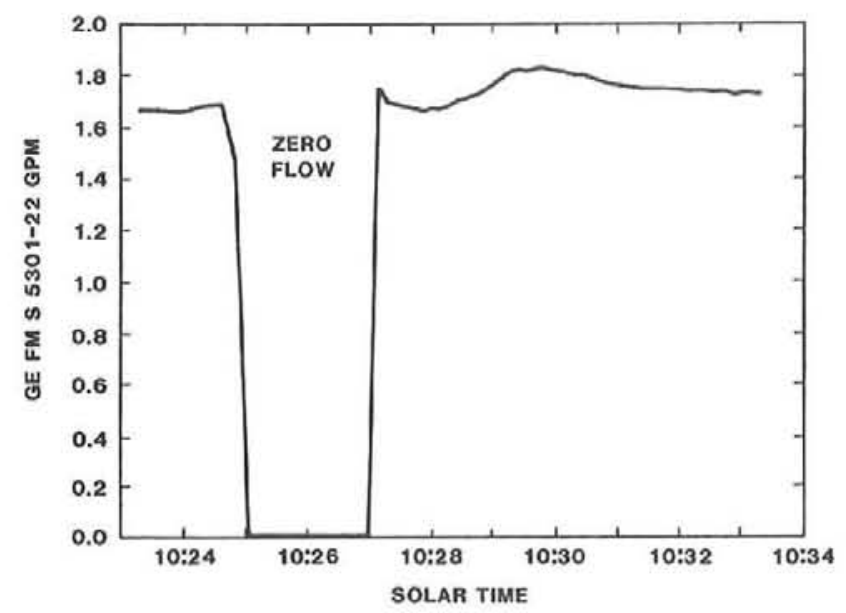

(a) Flow Stoppage

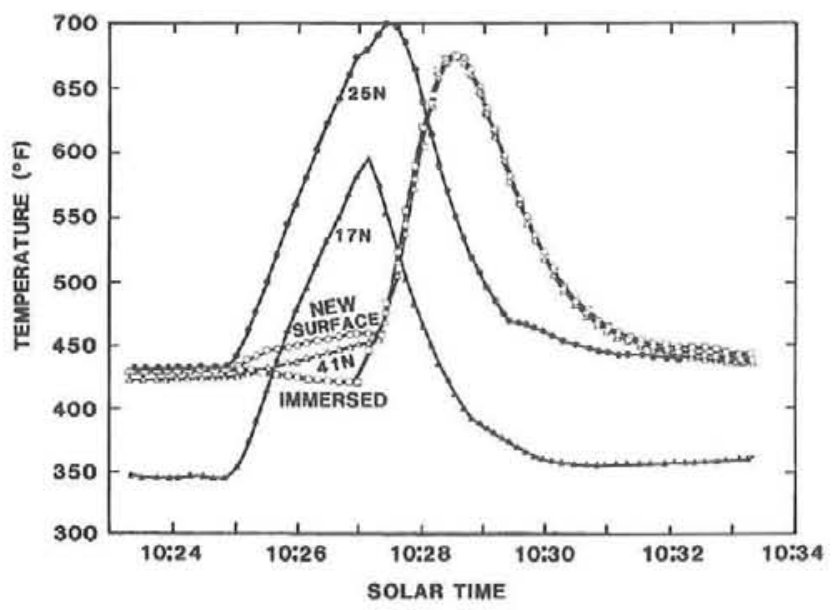

(b) Temperature Rise

Figure 44. Relative No-Flow Response Times
To conclude the receiver testing, a condition of loss of flow coupled with a loss of tracking was simulated to determine the extent of damage that could result to the receiver. The receiver was brought into focus and fluid flow and tracking was terminated. The reflected sun image moved across the receiver aperture at the slow sun travel rate of $0.25 \% \mathrm{~min}$. Postmortem of the receiver did not indicate any coking of the HTF in the coils or mechanical damage to the coil. The aperture plate is segmented into four sections, and the protective astro-quartz cloth of the segment across which the sun track migrated was incinerated and the stainless steel plate was grossly distorted from the heating. The section of the fiber-optic tracking system located on the aperture plate segment had been totally consumed and the metal housing was fused into a formless mass as shown in Figures 45(a) and (b). The other three sections were not affected. The replacement of the affected segment plate and installation of another fiber-optic section was effected without difficulty and would have permitted early resumption of collector operation. It was noted that the fluid had apparently "boiled" in the receiver, creating sufficient pressure to drive the heat transfer fluid into the expansion tank, creating a large void in the HTF line. The evacuated pocket was eliminated by cycling the fluid through the expansion tank and allowing the bubble to percolate out of the system. Analysis of the remaining fluid drained from the receiver indicated some formation of cyclics, but no decomposition that would prevent its use as a heattransfer medium. The fluid loss to the system was estimated at a few gallons and was replaced. These results indicate that even the most severe collector field malfunction will not produce the dire effects predicted prior to the tests (the costly replacement of receivers, the need to drain and clean out piping, and the conditioning and replacement of new fluid in the field).

The initially recommended collector alignment procedure was to aim the collector at a precisely located light source and to correlate the collector position with the computer tracking algorithm. Because of the difficulty in locating a proper beacon for the Georgia application, this procedure was not followed at Shenandoah. For the Sandia test site alignment, however, a strong light source was located some distance from the collector but at a precisely known location (in azimuth and elevation) and the collector was initially "bore sighted" on it. A target was then located at the receiver aperture position and the reflected light image was carefully centered on the 
bullseye. The corresponding position potentiometer readings of the collector were then correlated with the angular position of the collector to establish the necessary position information for computer-controlled tracking. The target was then moved along the optical axis to obtain the brightest and smallest image on the target, and a photograph of the light image was taken to obtain an indication of how much energy entered the receiver. The developed negative was read with $a_{i}$ densitometer to get an indication of the percentage of the reflected image intercepted within the diameter of the 18-in. receiver aperture. Similar intercept factor determinations were made on those evenings when a full moon was evident to obtain illuminations of the target at greater light intensity. A good definition of the reflected image was obtained on the target. These densitometer readings indicated that approximately $96 \%$ of the light from the reflector was being intercepted within the 18-in. diameter of the receiver aperture. The focal point on the four dishes was found to be within 0.5 in. of the predicted intercept position and the repeatability of the focal point location on any given dish was within \pm 0.25 in. These findings indicated that no adjustments in focal distance would be required on the Shenandoah dish.

The modified alignment procedure proposed for Shenandoah was tested on the collectors at the test site, and its applicability to provide an accurate pointing reference was established. The approach was to position the collector at its zero declination and polar position (i.e., solar noon at equinox) by the simple expedient of leveling the counterweight in the horizontal plane and using a level to position the reflector hub assembly to be parallel to the polar axis. The position-indicating potentiometer for the polar and declination axes were then set to their "mid" position as indicated by a $5-\mathrm{V}$ reading when a $10-\mathrm{V}$ supply was impressed across the entire potentiometer. The collectors were then manually brought into focus with the sun, the fiber-optic circuits were balanced (equal outputs from the N-S and E-W optical circuits), and the collectors were allowed to track the sun automatically. The potentiometer readings obtained under automatic fiber-optic tracking were then correlated with the position of the sun from the ephemeris for the sun for that time and date. These data were obtained over the widest range of tracking possible. The position data were used to define a third order, least squares fit trajectory equation. The four constants derived from this analysis were used in a tracking algorithm implemented in the computer which provides a tracking gate within $\pm 0.6^{\circ}$.

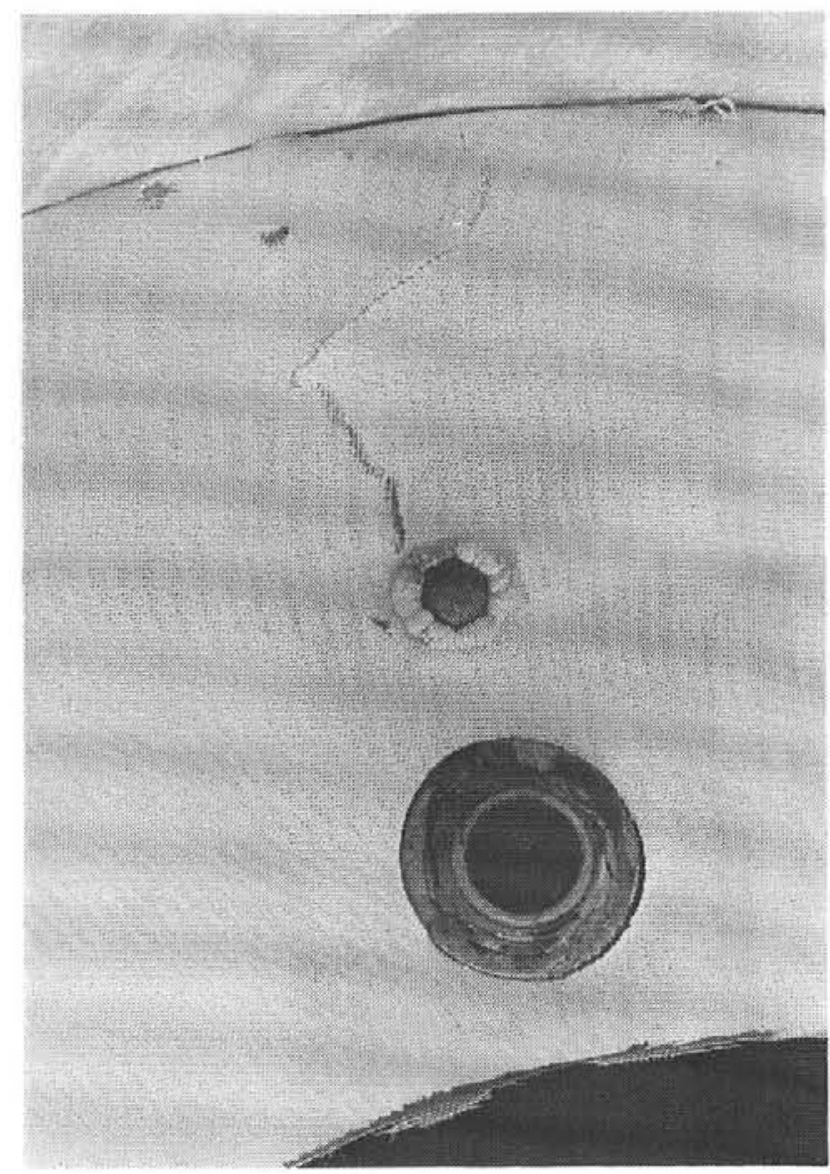

(a) Aperture Plate

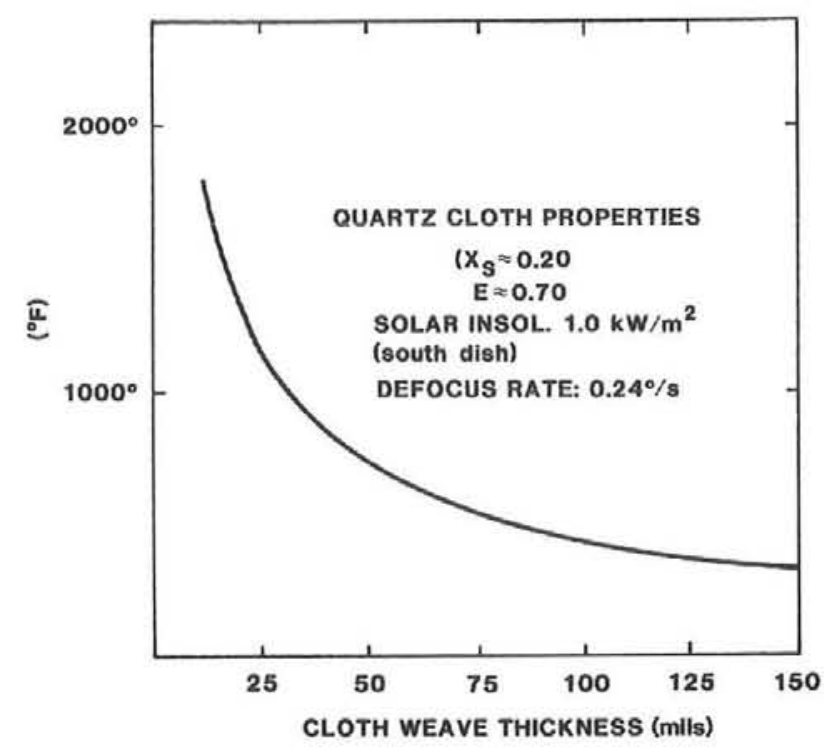

(b) Predicted Temperatures With Quartz Cloth

Figure 45. Receiver 
The accuracy of visual observations of the solar image position on the receiver is remarkably precise. A trained observer can recognize an offset of as little as $0.1^{\circ}$. This visual acuity was demonstrated by an observer noting the image offset when the collector was moved to produce a $4-\mathrm{mV}$ change in the position potentiometer output ( $10 \mathrm{~V}$ for $270^{\circ}$ rotation). Thus the tracking alignment procedures for Shenandoah have been demonstrated to be simple but accurate. The $\pm 0.1^{\circ}$ alignment accuracy under automatic tracking is calculated to affect operating efficiency of the Shenandoah system by no more than $1 \%$.

The MSSTF tests of the dish collectors indicated that changes to the tracking hardware were warranted. The position potentiometer bracket was stiffened, and the holder was modified to permit $360^{\circ}$ of rotation. The fiber optics (for automatic tracking) were found to be subjected to temperatures beyond the survival level of materials used in their assembly. After relocation of some elements of the optical tracking system, protection of the elements with additional insulation, and substitution of elements capable of tolerating higher temperatures, the optical system is now considered to be free from temperature limitations. In addition, the coupling of the fiber-optic sections was modified to improve the light transmission as well as expedite the replacement of sections of the optical system.

The sensitivity of the photodiode circuits in the collector control unit (CCU) to the changing intensity of light when the CCU door was opened and closed required that they be painted with an opaque RTV to prevent a change in bias in the fiber-optics electronics. Also, opaque covers were put on the fiber optic cables to prevent light incursion from this source. CCUs for Shenandoah will incorporate shielding to preclude this light sensitivity.

The capability of the collectors to track the sun under very low insolation levels was demonstrated when early morning and early evening levels of 150 to $170 \mathrm{~W} / \mathrm{m}^{2}\left(50 \mathrm{Btu} / \mathrm{ft}^{2} / \mathrm{h}\right)$ provided sufficient intensity for the collectors to maintain tracking. Also, thin cloud cover that dispersed direct normal insolation did not deter tracking. Some tendency to oscillate between automatic tracking and computer-guided tracking was evidenced when the insolation fell to threshold levels. In such instances, control was switched to computer tracking to preclude the hardship on components that such "hunting" would have imposed.

Automatic tracking updates occurred approximately every 10 to $15 \mathrm{~s}$. This reflects an angular correction of the collector when the sun has moved only $\sim 0.05^{\circ}$. This rate was maintained by the closed circuit tracking system from morning start-up to evening shutdown, indicating the high resolution of the tracking system throughout the day.

During the course of testing, large-amplitude, spurious signals appearing on the control lines to the CCU or control room rack caused defocus on several occasions. The source was never isolated, but relief was provided by filtering at the CCUs and at the control room rack. This noise problem was not expected to be a serious concern with the change to the unique serial address control program that is to be implemented for Shenandoah.

A relay race problem is suspected to have been the cause of several relay contacts that fused and caused motor circuit fuses to open. A serial connection with a delay between relay sequencing was substituted for the parallel circuit that had been used to control motor reversals. This change, coupled with a change to a heavier duty relay incorporating arc suppression, eliminated the problem.

For the quadrant tests, the receivers were fabricated with a mounting bracket that would permit moving the receiver along the axis of the paraboloid to adjust the receiver at the proper focal point. The EPC tests had indicated that such a capability might be needed since there was some question as to the actual focal point existing where calculations had indicated. The receiver was cantilevered off these brackets from three struts anchored to the support ribs of the dish. The clevis attached to the receiver was mated to the struts to hold the receiver in place. However, the clevis attachment to the receiver allowed a few degrees of rotation of the receiver relative to the clevis and struts so that the aperture end sagged. To maintain the receiver position at the correct attitude, an adjustable support post was attached to the three struts, fixing the position of the receiver relative to the struts.

During tracking, the receiver was observed to move relative to the reflector due to the flexing of the struts, reflector petals, and support ribs. Sightings of a target mounted on the receiver aperture through a rifle scope mounted on the collector yoke structure disclosed movements of the target relative to the yoke of \pm 1 in. in the $\mathrm{E}-\mathrm{W}$ direction and $1 / 2 \mathrm{in}$. in the northerly direction. Receiver position relative to the reflector, as it tracks from east to west, is compensated for during fiber-optic tracking by collector positioning that produces the maximum solar intercept by the receiver. The degree of receiver movement is a tradeoff between the energy loss due to cosine effects versus 
the cost in stiffening the structure to minimize movement. Correlating the potentiometer (collector position) readings (during fiber-optic solar tracking) with the time of day can assure proper collector orientation when computer controlled tracking must be implemented.

Exposed cabling from the receiver to the $\mathrm{CCU}$ was strapped to the southwest strut and protected with reflective aluminum foil to preclude heating during tracking into or out of focus. For Shenandoah, protection will be provided by routing the cables within the receiver support strut.

The heating of the aperture plate on the receiver, which occurred when bringing the collector into or out of focus and during sustained operation, was of sufficient intensity to cause severe mechanical distortion of the plates and damage to the fiber-optic tracking circuit. Thicker stainless steel did not allow dissipation of the heat to a temperature that could be tolerated. Incorporation of a 1/10-in. quartz fiber cloth mat as a thermal barrier reduced temperatures on the plate to a level that prevented distortion and permitted the fiber optics to survive and operate safely. Figure 45(b) shows that a 0.1-in.-thick cloth limits heating to $\sim 400^{\circ} \mathrm{F}$.

The collector base-frame structure was found to be sufficiently rigid to meet requirements for the system even under $30-\mathrm{mph}$ winds. Survival from winds of $70 \mathrm{mph}$ was demonstrated during an afternoon storm with winds of that magnitude that hit the MSSTF. No structural deformations could be identified.

Performance of motors used to drive the jackscrews to move the collectors was found to be adequate. Length of operation of the totally enclosed motors is limited because of the heat generated. A thermal overload switch incorporated within the motor windings will open the circuit to protect the motor when high temperatures generated from extended operation are sensed. Continuous motor operation required to drive the collector from any position back to stow is possible, however, without thermally overloading the motor.

The torque developed by the polar drive motors was measured to be a minimum of $9000 \mathrm{ft}$-lbs. The torque requirements for collector movement during a $30-\mathrm{mph}$ wind is calculated to be $5000 \mathrm{ft}-\mathrm{lbs}$. Thus the motors provide an adequate margin of safety for driving the collectors under required wind loads.

During testing, the declination jackscrew on one of the dishes ran off the end of the threaded rod when the stop washer fractured. A thicker washer was incorporated as indicated in the failure analysis of the part. No further incidence of run-off was observed. In addi- tion, for Shenandoah, a left-hand thread was incorporated on the jackscrew to prevent the nut holding the stop washer from being unscrewed.

The two pumps compared during the MSSTF testing of the four-collector dish system were a Dean Brothers and an Ingersoll-Rand model. Either pump appeared to be suitable for $500^{\circ} \mathrm{F}$ operation at Shenandoah. Neither was tested to determine its capability of sustaining operation at $750^{\circ} \mathrm{F}$.

Instruments used during testing to obtain pressure and flow/rate data were found to provide adequate responses and are suitable for Shenandoah use. These instruments were Data Instruments, Inc. pressure transducers and Invalco and Flow Technology flow meters. Honeywell and Masoneilan valves were investigated to provide system flow control in the MSSTF during testing of the dish collector field. After adjustments to the operating range and adjustments in the controllers, a linear correlation between flow/ rate and current was established. These valves, adjusted for the application, are considered adequate for Shenandoah use at $750^{\circ} \mathrm{F}$.

\section{Conclusions}

These tests at the MSSTF provided valuable information for upgrading the system to be implemented at Shenandoah. The important point emphasized by these tests was that operational responses of components manifested under laboratory testing are not necessarily the same in a field environment where the component is incorporated into a working system. This fact was most evident in the reflector material decisions based on laboratory tests compared to actual field results. A similar departure was observed in the receiver coil performance under operating conditions compared to results of analysis and laboratory testing.

Design modifications were also indicated for the jackscrew stops, the fiber-optics circuitry, the receiver aperture plate thermal capabilities, the receiver structural support, the motor control circuitry, the position potentiometer support, and placement of the overtemperature monitor. Not all elements required alternatives. Most components manifested required operational capabilities and the responses anticipated from analysis and laboratory tests. Some required only adjustments compatible with the application to realize their full potential.

\section{Solar Kinetics, Inc. Production Model}

Solar Kinetics, Inc. (SKI) was awarded the Shenandoah project contract to fabricate the GE-designed 
7-m parabolic dish collector. Part of the contractual obligation was the requirement to provide the first unit for evaluation relative to structural assembly and mechanical operation. The parts were fabricated under production tooling and production processing. The parts were shipped to Sandia's MSSTF, and the north GE prototype dish was disassembled to permit installation of this first production unit (Figures 46(a), (b) and (c). Except for the base support frame, the collector installed at the MSSTF was identical to the instrumented receiver collectors scheduled for installation at Shenandoah. The base support frame on which the collector is mounted was not used in the MSSTF installation because the existing foundation could accommodate it only if major structural modifications had been made. By slotting the holes in the collector base frame assembly, the collector was easily adapted to fit onto the existing foundation at the test site.

SKI used the personnel contracted to install the collectors at Shenandoah to assemble the dish at the MSSTF so that they could gain some experience in the sequence and procedures required to assemble the structure properly.

The reflector petals for the Shenandoah project are covered with an opaque polyolefin film to protect the FEK-244 film during the stamping of the laminate. On those units shipped to the MSSTF, the opaque film was no longer adhering to the FEK film. An oil used to lubricate the press/die during stamping of the petal reflector sections was attacking the adhesive on the protective film. Because it was desirable to leave the opaque film on the reflector during assembly of the collector to avoid eye hazards from concentrated sunlight, the firm fabricating these petals was requested to change to a lubricant (beeswax) that would not attack the film adhesive. This change also alleviated the concern that the lubricant might affect the adhesive on the reflective film. The oil was washed off the affected petals with detergent. No deleterious effect on the reflectivity of the film was noted.

The CCU at the MSSTF was not the same vintage as the CCU scheduled for incorporation at Shenandoah. The modifications to the existing computer control system at the MSSTF to implement a serial address link, which was used at Shenandoah, would have been prohibitively expensive. Therefore, the SKI collector was installed, with the existing CCU providing the necessary computer interface with the collector.

After assembly of the receiver and the associated piping, the plumbing was pressure-tested and insulated. The collector was then rotated through its range of motion, and points of interference were noted and corrected. Rotation to the west, about $10^{\circ}$ below the horizon, caused pinching of the insulation on the piping by the reflector support ribs. Aluminum plates, approximately $5 / 8 \mathrm{in}$. thick, were attached to the rectangular polar axis tube to stop the yoke assembly and thus restrict the over-travel.

Maximum rotation to the east also caused interference and similar actions were taken to relieve these conditions. The support ribs on the reflector impacted the structural member of the frame assembly resulting in indentation of the rib, which imposed a high stress on the collector assembly. A mechanical stop was added to this side of the polar axis mount to limit the over-rotation. Even with these stops the collector attitude at stow continued to be maintained toward the ground so that protection from hail and prevention of dew formation could be preserved.

The collector intercept factor was determined by photographing a lunar image on a target mounted at the receiver aperture. The film was processed, and the total image and the amount in the 18-in.-dia aperture was read on a densitometer to obtain the percentage of reflected energy captured by the receiver. The results showed that the production design collector provided a $95 \%$ intercept factor.

The collector position indicating potentiometers was oriented to provide a $5-\mathrm{V}$ reading with $10 \mathrm{~V}$ impressed across the potentiometers when the collector was positioned to its solar noon position in the polar direction and to its equinox position along the declination axis. The amplifier circuits in the CCU were initialized using a tester that simulated position resistances. The position potentiometers were reconnected and the amplifiers adjusted to provide the required correlating voltages for the angular position of the collector.

The fiber-optic circuitry, which provides a closed circuit tracking capability, was initially balanced using a light source at the receiver and adjusting the photo circuit amplifier output at the CCU to be equal for the north and south optical circuits and for the east and west circuits. The collector was then brought into focus, and the tracking circuit outputs were readjusted to be balanced with the reflected solar image positioned in the receiver (Figure 47). The image was repositioned as required to keep it centered in the receiver aperture during this adjustment. The collector was then allowed to track the sun automatically.

During the period the collector tracked the sun under fiber-optic circuit control, the readings of the position potentiometers were obtained relative to the time of day. These data were then used to establish the tracking algorithm for the computer control of the collector. 


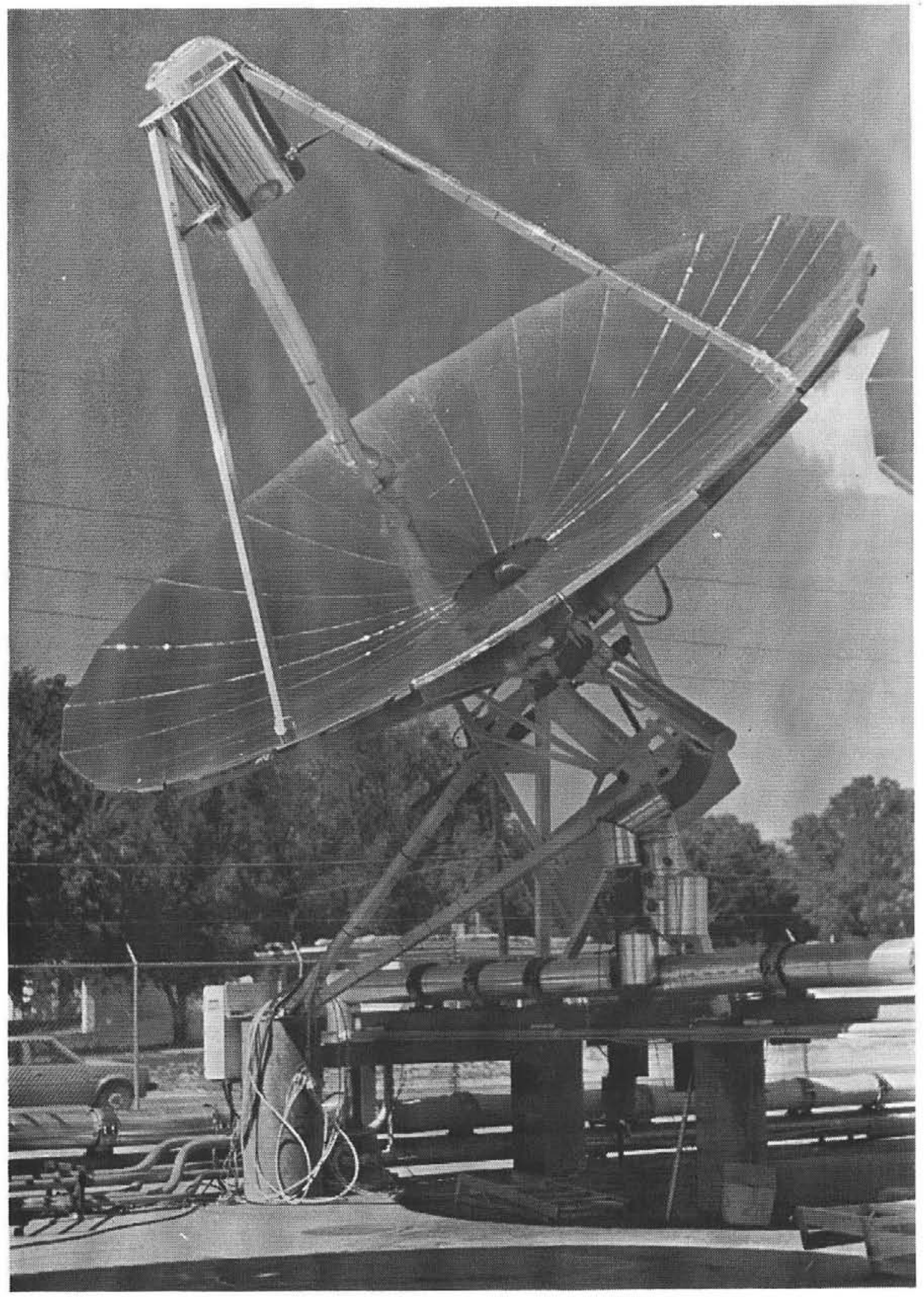

(a) Alone

Figure 46. Shenandoah Prototype Collector 


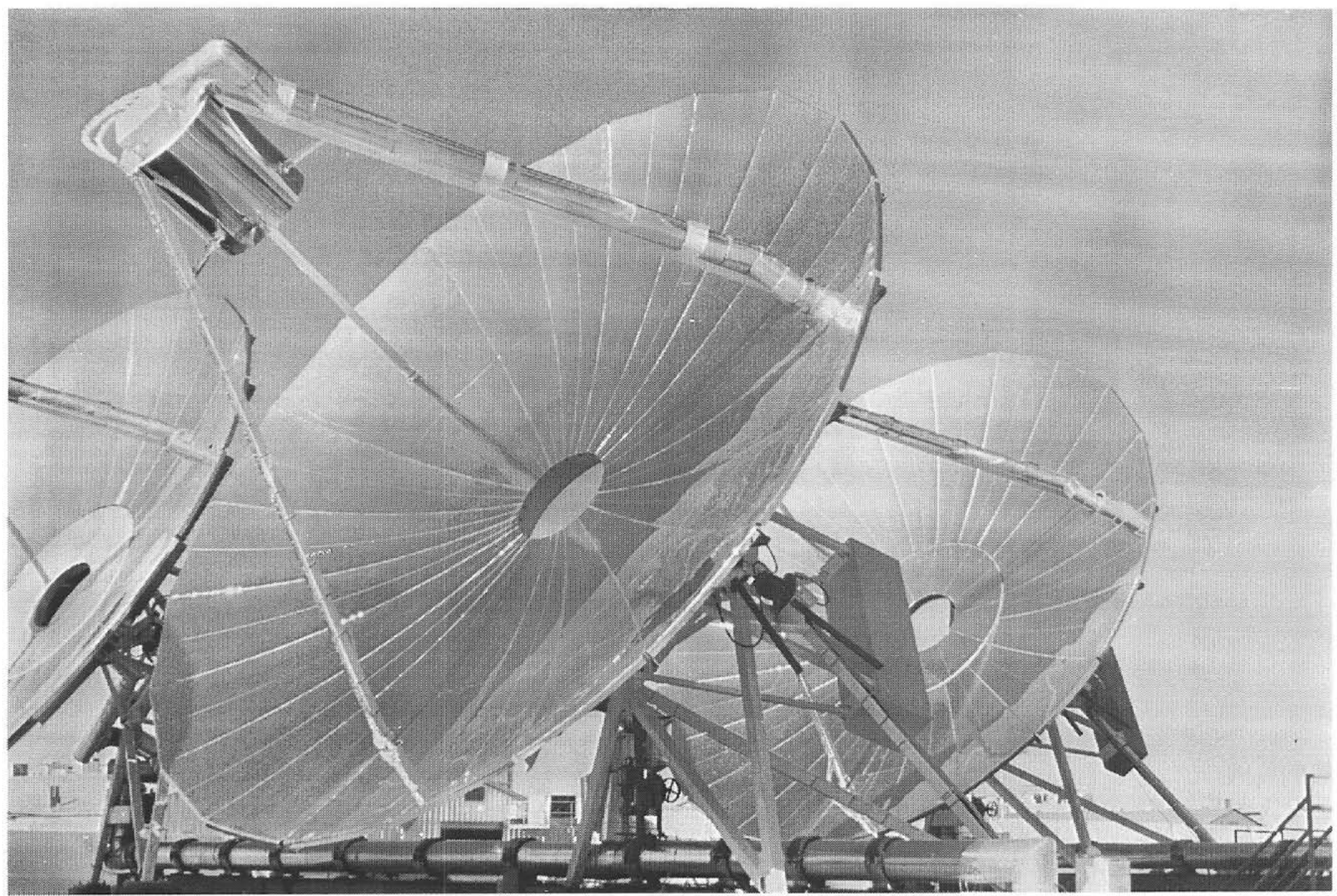

(b) In Quadrant Test Field

Figure 46. Continued 


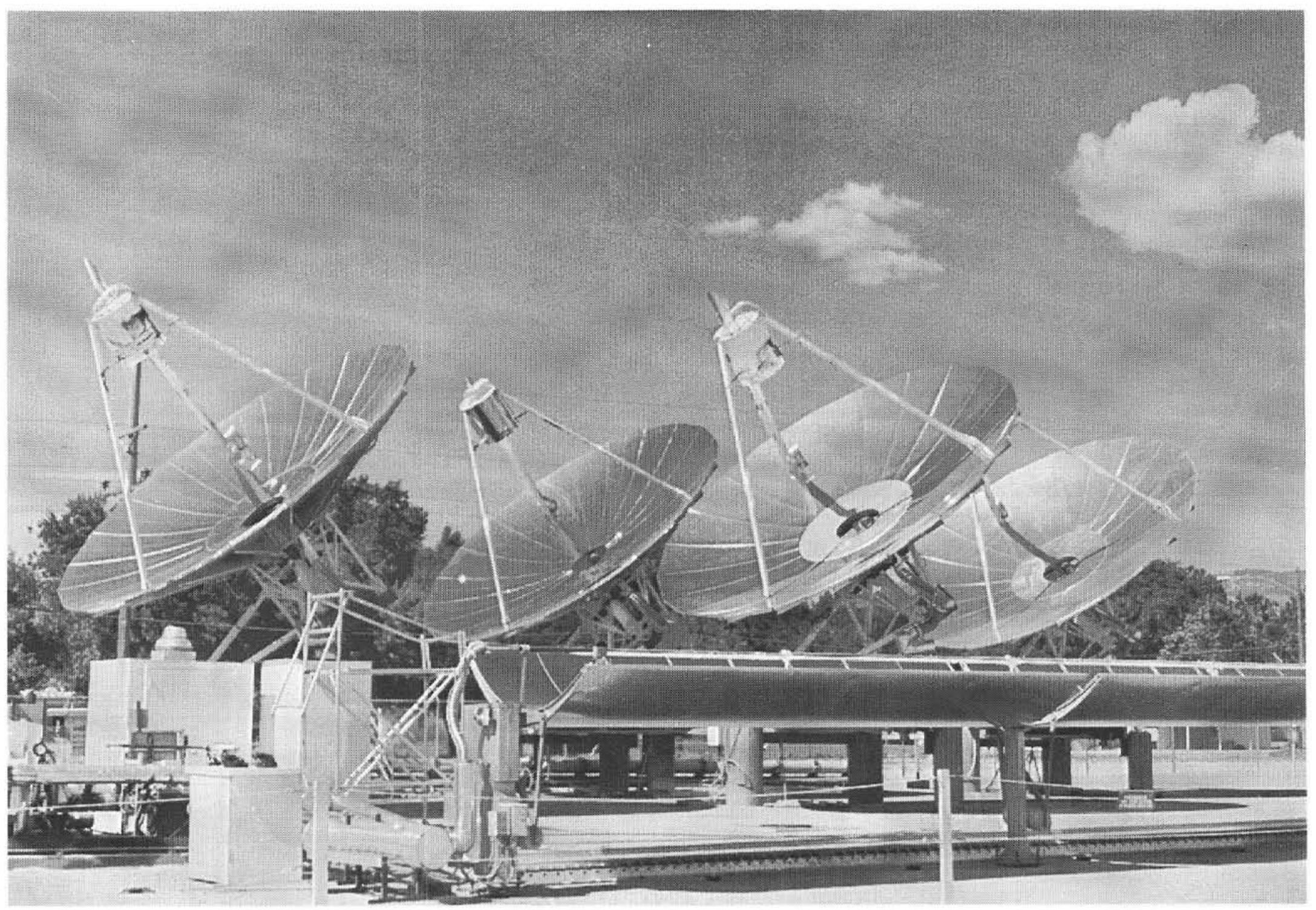

(c) Entire Quadrant Test Field

Figure 46. Continued 


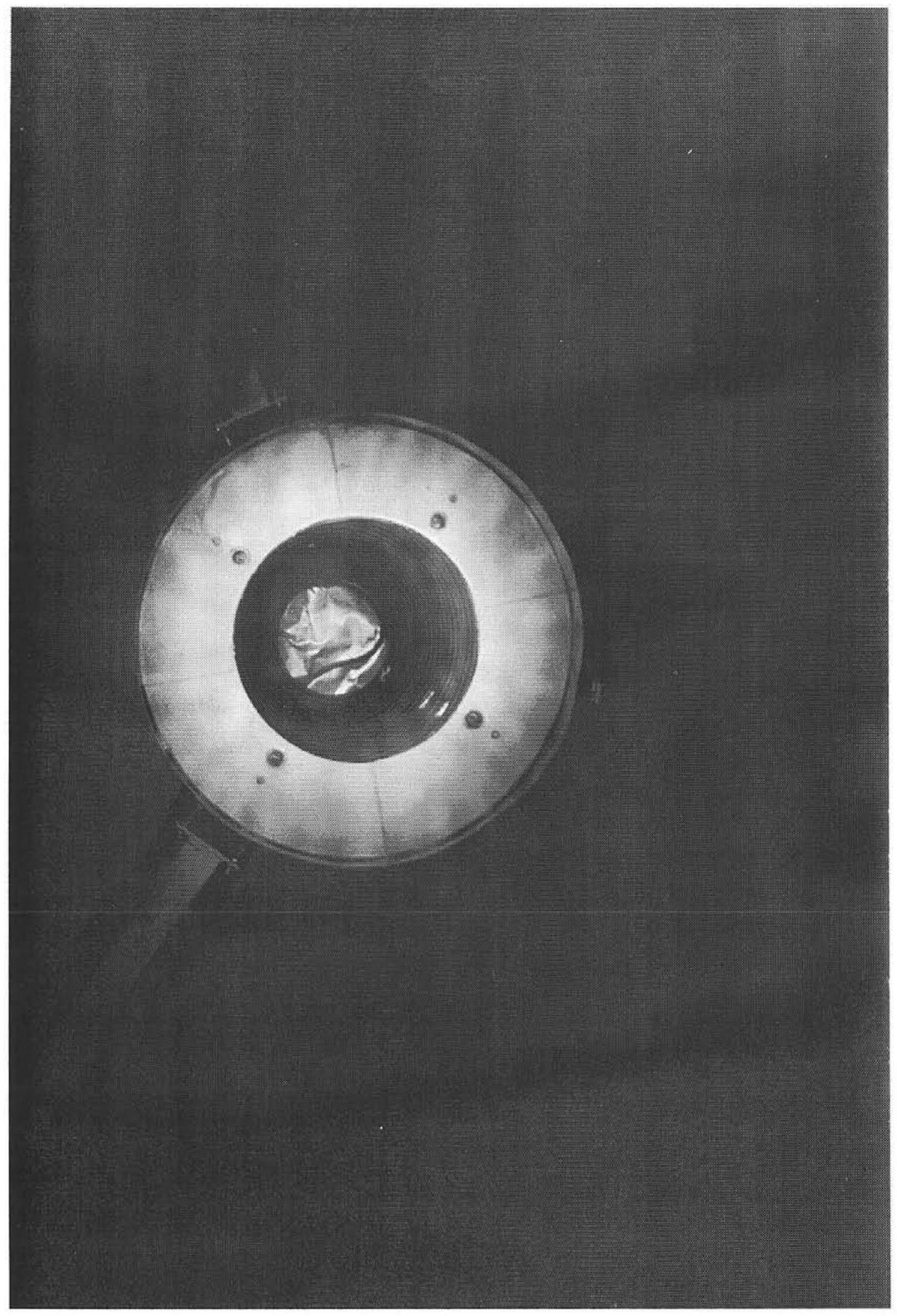

Figure 47. Focused Solar Image in Receiver 
The collector surface was washed and the collector was put into focus to obtain operating information. No manifestation of the temperature anomaly evidenced with the two-coil GE prototype receiver was noted with this single-coil production model. Performance analysis showed the efficiency of the collector to be about $63 \%$ at the operating temperature of $750^{\circ} \mathrm{F}$ for insolation levels of $1 \mathrm{~kW} / \mathrm{m}^{2}$. This compares favorably with the FEK-coated GE prototype collector efficiency. The slight difference in efficiencies, when insolation differences are considered, is attributed primarily to the greater slope error associated with the $10-\mathrm{ft}$ petal sections compared to the $8-\mathrm{ft}$ sections of the GE prototype and is reflected in the slightly lower intercept factor obtained on the SKI dish.

The closed circuit tracking system developed erratic behavior after a few weeks of operation, and its use was discontinued for the rest of the testing period since computer tracking control was still available.
The need to expedite delivery of collectors to Shenandoah to maintain schedule requirements influenced the decision to proceed with the tests using computer control rather than to correct what was suspected to be a noise problem similar to that experienced earlier with the GE prototype collector.

Since assembly and operational capabilities were satisfactorily demonstrated, fabrication and shipment of collector parts to Shenandoah was authorized.

The production collector was retained at the MSSTF as a possible test bed to check out design changes that might be considered in the course of production and to test other aspects of possible collector operation alternatives. Before collectors were installed at Shenandoah, the standby status of this test collector was terminated in favor of conducting any trial design changes or procedures on collectors at the Shenandoah site. This test collector has been scheduled for use as a spare at Shenandoah. 


\section{Shenandoah Dish Construction and Installation}

\section{Parts Manufacture}

\section{Government Furnished Equipment (GFE)}

To expedite production of the GE-designed collector for the Shenandoah STEP, procurement of the aluminum and the FEK-244 film for the reflector was made under government funding. Lamination of the two materials was also performed under government contract (Figure 48). 2600 FEK laminated aluminum sheets covered with a white premask protective film was provided as GFE to the collector contractor. Loan of the die and gauges for fabricating and checking the reflector petal sections was also made to the contractor.

\section{Solar Kinetics, Inc Contract}

The fixed-price contract for the manufacture and installation of the Shenandoah collector was awarded to SKI, of Irving, Texas, under a competitive request for proposal (RFP). A total of 115 collectors (one for evaluation at the MSSTF) plus spare parts and special tooling for installation, as well as field installation manuals, were required under the contract.

Petal Production Subcontract. Dekalb Tool and Die Company, of Tucker, Georgia, was engaged by SKI to stamp the petal reflector sections of the collector. Dekalb was the manufacturer contracted by General Electric to make the petals for the prototype collector. At that time, Dekalb was limited by their press capability to an 8 -ft die, requiring GE to add an annulus section to the reflector to preserve a maximum reflecting surface for the 7-m-dia dish collector. With the subsequent acquisition of a 300 -ton press, the full length $(\sim 10 \mathrm{ft})$ petals could be die-stamped. The die was modified by extending the narrower section, and the surface was recontoured to provide the proper "spring-back" of the laminated petals after stamping to effect the desired parabolic shape.

The premask protective film on the FEK laminated aluminum sheets permitted the stamping operations to proceed with dispatch since it eliminated the somewhat tedious alignment of a mylar protective template associated with stamping operations on the 8-ft petals (Figure 49).

The laminated aluminum, which was provided as $46 \times 129$ in. sheets, was first trimmed to the triangular shape. The film was then sectioned into six approximately equal areas by skiving a $3 / 32$-in. piece of the reflective film. To avoid stress-cracking, the film was also removed at the edges where the material was to be bent over. FEK-244 film has only a $7 \%$ stretch capability. The prepared sheets were then die-stamped to the required parabolic shape.

Dekalb Tool and Die Company was originally selected by GE because of their long association with Scientific Atlanta in the manufacture of dish communications and tracking antennas using manufacturing techniques for antennas that were also suited for fabricating solar reflectors. Scientific Atlanta had been retained by $\mathrm{GE}$ as a technical advisor for the design, fabrication, assembly, and determination of costs for a dish solar collector.

Three of the production petals were laser-ray traced at Sandia's facility established to measure the slope error of parabolic solar mirrors (Figure 50). Results showed the petals had radial slope errors of $\sim 3.5 \mathrm{mrad}$ and circumferential slope errors of $\sim 4.3$ mrad, resulting in an rms slope error of about 5.5 $\mathrm{mrad}$. This slope error is less than the 8 -mrad design goal established by GE as the criterion needed to achieve a collector efficiency of $65 \%$. The four radial and four circumferential laser-ray traces of a typical sweep are shown in Figure 51. The 432 individual laser-ray measurement points were reflected toward a photodiode target located at the nominal focal point. Of the total of 432 reflected points, $373(86 \%)$ fell within the 10-in.-dia active area of the photodiode target (Figure 52). Subsequent intercept factor determinations of the entire dish assembly were made by making densitometer measurements of the moon's image at the receiver. These tests showed a $95 \%$ capture within the 18-in. diameter of the receiver aperture. 


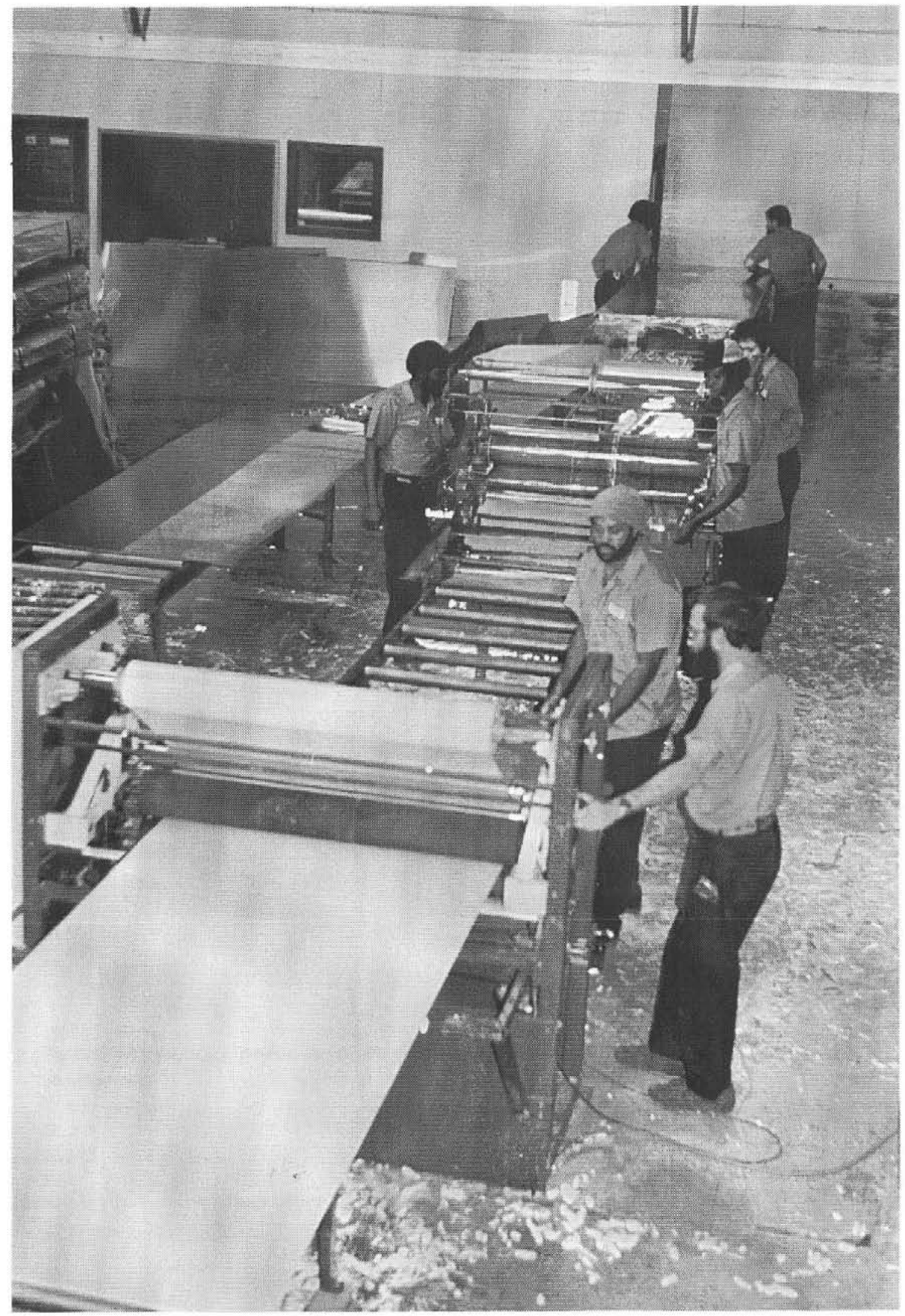

Figure 48. Reflector Laminating Process 


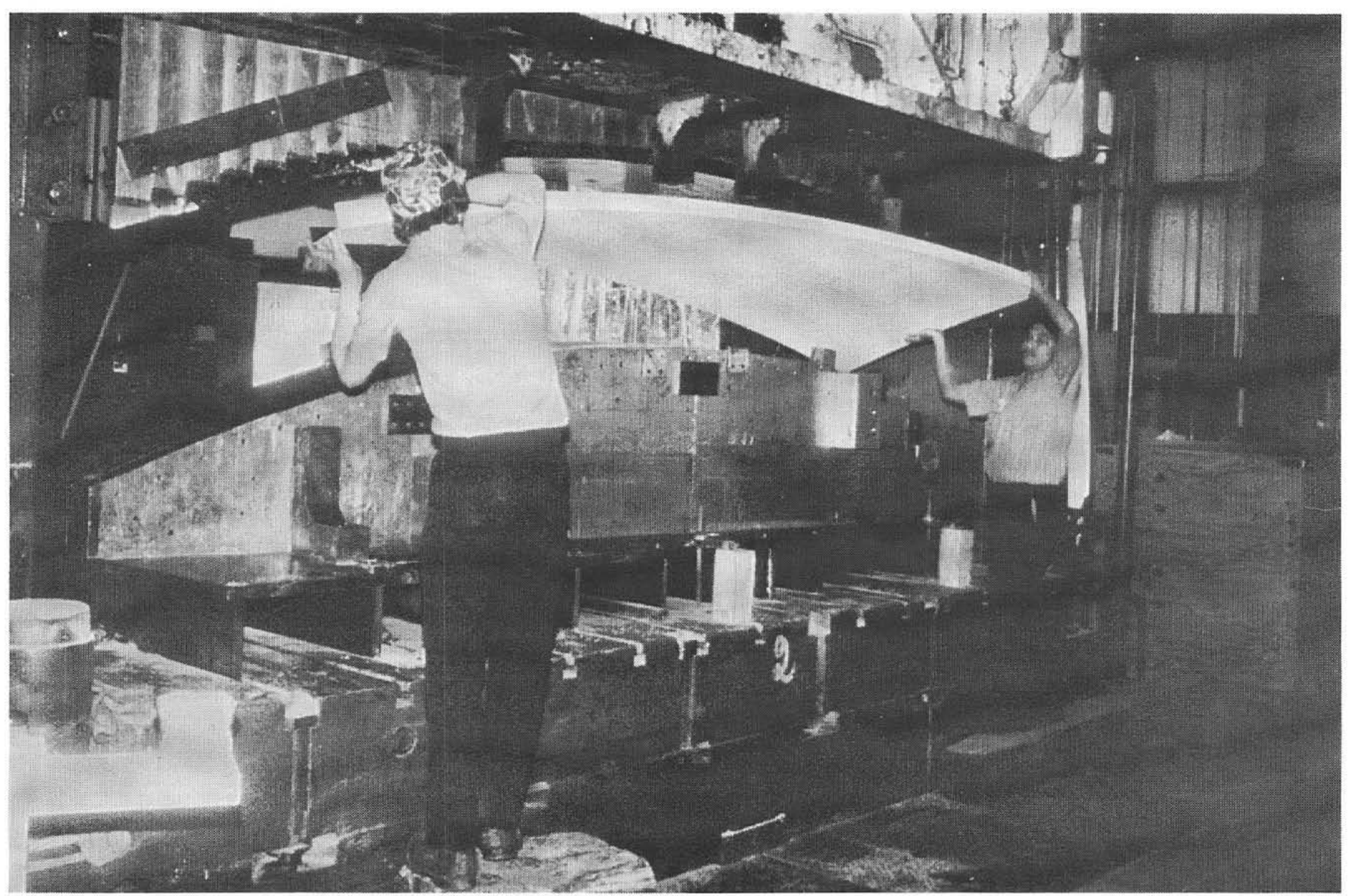

Figure 49. Die Stamping 


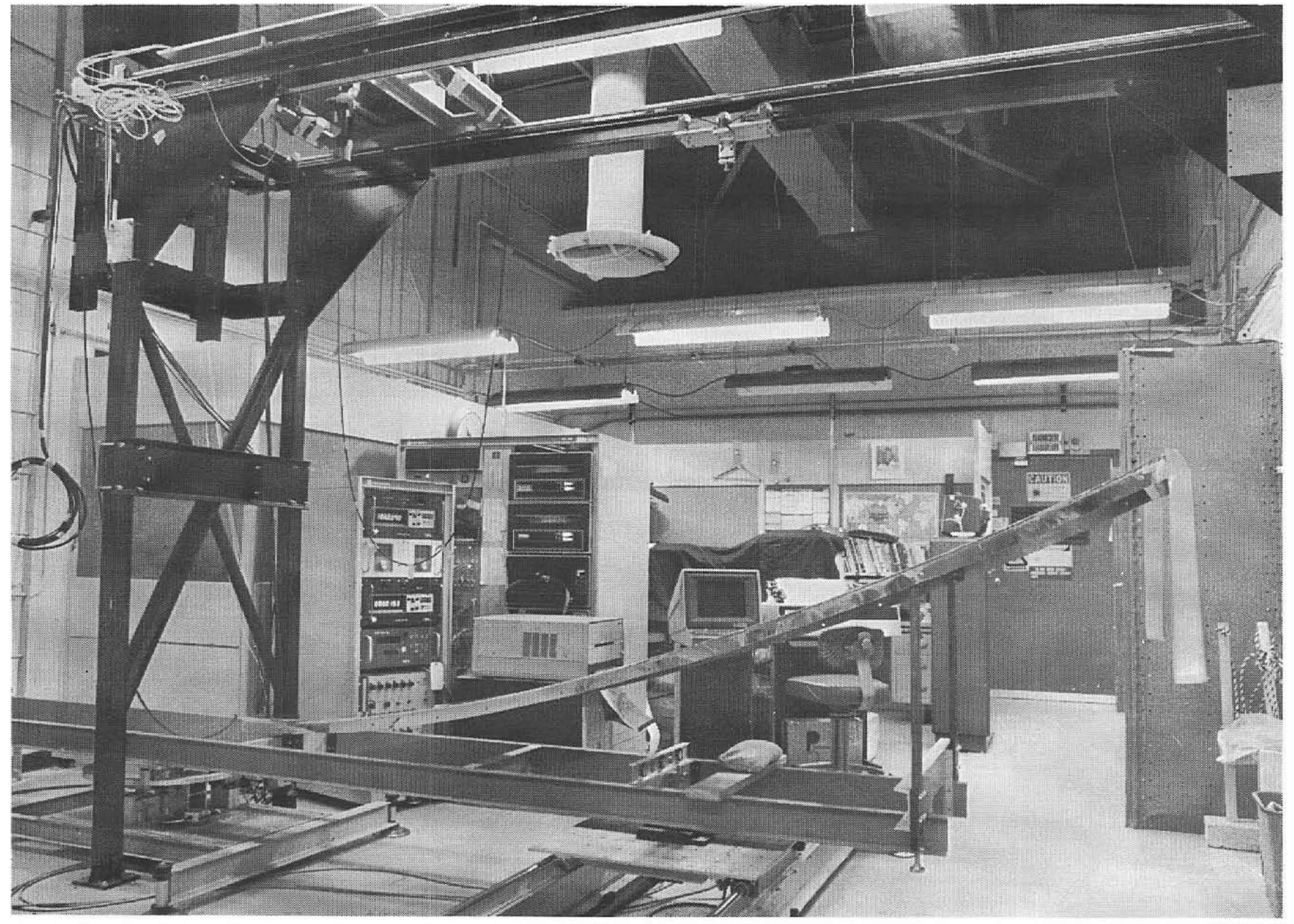

Figure 50. Laser-Ray Tracing 
ESCO2 SCANNED 08-JUN-81 10:52:03

134.2 NOMINAL FOCAL LENGTH 373 POINTS OF 432

RAD 3.51588, TANG 4.02924, RMS 5.34754

UPPER PLOT SHOWS RADIAL ERROR, LOWER SHOWS TANGENTIAL ERROR

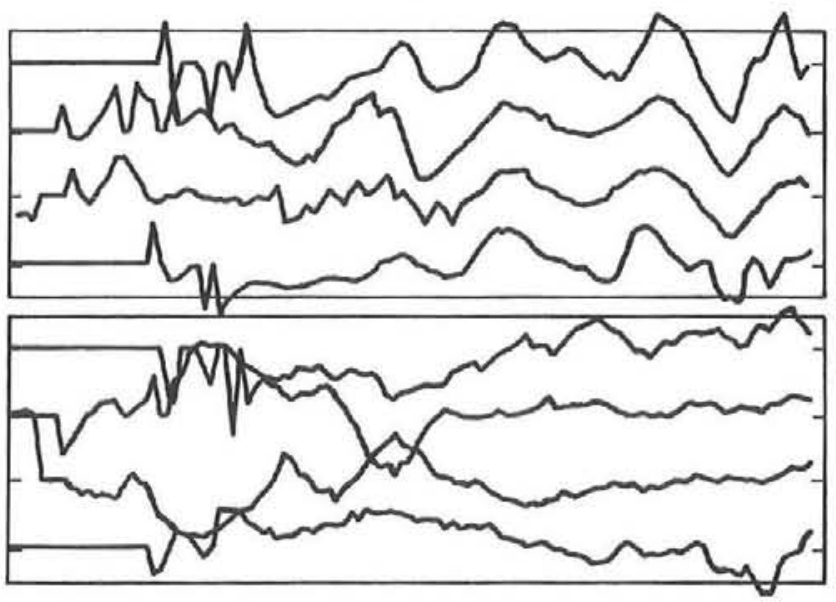

Figure 51. Slope Error Plot From Laser-Ray Tracing
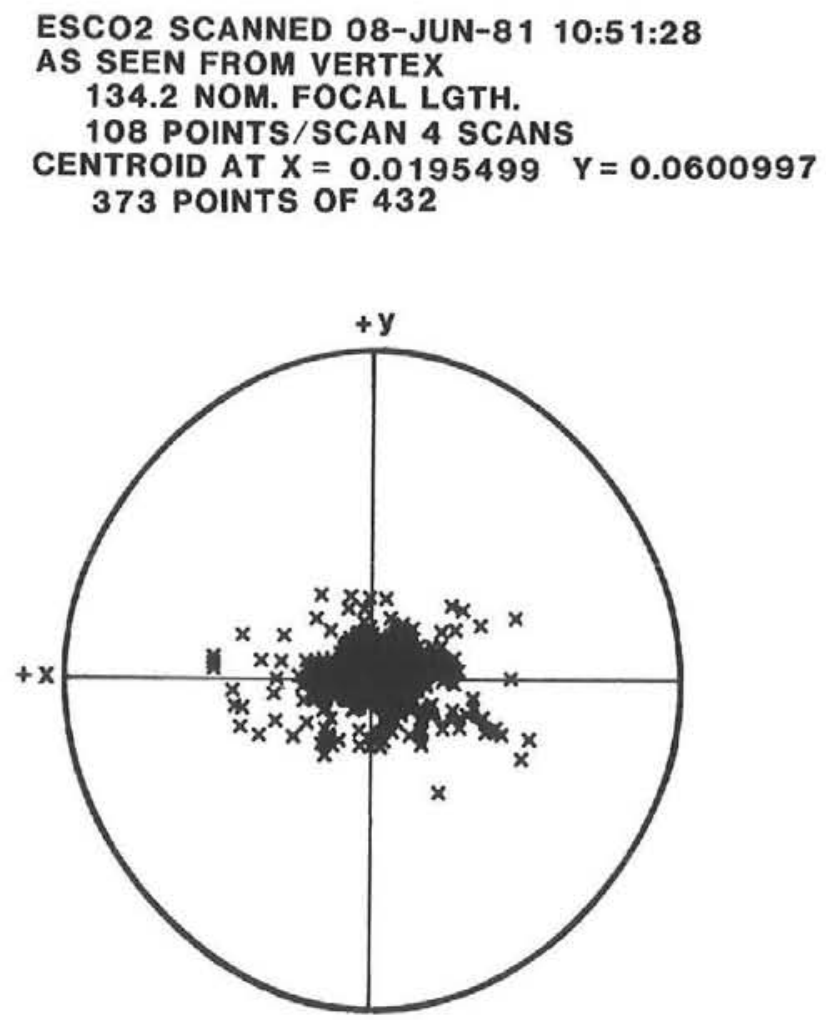

Figure 52. Focal Plane Distribution Plot 
Structural Production Subcontract. American Alloy, Inc, of Tucker, Georgia, the firm that had fabricated the base frame assembly and the yoke assembly of the collector for GE was engaged to conduct the same functions for SKI in the production of the Shenandoah Solar Collectors. An additional function performed by American Alloys was the assembly of the base frame and yoke and the installation and functional checkout of the two polar drive jackscrew assemblies on the frame assembly. The preassembled structure was delivered intact to the Shenandoah site, some 75 miles away, by American Alloys using their specially fabricated "lowboy" trailer. Every effort was made to install the frame assembly on the foundations at the time they were delivered to avoid extra handling (Figure 53).

Hub and Other Parts. SKI contracted with a local Dallas firm, Walden Industries, to fabricate the hub assembly, which is the structural form on which the reflector ribs and petals are assembled and which interfaces with the yoke to form the collector (Figure 54). The hub pivots on the yoke to assume the declination position required for acquisition of the sun.

The early design of the hub specified an aluminum casting to keep the total collector weight down. However, the cost was prohibitive, so a rolled and welded aluminum structure was fabricated for the GE prototype collectors tested at the MSSTF. Because the costs for these aluminum hubs were still high, a steel weldment substitute was specified, and structural reinforcements were incorporated into the collector where analysis indicated a need due to the added weight of the steel hub.

The same firm, Walden Industries, also fabricated the swing-arm assembly that is the pivoting platform to which both polar drive jackscrews are attached and that moves the collector from horizon to horizon.

In addition, Walden Industries fabricated the receiver coil. Some difficulty was encountered initially with the stainless steel tubing retaining its configuration when it was removed from its coil mold. Subsequent material analysis disclosed the tubing supplier had shipped material with other than the specified annealing. The correct material permitted coil fabrication without difficulty. The coils were painted with Pyromark (a black absorber material made by Big-3 Industries) and baked in a kiln to vitrify the material. The procedures for firing specified by GE were followed faithfully. However, it was noted that some receiver coils had shiny surfaces whereas others had a dull black finish. The as-received samples of the two finishes were analyzed for absorptivity and emissivity and found to be slightly different $(\alpha / \epsilon=0.96 / 0.83$ shiny, $=0.94 / 0.7$ dull). The differences were small and any noticeable distinction in collector operation as a result was not expected to occur. It was determined that the variation in surface finish resulted in part from the temperature at which the samples were removed from the oven after the final curing cycle. Remaining coils were subjected to the same conditions prior to removal from the oven to maintain consistency in the finished product.

Receiver. Receiver parts were fabricated by various small businesses and shipped to SKI for assembly. SKI installed thermocouples on two of the receiver coils. These were highly instrumented to provide an indication of collector behavior under Shenandoah operating conditions. Two resistance temperature devices (RTDs) were installed in each receiver coil to be used as control elements to sense over-temperature conditions. One was inserted in an immersion well at the mid-point of the receiver, and the other at the outlet. Either RTD that sensed a temperature greater than $770^{\circ} \mathrm{F}$ would initiate collector defocusing. The RTDs were secured to the receiver with Saverisen cement, a water-based compound, which dried into a hard, heat resistant, refractory material. Each circuit was checked after installation for a resistance of 100 ohms to confirm its integrity.

The four fiber-optic circuits were carefully emplaced and thermally protected from the receiver coils by Kaowool insulation. Additional insulation was inserted in locations where direct concentrated solar energy impingement could occur. 'Light continuity through each fiber-optic channel was confirmed after installation.

\section{Installation}

\section{Assembly Procedure}

SKI subcontracted with Trojan, Inc., of Stone Mountain, Georgia, to assemble and install the collectors at the Shenandoah site. Trojan had personnel at Sandia for the installation of the first production collector in the MSSTF to gain insight into the procedures and processes that would be required at Shenandoah. These procedures were incorporated into an Installation Manual by SKI that described the steps in the assembly and erection of the collector. See Appendix A. 


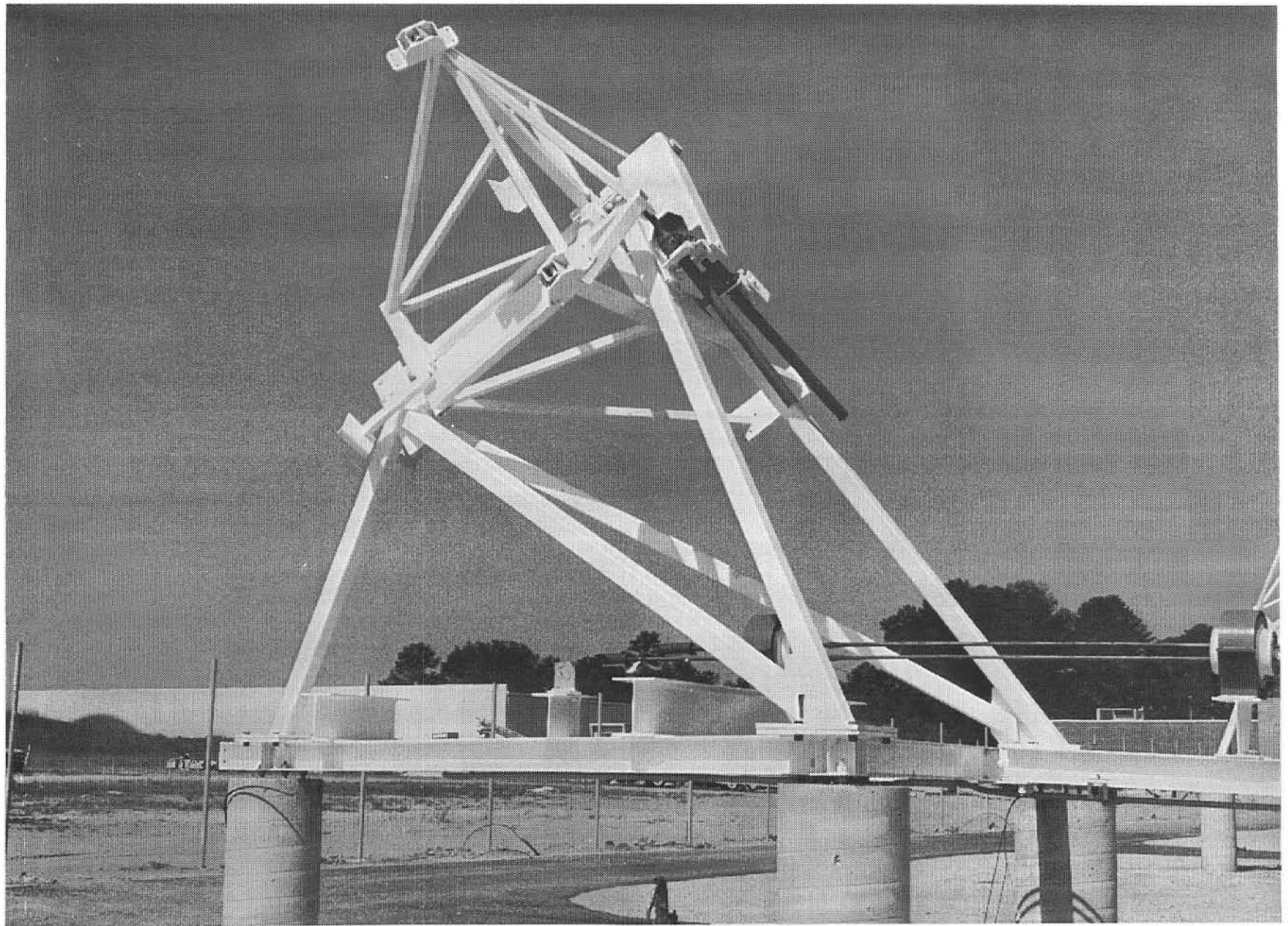

Figure 53. Preassembled Frame 


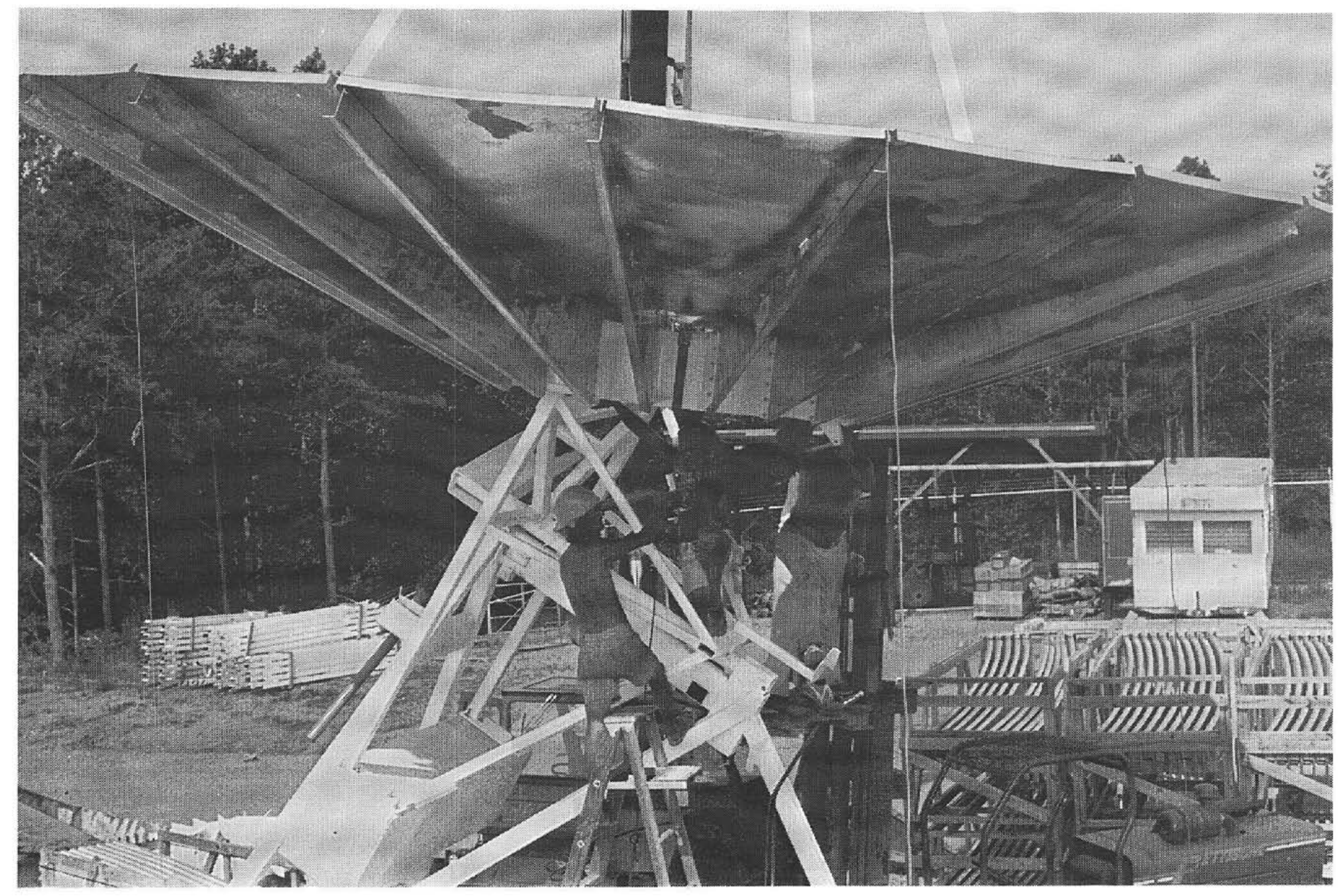

Figure 54. Reflector/Yoke Assembly 
The initial site assembly activity, which was not exercised with the MSSTF collector, was the emplacement of the triangular support assembly (on which the collector frame was erected, and which also supported the collector piping) on the concrete foundations (Figure 55). As the collector frame assemblies were delivered to the site, they were mounted on the support assemblies (Figure 56).

The next step was to attach the precast, 2650pound concrete counterweight to the frame assembly in preparation for counterbalancing the reflector assembly (Figure 57).

Support ribs were attached to the hub and the 21 reflector petals were then assembled to the supporting structure (Figure 58). The receiver struts were then attached to the reflector assembly. The premasked surface of the reflector allowed the assembly and installation to proceed without requiring sun-shading measures for protection of personnel (Figure 59). The total reflector assembly was then attached to the yoke section of the collector frame, and the declination jackscrew was installed to control the reflector position relative to the yoke (Figure 60).

The receivers were then lifted into place and positioned with the adjustable struts on the main struts to locate the receiver axially with the reflector. No major difficulties were encountered in this procedure. However, some wind screens (which are the extension of the shell beyond the aperture plate) were inadvertently deformed during installation and had to be replaced.

The piping between the receivers and the field plumbing was emplaced next (Figure 61). The 3/4-in.dia tube carries the cooler incoming heat transfer fluid, and the 1/2-in.-dia tube carries the expanded solar heated fluid. After pressure-testing, the collector piping was connected to the collector row plumbing. Fluid was passed through the receiver to flush the system and to check for any fluid leaks. The HTF lines were then insulated and covered with a protective aluminum casing.

RTD and optical connections were made between the receiver and the CCU through the southeast receiver mounting strut. This expedient was used to provide protection against thermal heating during solar acquisition or defocusing of the collectors. Cable routing from the receiver to the CCU was not a trivial matter because the cables had to be supported without being constrained to avoid damage during collec- tor motion. The connections to the three drive motors and the two position-indicating potentiometers were then made and terminated at the CCU. Each connection completed at the CCU was checked to substantiate the integrity of the particular circuit prior to its termination in the CCU.

The final installation activity was the removal of the premask from the reflector petals. The first set of collectors installed at the site had been exposed to the atmosphere for about 6 months. Previous tests of samples at Sandia had indicated that ultraviolet exposure of the premask would affect the adhesive and cause the film to bond to the reflective surface after about 6 to 7 months of exposure. This was the case on those first collectors at Shenandoah. The premask removal was a tedious time-consuming process. The removal of premask from other collectors was easily effected since they had been protected from ultraviolet exposure prior to their assembly, and premask removal operations were conducted shortly after assembly.

\section{Preliminary Checkout}

Prior to transfer of each of the collectors to the DOE, SKI was charged with the responsibility of ensuring the completeness of the assembly and prior installation according to the drawings and instructions defining that assignment.

- Each motor was activated to exercise the collector to the limits of its travel.

- Each fiber-optic channel was checked for a minimum output at the CCU with a calibrated light source illuminating the fiber at the receiver aperture.

- Each RTD was checked for the proper resistance reading $(\sim 100 \mathrm{ohms})$ for the existing ambient temperature.

- The position potentiometers were adjusted to provide the proper voltage reading with the collector oriented at the noon-equinox attitude.

- The electrical cables were also checked to insure that faults to ground or to other circuits did not exist.

As soon as each row of collectors was judged by SKI to meet assembly and installation requirements, it was turned over to the DOE for inspection and acceptance-testing. 


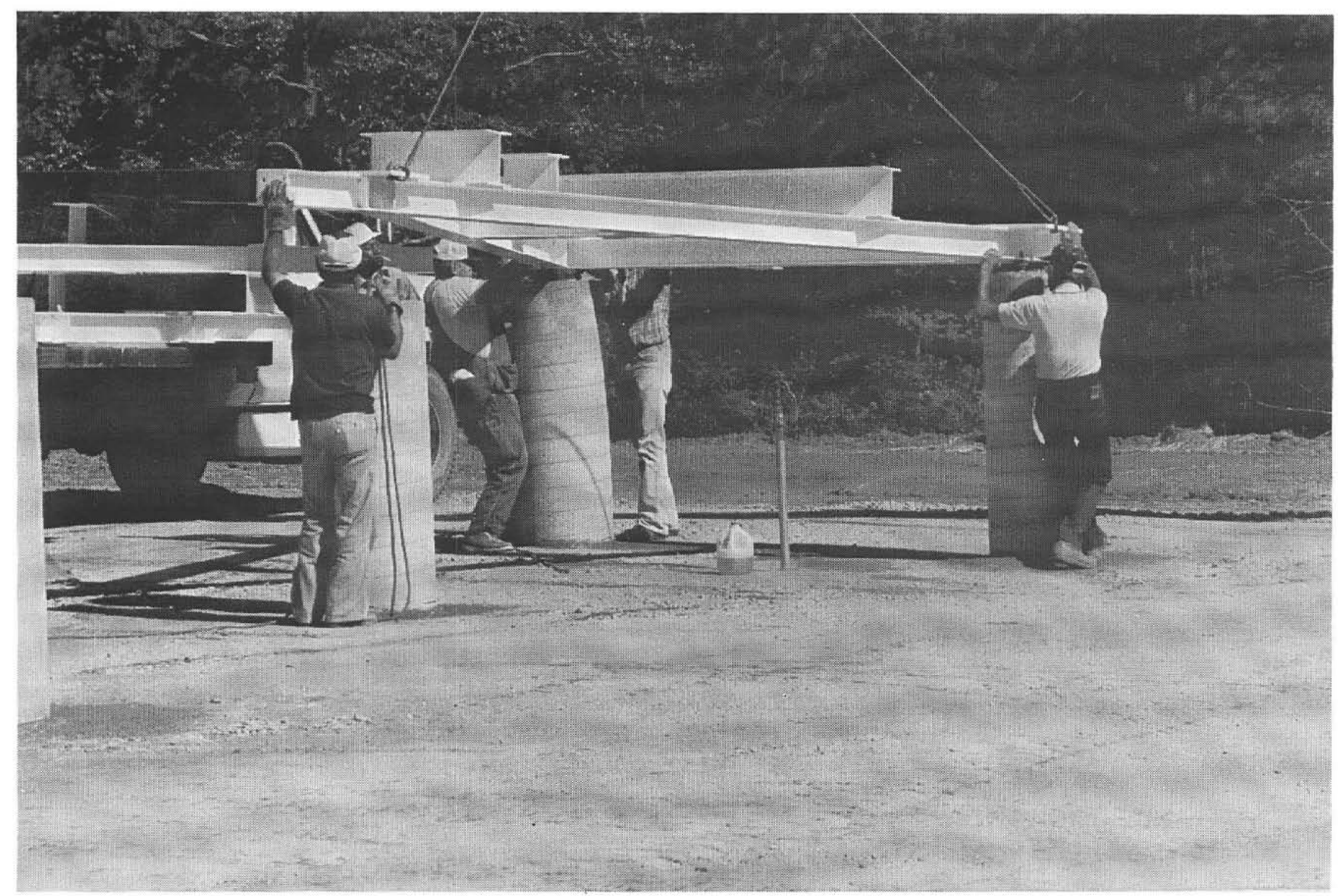

Figure 55. Support Assembly Installation 


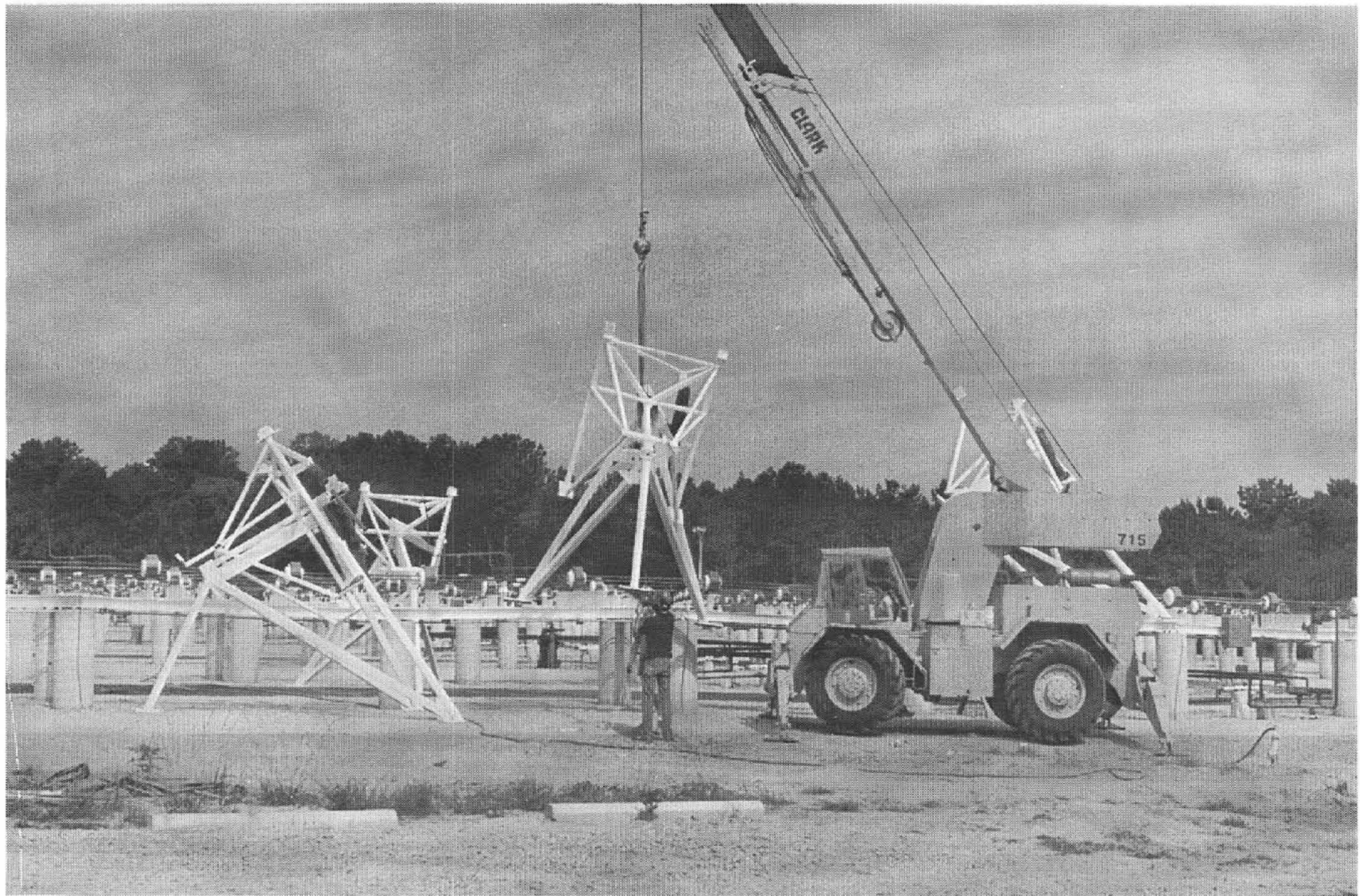

Figure 56. Frame Assembly Installation 


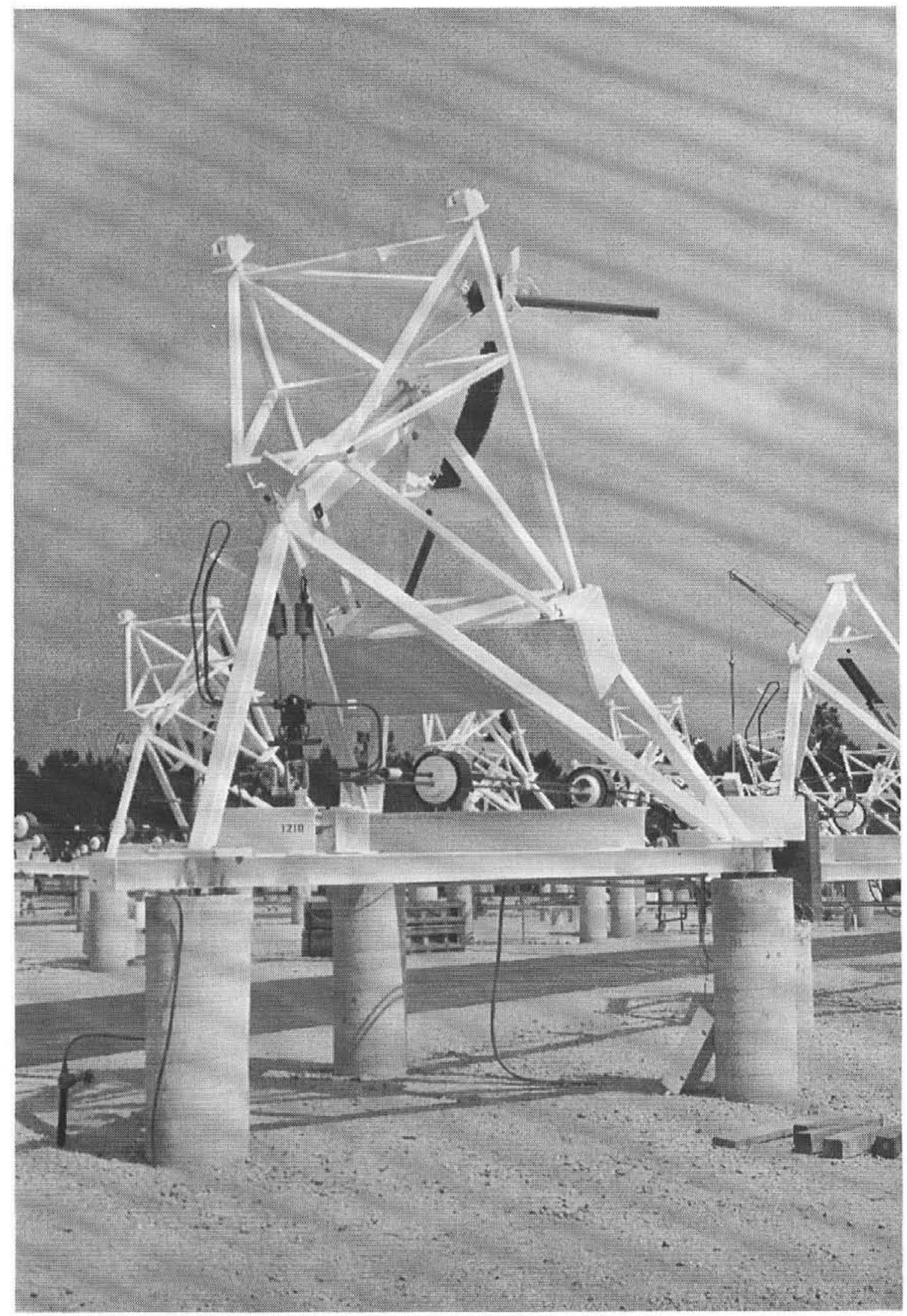

Figure 57. Counterweight Installation 


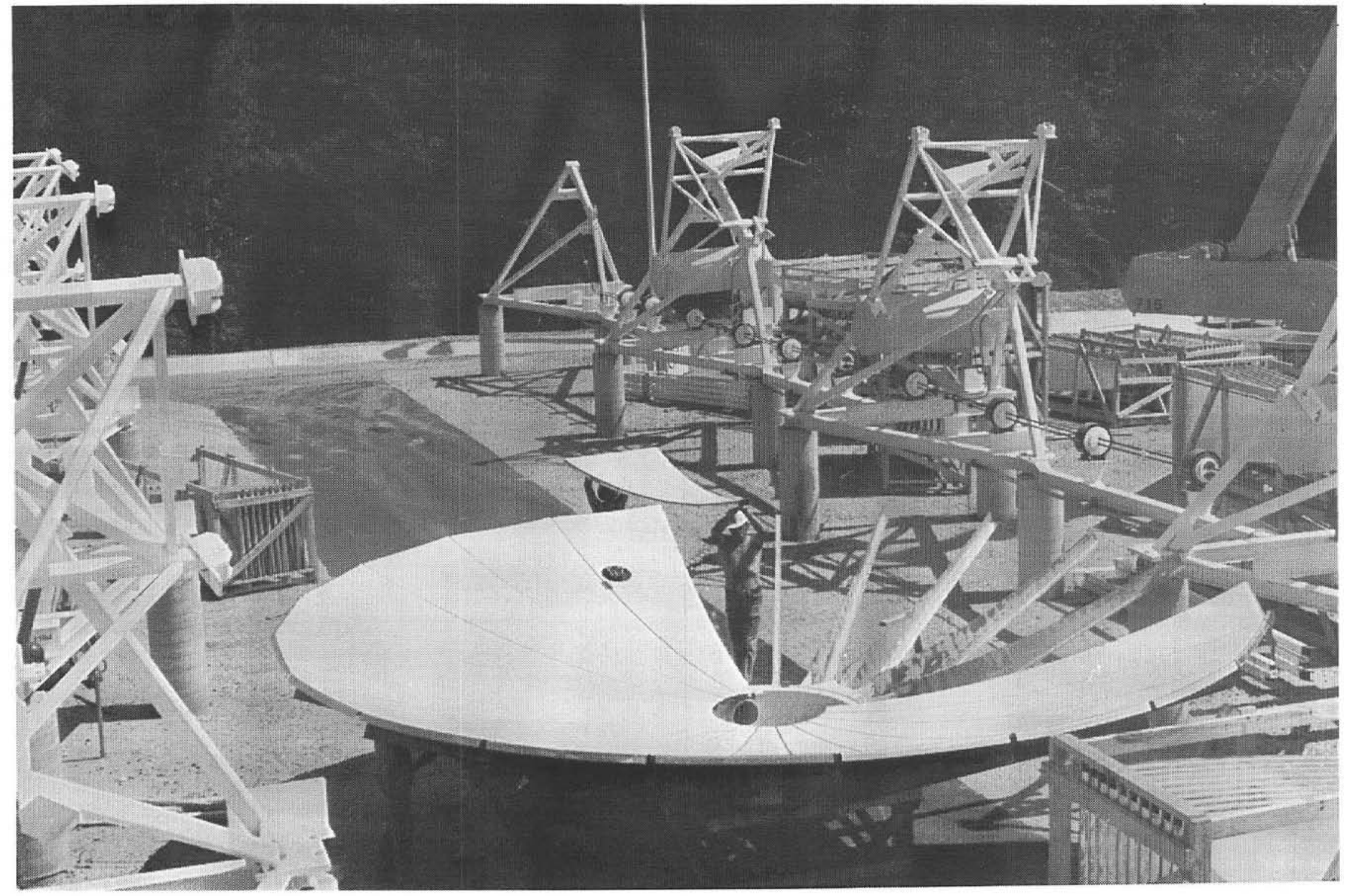

Figure 58. Reflector Assembly 


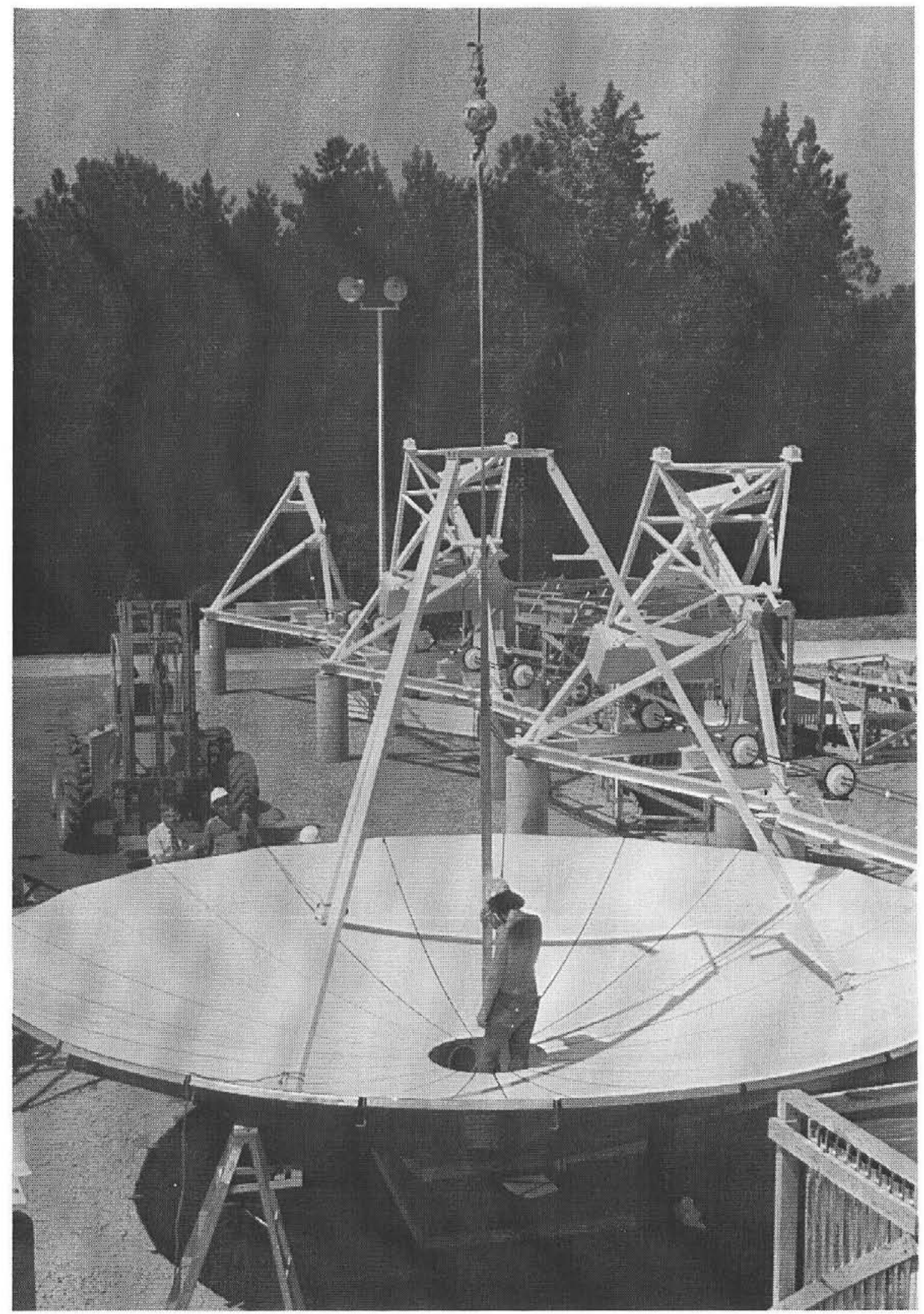

Figure 59. Reflector Assembly 


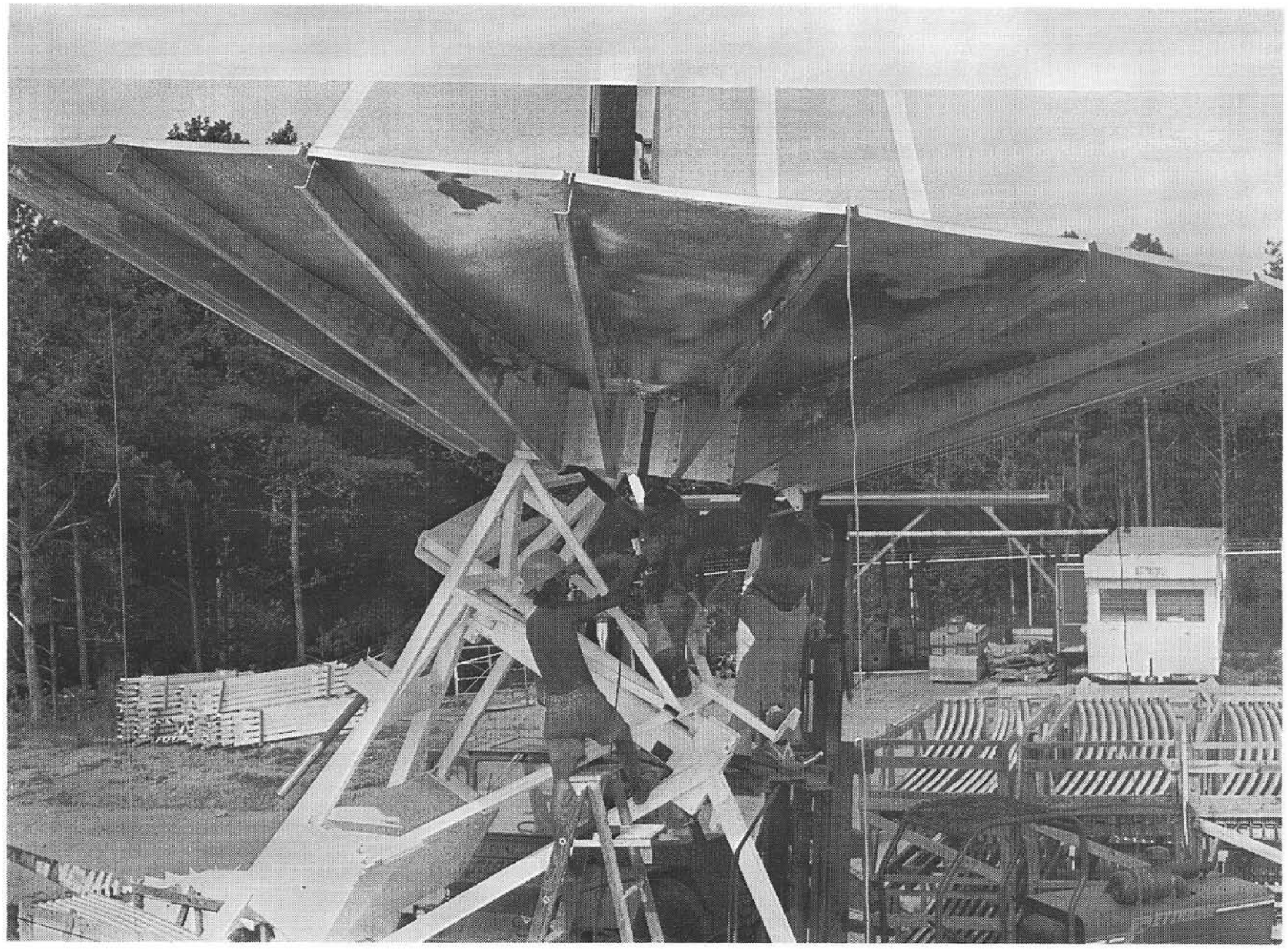

Figure 60. Reflector/Jackscrew Installation 


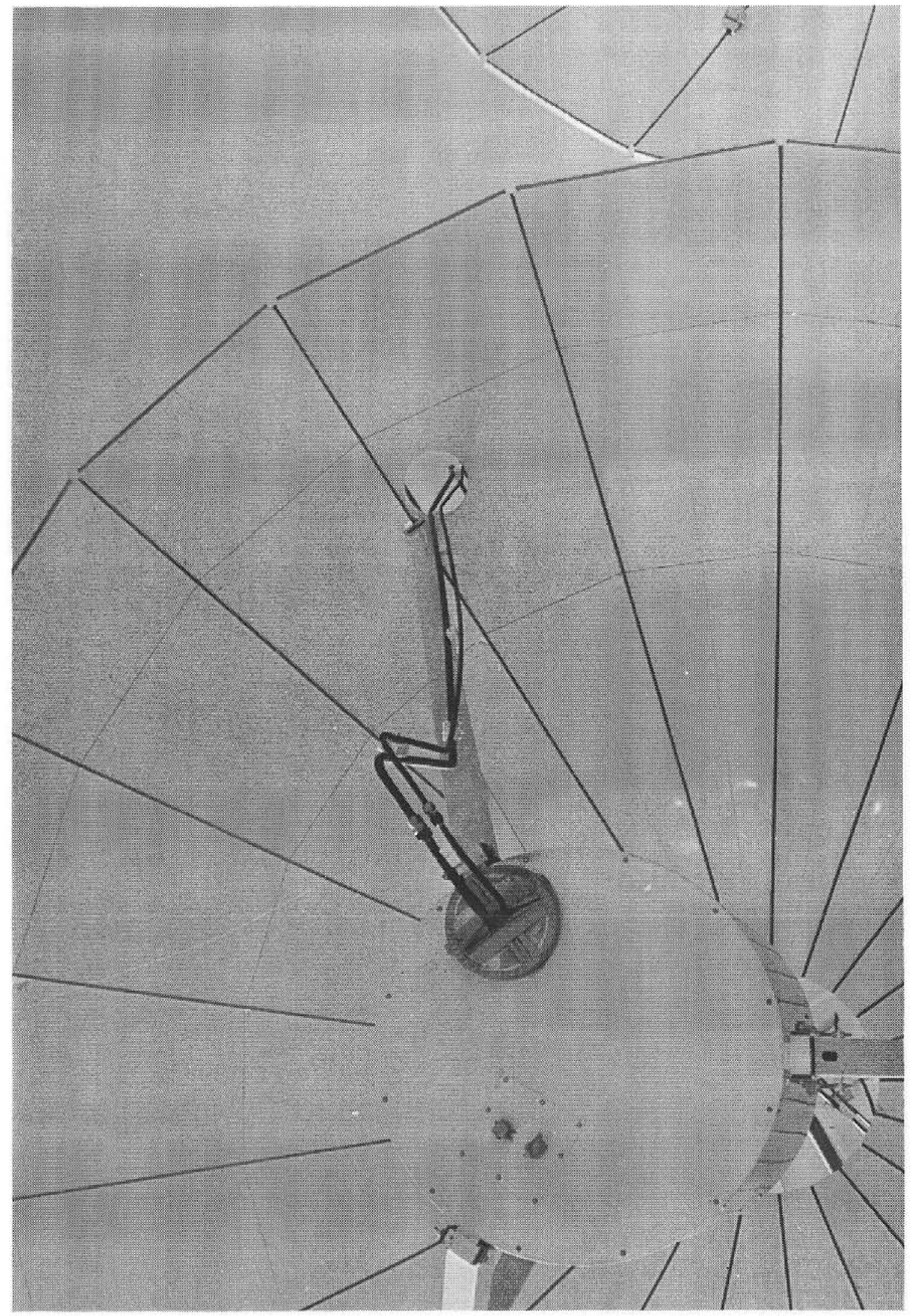

Figure 61. Piping 


\section{Site Operation Requirements}

\section{Collector Inspection}

The DOE had retained Heery and Heery, an Atlanta-based architecture and engineering firm, to provide construction inspection services at the Shenandoah site. Part of these duties called for the inspection and acceptance-testing of the collectors. As each row of collectors was transferred to DOE custody by SKI, Heery and Heery checked to see that each collector assembly and its installation conformed to the appropriate specifications and drawings.

Mechanical inspection of the collector assembly included

- Examination of the quality of the painting and welding

- Assuring that the proper washers, flat and/or lock, were installed with the nuts in proper order and tightened to the proper torque

- Assuring that the cables were routed and secured properly and that hardware used was that specified

- Checking for evidence of cosmetic or functional damage

- Assuring that the swagelok tubing connections were properly torqued and the plumbing pressure-tested, that the subsequent piping insulation was properly jacketed and caulked, that the fiber-optic circuit at the receiver aperture was firmly affixed, that the receiver was properly centered, that the mechanical amendments to the collector, such as the mechanical stops, had been implemented and that no structural flaws existed in the mechanical assembly

Electrical inspection verified that proper connection of wires between the connector pins and the intended circuits had been made, that the collector could be cycled through its limits in polar and declination directions, that position potentiometers were properly set to produce the voltage readings in agreement with the collector orientation, and that thermocouple and RTD readings conformed to proper values. The fiber-optic circuits were also tested to verify that the light attenuation was below limits. A sample of the inspection report criteria for each collector is appended as Exhibit A.

\section{Calibration and Acceptance- Testing}

Following collector inspection, acceptance-testing was undertaken. Each CCU was mated to a tester and calibrated to produce the range of indications from expected collector inputs. The collector connections were then made to the $\mathrm{CCU}$, and the $\mathrm{CCU}$ was readjusted to provide the proper output with the collector positioned for noon at equinox. The collector was then exercised through its range of motion. Orientations at each of four compass headings (SE, SW, NW, and NE) were assumed by the collector and indicated readings were taken of the position potentiometers as the collector was "boxed" (traversed from "corner" to "corner").

If the potentiometer readings reflected less than the normal range of readings or produced anomalous readings, the potentiometers were replaced and the sequence was repeated. Postmortem examinations of the faulty potentiometers revealed that the units did not have a hermetic seal. As a result, the cases "breathed" and ingested humid air, which condensed moisture internally. As a result of this disclosure all potentiometers were removed from the field, processed through a 2- to 3 -day bake period in an incubator at $\sim 200^{\circ} \mathrm{F}$ (to prevent damage to the potentiometer), then sealed around the cover and shaft. The sealed potentiometers were then checked for any erratic resistance readings as the shaft was slowly turned through $360^{\circ}$ of rotation, and a number of them had to be replaced. The process of accepting collectors was resumed with the newly sealed position potentiometers. However, not all refurbished potentiometers functioned properly in the field. Apparently the laboratory environment under which the potentiometers were screened did not duplicate the field environment stresses well enough to reveal potentially weak units. All the potentiometers that failed in the field were replaced, and collector acceptance was continued.

Another irregularity noted with the position potentiometer was the indicated constant reading even though the collector position varied. The problem was traced to setscrew failure-the small setscrews in the flexible coupler that interfaced the rotating collector member to the potentiometer shaft did 
not hold securely. The condition was accentuated with the moisture seal implemented on the potentiometer shaft, which created a need for greater torque to turn the shaft. The setscrews were replaced with capscrews that permitted the couplers to retain a firm grip on the potentiometer shaft. In a few instances, the pin driven into the rotating collector member did not hold and had to be redriven or replaced with other knurled pins having a greater nonslip surface.

On a number of collectors, RTD circuits manifested open-circuit or short-circuit resistance conditions in contrast to the nominal $100 \mathrm{ohms}$ expected under the ambient conditions at the site. Inspection revealed the most prevalent cause for open circuits was the detachment of the lead wire at the weld to the platinum leads of the RTD at the receiver thermalwell. The cause appeared to be the corrosive action of the Sauerisen cement (used to bond the RTD leads to the receiver coil) on the copper lead wires. Exercising care in insulating the wires prior to bonding and changing the formulation for compounding the cement removed this cause for open RTD circuits. Other open circuits were found to be caused by broken leads at the terminal board at the rear of the receiver. Short circuits were also caused by the corrosive action of the Sauerisen cement. The corrosive copper compound either leached and directly shorted leads or formed shorts to the coil and to system ground. The previous measure for preventing open circuits also resolved the problem of short circuits arising from this cause. Other causes for short circuits were attributable to displaced connector pin assignments at the $\mathrm{CCU}$ and were easily corrected.

A few initial instances of low light transmission through the fiber-optic circuits were traced to broken glass rods or to the glass fiber bundle in the main cable between the receiver and CCU. These were easily corrected. A few reduced transmission cases were resolved by merely closing the gaps at the joints and/or cleaning the faces of the optical interfaces.

The nonsealed drive motors were also disposed to humidity effects. The prevalent manifestation was a low starting torque motor that would, once started, reverse rotation upon driving the collector to its limit, instead of stopping. The cause was an open start winding. All motors in the field were refurbished to correct the faults and dip-coated to prevent future humidity effects on the coil. The gearbox was also relubricated, and the case was sealed after reassembly.

A few collectors could not be driven completely to their stow position or, having achieved stow, could not be driven out of stow. The defect was found to be a misalignment of the clevis that accepted the jackscrew. Interference of the jackscrew occurred in the stow position and effectively froze the joint, preventing collector movement. To correct this problem, the clevis spacing was expanded and the jackscrew mount was shimmed for better alignment of the shaft with the clevis.

With the resolution of the noted problems, the field of 114 collectors was accepted.

\section{Maintenance}

During the period when control of the collector field was being interfaced to the computer, individual collectors were found to require additional maintenance. Some instances of mid-point and outlet RTDs having interchanged pin assignments in the connector were easily resolved. However, RTDs manifesting low resistance or shorted conditions were also evidenced. For these cases, it was found that the circulation of warm heat-transfer fluid through the receiver would alleviate the low-resistance condition. The heat would drive off the moisture which the Kaowool insulation in the receiver had absorbed and subsequently transferred to the hygroscopic Sauerisen cement covering the RTDs. The wet cement caused these low readings. Because water entry into the receiver during rainstorms with the collector in its stowed position is difficult to avert, low RTD readings after heavy precipitation is to be expected. Since the condition is alleviated upon operation, it is not considered a cause for concern.

During an exercise to establish compatibility with the computer, some of the collectors were inadvertently left in a vertically facing orientation. Subsequent movement of the sun directed the caustic from the collector to impinge on the back of the adjacent southerly collector. The aluminum petals absorbed sufficient energy to raise the temperature of the aluminum to a level that caused sections of the reflective film on the front to turn an opaque, milky white. The damaged film was removed with some difficulty because the film adhesive had vulcanized to the aluminum substrate. The reflective surface was repaired according to the recommended procedures of the film supplier. Operating procedures have been revised to prohibit collector orientations that can produce such conditions.

Computer interfacing with the collector also revealed faults in the CCU. The modular construction of the CCU allowed the substitution of the complete printed circuit board, permitting the computer interfacing to continue with minimal interruption. Repairs were promptly performed on defective boards, making them available as spares. Also, a few CCUs required replacement of one or both of the dc power supplies, and relays had to be exchanged in one of the CCUs. 


\section{Exhibit A}

\section{SOLAR TOTAL ENERGY PROJECT \\ SHENANDOAH, GEORGIA \\ INSPECTION REPORT CRITERIA \\ FOR ALL SOLAR COLLECTORS}

\section{A. FRAME ASSEMBLY}

1. Base Assembly

Required hardware (per Dwg 47J240738)

Required bolt torque (per Dwg 261A2905)

Condition of welds

Condition of paint

Any structural flaws

2. Yoke Assembly

Required hardware (per Dwg 919E116 \& 47J240735)

Required bolt torque (per Dwg 261A2905)

Condition of welds

Condition of paint

Any structural flaws

3. Counterweight

Required hardware (per Dwg 47J240738)

Required bolt torque (per Dwg 261A2905)

Required weight $(2650 \pm 50$ pounds)

Any structural flaws

4. Mechanical Drive Stops

Required number of stops (2)

5. Ground Straps

Hub to yoke assembly (per Dwg 47J240738)

Yoke assembly to base assembly (per Dwg 47J240735)

Base assembly to field ground

6. Polar Drive Assembly \#1

Required hardware (per Dwg 147D9655 \& 147D9637)

Required bolt torque (per Dwg 261A2905)

Keys in keyway

Correct drive alignment

Bellows correctly installed

LB correctly mounted, oriented, and inserted

Any structural flaws

Condition of paint

7. Polar Drive Assembly \#2

Required hardware (per Dwg 147D9655 \& 147D9637)
Required bolt torque (per Dwg 261A2905)

Keys in keyway

Correct drive alignment

Bellows correctly installed

LB correctly mounted, oriented, and inserted

Any structural flaws

Condition of paint

8. Drain Hole at Potentiometer

\section{B. COLLECTOR REFLECTOR}

1. Petal to Petal Assembly

Required hardware (per Dwg 149D9876)

Required bolt torque (per Dwg 261A2905)

Petals butted together at the bolts

Correct assembly of petals (per Dwg 47J240736)

2. Petal to Hub Assembly

Required hardware (per Dwg 919E139)

Required bolt torque (per Dwg 261A2905)

Condition of paint

3. Reflector Surface

Condition of premask

Condition of FEK-244

4. Declination Drive Assembly

Required hardware (per Dwg 221B3013 \& 147D9637)

Required bolt torque (per Dwg 261A2905)

Keys in keyway

Correct drive alignment

Bellows correctly installed

LB correctly mounted, oriented, and inserted Any structural flaws

Condition of paint

\section{COLLECTOR RECEIVER}

1. Strut Assembly

Required hardware (per Dwg 147D9880)

Grade 8 bolt for struts to reflector

Required bolt torque (per Dwg 261A2905) 
Exhibit A. Continued

Correct alignment of struts to receiver No free play between struts and receiver Condition of paint

\section{Receiver Assembly}

Fabric covering in place

Tubes properly anchored

Receiver at focal point of reflector

\section{TUBING}

Tubing installed with no tubes touching each other

Flexible hose installed (per Dwg. 147D9633)

Flexible hose correctly oriented

Correct tubing connections (per Dwg. 919E145)

Correct tubing routing (per Dwg. 47J240738)

Pressure test (100 psi minimum to 125 psi maximum)

\section{E. INSULATION}

Correct number of spacers

Correct type of insulation

Fully covered

Fully bracketed and caulked

\section{F. ELECTRICAL}

1. Polar Motor \#1

Pin Connector P7 (per Dwg 184C8033)

From P4 red to PM \#1 white for main winding

From P5 orange to PM \#1 black for main winding

From P6 white/blue to PM \#1 yellow for capacitor winding

From P7 green/yellow to PM \#1 green for case ground

From P8 black to PM \#1 blue for capacitor winding

Proper routing and tie-down

2. Polar Motor \#2

Pin Connector P7 (per Dwg 184C8033)

From P11 red to PM \#2 white for main winding

From P12 orange to PM \#2 black for main winding

From P13 white/blue to PM \#2 yellow for capacitor winding

From P14 green/yellow to PM \#2 green for case ground

From P15 black to PM \#2 blue for capacitor winding

Proper routing and tie-down
3. Declination Motor

Pin Connector P7 (per Dwg 184C8033)

From P18 red to DM white for main winding

From P19 orange to DM black for main winding

From P20 white/blue to DM yellow for capacitor winding

From P21 green/yellow to DM green for case ground

From P22 black to DM blue for capacitor winding

Proper routing and tie-down

4. Potentiometers

Pin Connector P3 (per Dwg 184C8042)

From P1 black to P2-A for excitation $(-10 \mathrm{Vdc})$

From P2 clear to P2-B for wiper (signal-polar)

From P3 red to P2-C for return

From P4 bare to P2-D for shield drain

From P5 black to P1-A for excitation $(-10 \mathrm{Vdc})$

From $\mathrm{P} 6$ clear to $\mathrm{Pl}$-B for wiper (signal-polar)

From P7 red to Pl-C for return

From P8 bare to Pl-D for shield drain

Proper routing and tie-down

5. RTDs \#1 and \#2

Pin Connector P4 (per Dwg 184C8043)

From P1 black to TB-1 for S1

From P2 clear to TB-2 for S2

From P3 red to TB-3 for R

From P4 bare to TB-4 for shield

From P5 black to TB-5 for S1

From P6 clear to TB-6 for S2

From P7 red to TB-7 for R

From P8 bare to TB-8 for shield

Proper routing and tie-down

6. Fiber Optics (N, S, E, W)

Correct connections (per Dwg 128C8690 \& 295A8367)

Proper routing and tie-down

7. Thermocouples

Correct connections on $\mathrm{G} 2$ solar collectors (0603 \& 0610)

See Dwg 221R957

\section{G. OPERATIONAL CHECK}

1. Movement of Collector

Polar \pm 90

Declination $\pm 231 / 2$

2. Potentiometer Settings

3. Fiber Optics

Attenuation measurements and designation 
Exhibit A. Continued

\section{H. PAINT}

Inspect for proper finish

Torque Specifications

\begin{tabular}{|c|c|c|c|c|}
\hline Drawing & Name & Size & Quantity & $\begin{array}{l}(\mathrm{ft} \mathrm{lb}) \\
\text { Torque }\end{array}$ \\
\hline \multirow[t]{10}{*}{471240738} & Caisson to Base Assy & $7 / 8-9$ & 9 & 525 \\
\hline & Base Assy to Collector Frame & $3 / 4-10 \times 3.00 \mathrm{LG}$ & 12 & 365 \\
\hline & Flexible Hose to Mtg Bracket & $1 / 4-20 \times 13 / 8 \mathrm{LG}$ & 10 & 6 \\
\hline & Counterweight to Yoke Assy & $1 / 2-13$ & 12 & 30 \\
\hline & Yoke Assy to Hub Assy & $3 / 8-24 \times 129 / 64 \mathrm{LG}$ & 8 & 15 \\
\hline & Grn Strap Hub Assy to Yoke Assy & $3 / 8-16 \times 11 / 2 \mathrm{LG}$ & 1 & 15 \\
\hline & Potentiometer to Mtg Bracker & $1 / 4-20 \times 1 / 2 \mathrm{LG}$ & 2 & 6 \\
\hline & Bolt for Cable Strap for Declination Pot & $1 / 4-20 \times .62 \mathrm{LG}$ & 1 & 6 \\
\hline & Bolts for Cable Straps for Receiver & & & \\
\hline & Cables & $1 / 4-2 \times .62 \mathrm{LG}$ & 3 & 6 \\
\hline \multirow[t]{4}{*}{ 47J240735 } & Lower Bearing on Yoke Assy & $3 / 4-10 \times 6 \mathrm{LG}$ & 3 & 365 \\
\hline & Upper Bearing on Yoke Assy & $3 / 4-10 \times 23 / 4 \mathrm{LG}$ & 4 & 365 \\
\hline & Grn Strap Collector Frame to Base Assy & $3 / 8-16 \times 3 / 4 \mathrm{LG}$ & 2 & 15 \\
\hline & Grn Strap Yoke Assy to Hub Assy & $3 / 8-16 \times 3 / 4 \mathrm{LG}$ & 1 & 15 \\
\hline \multirow[t]{4}{*}{ 47J240737 } & $\begin{array}{l}\text { Bracket to Strut for Insulated Tubing } \\
\text { (Self-Tap) }\end{array}$ & $8-32 \times 1 / 2 \mathrm{LG}$ & 12 & $11 / 2$ \\
\hline & Strut to Receiver & $1 / 2-13 \times 43 / 4 \mathrm{LG}$ & 3 & 30 \\
\hline & Brace at Reflector for Strut Support & $5 / 16-18 \times 13 / 4 \mathrm{LG}$ & 6 & 12 \\
\hline & Strut to Reflector (Grade 8) & $5 / 16-18 \times 21 / 4 \mathrm{LG}$ & 10 & 6 \\
\hline \multirow[t]{4}{*}{$47 \mathrm{~J} 240736$} & Hub Assy to Rib Support & $3 / 8-16 \times 11 / 4 \mathrm{LG}$ & 125 & 15 \\
\hline & Panel to Panel & $5 / 16-18 \times 1 \mathrm{LG}$ & 186 & 12 \\
\hline & Panel to Panel at Hub Assy & $5 / 16-18 \times 7 / 8 \mathrm{LG}$ & 42 & 12 \\
\hline & Jacket around Tubing Insulation & $1 / 4-20 \times 3 / 4 \mathrm{LG}$ & 10 & 6 \\
\hline \multirow[t]{2}{*}{ 147D9637 } & Gearmotor to Mtg Bracket & $1 / 4-20 \times 11 / 4 \mathrm{LG}$ & 4 & 6 \\
\hline & Jactuator to Mtg Bracket & $5 / 8-11 \times 11 / 4$ LG & 4 & 75 \\
\hline $184 \mathrm{C} 8016$ & Counterweight $\mathrm{J}$ Bolts & $1 / 2-13 \times 21 / 4 \mathrm{LG}$ & 12 & 30 \\
\hline $184 \mathrm{C} 8044$ & Strut Adjustment & $3 / 8-16 \times 3 \mathrm{LG}$ & 2 & 15 \\
\hline
\end{tabular}




\section{Field Performance Results}

\section{Availability}

After acceptance of the collectors and their interfacing with the computer for control and information accessing, the collectors were individually rechecked to assure that the initial calibration had been preserved. If not, needed corrections were made to restore the unit to its operational state. Individual collectors were then brought into focus so that adjustments to the fiber-optic tracking system could be made. The E-W and N-S optical circuits were balanced while the collector was manually adjusted to keep the receiver apertures visually aligned with the reflected solar image. After all 114 collectors had been balanced, field operations were directed toward row operation and total field operation whenever solar conditions were adequate.

During such exercises, some collectors manifested operational anomalies symptomatic of previous conditions requiring correction. With each succeeding field operation, however, these conditions diminished in number. Such anomalies will probably not be totally eliminated, but they will be reduced to occasional occurrences not unexpected in the operations and maintenance requirements of mechanical components of a solar system.

A condition that had not materialized previously began appearing with repeated acquisition of the sun. This was the deterioration of the automatic tracking capability of the collectors. Investigations into the cause disclosed that the receiver insulation contained "thermal holes," which allowed the fiber-optic cables to be subjected to temperatures that, in some instances, fused the optical fibers in the cable bundle or burned through the bundle. The cables were rerouted and additional insulation was installed to plug these holes. These measures have been effective in protecting the fiber-optic cables from the thermal effects of the concentrated solar beam. A related effect due to the thermal leak in the receiver was the occurrence of low RTD readings from some of the collectors. The cause of these low readings was traced to the melting of the insulation on the interface cable that connects to the RTD leads at the junction terminal block at the rear of the receiver. The melting insulation allowed the leads to short. Progressive improvement has been made in eliminating these conditions with each operation of the collectors as more of the collectors with thermal protection weaknesses are revealed and subsequently rehabilitated.

\section{Energy Collection}

The availability of the system has not allowed a comprehensive program to be conducted from which the operational capability of the collector field could be characterized. However, a measure of its capability is indicated by some data collected on October 15, 1982, during an all-day tracking exercise. The existing insolation on that day, the energy collected, and the energy produced are shown in Figures 62 and 63, and Table 9, respectively.

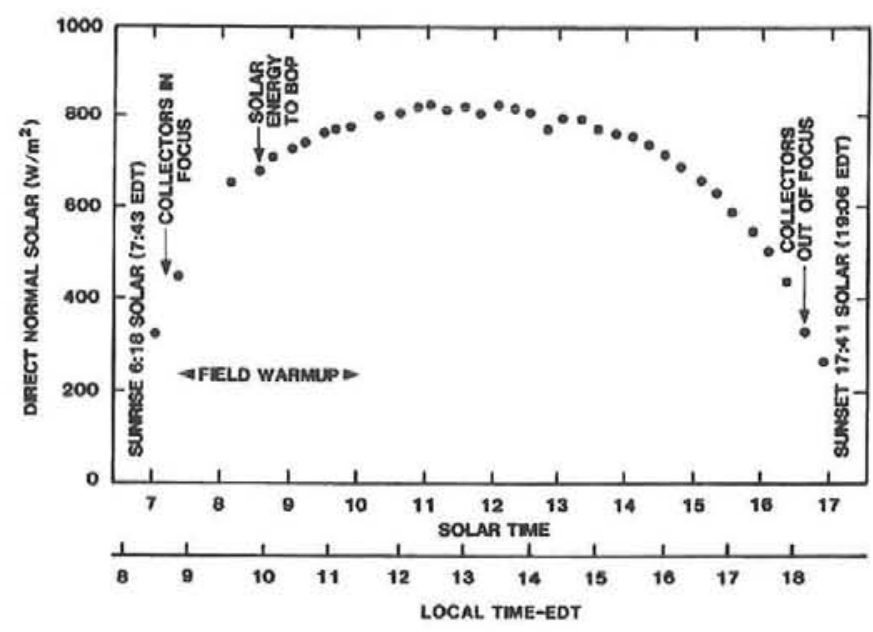

Figure 62. Shenandoah Direct Normal Solar, October 15, 1982 


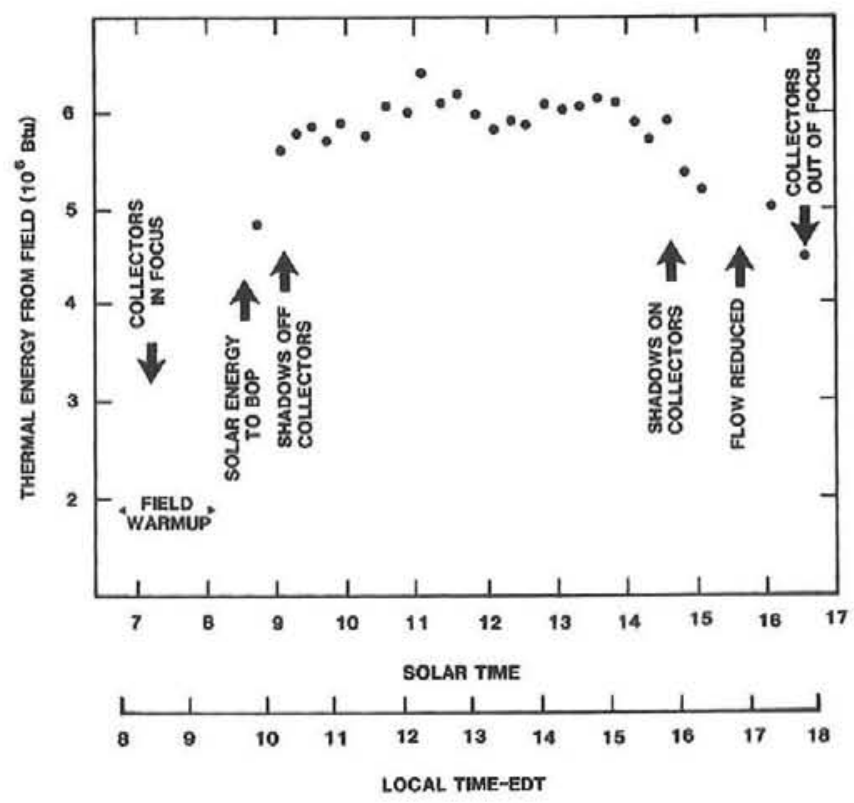

Figure 63. Collected Solar Energy

\section{Table 9. Shenandoah Operation - October 15, 1982 Summary}

\begin{tabular}{|c|c|c|c|}
\hline Item & \multicolumn{2}{|c|}{ Data } & \\
\hline $\begin{array}{l}\text { - Collectors in Focus } \\
\text {-Sunlight }\end{array}$ & \multicolumn{2}{|c|}{9 hours 23 minutes } & \\
\hline - Constant Flow in Collector Field & \multicolumn{2}{|c|}{$235 \mathrm{gpm}$} & \\
\hline - Collector Temperatures & \multicolumn{2}{|c|}{ up to $650^{\circ} \mathrm{F}$} & \\
\hline \multicolumn{4}{|l|}{ - 104/5 Collectors Operating } \\
\hline - Thermal Energy at Edge of Field & \multicolumn{2}{|c|}{$11,300 \mathrm{kWh}$} & \\
\hline \multicolumn{4}{|l|}{ - Energy to Bleyle: } \\
\hline & Fossil & Solar & $\%$ Solar \\
\hline Chilled Water (ton-h) & 95 & 242 & $72 \%$ \\
\hline Process Steam (lb) & 1800 & 4300 & $71 \%$ \\
\hline $\begin{array}{c}\text { - Balance of Solar Energy } \\
\text { High Temp Storage } \\
\text { Steam Condenser }\end{array}$ & \multicolumn{3}{|c|}{$60^{\circ} \mathrm{F}$ Rise $435 \mathrm{kWh}$} \\
\hline
\end{tabular}




\section{Tracking Control}

Experience with the CCUs has paralleled that with the collectors. The weak elements of the CCU have been disclosed with continued operation of the units. With the accumulation of operating time, CCUs require repair less frequently.

Computer-CCU compatibility has been established with the iterative operation of the collector field. These solar tracking exercises provided the information from the collector position potentiometer readings to correlate the collector position with that of the sun so that a collector position algorithm could be incorporated in the computer. Complete computer control of collector operation has now been demonstrated.

\section{Receiver Performance}

Thermal loss tests of the receiver have not been conducted but are scheduled to be performed in the future.

\section{Reflector Performance}

Specified collectors in the Shenandoah field of 114 have been designated as control units on which reflectivity data is obtained. A portable reflectometer, designed by Sandia, is being used to obtain this data periodically. Graduate students from the Georgia Institute of Technology (Georgia Tech) have been engaged to obtain and analyze this information.

An early concern in the use of FEK-244 film on a compound curved surface was its ability to maintain its adhesion to such a surface. Inspection of the reflec- tors that have now been subjected to the Shenandoah environment for over a year reveals no proclivity toward loss of adherence from the substrate. As has been observed on FEK panels in other applications, some panels have developed "tunnels" (ridge-like lifting that develops at the edge of the film due to expansion of the film when subjected to high humidity and temperature), from points of apparent stress. This form of delamination appears to be between the film aluminum and adhesive. The tunneling is minimal in the Shenandoah application and is not considered to be a point of serious concern. Another form of delamination is the "worm-track," which appears to be the separation of the film aluminum and the acrylic film. Worm-tracks start at cut edges and propagate under the influence of the moisture trapped in the track. The extent of the tracking can be arrested by incizing the film at the end of the track. The area affected by tunneling and worm-tracking is less than $1 \%$ of the total reflective area and is much less than the nonreflective area of the reflector (space between FEK sections on a petal).

The 3M Company, the film supplier, has suggested that exposed edges of the reflective film be protected with a sacrificial tape to seal the edges. Laboratory tests indicate that this is an effective deterrent to the delaminations noted and it is being implemented at Shenandoah.

The information on the optical properties of the Shenandoah collectors gathered by the Georgia Tech graduate students is being used to provide the basis for masters theses. Other areas of the Shenandoah STEP operation are providing data for similar use by them. 


\section{Conclusions}

\section{Design}

The Shenandoah collector is a design generated by the General Electric Company of Valley Forge, Pennsylvania, under a DOE contract specifically for the Solar Total Energy System emplaced in Georgia. The design was transformed into the four collectors tested at Sandia's collector test facility (MSSTF), and improvements based on this experience were designated. Unfortunately, schedules did not permit these changes to be implemented into hardware that could be thoroughly tested before being used in the construction of the Shenandoah project. However, the first Shenandoah collector fabricated with these improvements was installed and exercised at the MSSTF. The major shortcoming of these investigations was the difference in environmental conditions between Albuquerque and Shenandoah. Because of the environmental difference, the detrimental effect of humidity on the collector (such as on Sauerisen cement, drive motors, and potentiometers) was not evidenced until the collectors were installed at the Shenandoah site. Also, the short period available for the Sandia tests prevented a thorough investigation of evidences of irregular behavior (such as thermal effects on fiber optics) that in themselves did not prohibit collector operation at the test site. Not all of the conditions requiring attention can be categorized as design inadequacies. Some can be attributed to a misunderstanding between the design engineer and the vendor concerning component capabilities. For example, the phrase "for outdoor use" or "moisture resistant" cannot be understood to mean "hermetically sealed." Other cases can be attributed to interpretations in assembly not amenable to precise quality control (such as the routing of fiber-optic cables and insulation quantities required to prevent "thermal holes.") The result was that shortcomings had to be remedied after installation, not the most favorable condition for expeditiously incorporating changes required to make a collector operational. A thorough environmental test of designated components could have resolved some of the noted deficiencies, and an adequately long testing period might have disclosed some of the assembly inadequacies noted later.

The support structure (frame and yoke assembly) of the collector was fabricated with members specified from analytical studies based on wind loadings.
Destructive tests, in conjunction with the concrete foundations on which the frames were mounted, would have provided some insight into the safety margins inherent in the design. Possible reductions in material requirements might have been realized. Such was the case with the concrete foundations. Original designs based on handbook recommendations were found to be much in excess of requirements found from actual pier tests conducted on site, which led to material (and cost) savings. Similar contentions may be made regarding other parts of the collector structure.

The sizing of the petal sections for the reflector requires aluminum panels that are approximately $3 \mathrm{in}$. less than the nominal 48 -in. sheet size for aluminum. As a result, the 24 -in.-wide reflective film offered by $3 \mathrm{M}$ at the time had to be trimmed to accommodate the panel. 3M now offers 48 -in.-wide FEK-244 film. A reflector design using nominally sized aluminum panels would have resulted in some reflective material cost savings. The reflector diameter would have grown from $7 \mathrm{~m}$ to about $7.5 \mathrm{~m}$ with the 48 -in. panels, however.

Operational experience gained from Shenandoah indicates it would be of interest to reinvestigate those parameters that led to the collector sizing. There are arguments favoring larger collector sizes as a means of preserving a larger proportion of the collected energy from a given collector field size.

Design alternatives for all areas of the collector should be explored for a second-generation dish.

\section{Manufacture}

The element of the collector having the greatest number of manufacturing options is the reflector. Diestamping to form the Shenandoah dish was an obvious choice for the size specified since such forming operations had already been developed in the manufacture of communication antennas. The critical element distinguishing the solar dish in contrast to a communications dish is the requirement for a smaller slope error. The higher frequency or shorter wavelength of the solar medium is more sensitive to surface perturbations than the longer wavelengths of the communication frequency. Thus, the die or mold for the solar 
collector must be machined to greater precision to obtain the needed contour, and the "spring-back" of the stamped piece must be more carefully controlled to obtain the desired parabolic conformation in the finished piece. The maximum size of petal that can be formed by die stamping and still be amenable to support by simple structural members needs to be investigated if low cost, larger diameter solar dishes are to be considered. Die stamping appears to be a cost-effective approach to dish reflector manufacture. Petal width sizing is a variation that has not been thoroughly investigated, however.

The decision to preassemble the support structure at the point of fabrication insured the fit and function of these parts prior to field installation. The procedure disposed of the need for jigging and welding in the field and of subjection to the vagaries of the weather.

\section{Installation}

Preassembly of parts eased the installation of the support frame for the collector. A considerable amount of field assembly was still required, however, prior to the installation of the whole collector. The major section requiring field assembly was the reflector. Collector designs that could reduce the extent of field work required to assemble the reflector would be appropriate to expedite installation. Other collector parts, such as the plumbing and cabling amenable to prefabrication and preassembly, would have expedited installation.

The need to gain access to the rear of the receiver to couple the electrical and optical elements to the CCU lead to some of the difficulties experienced in the operation of the collectors. Inadvertent shifting of insulation and the fracturing of electrical leads are thought to have caused some of the problems noted with the tracking system and with temperature sensing. An open RTD lead would be indicative of a hightemperature condition that would drive the collector to stow. A design change to permit external connections to be made so that the internal order of the receiver would not be disturbed would eliminate the concern. A simpler optical geometry with a straight inline section from the aperture to the rear of the receiver would permit less interfaces, a single cable size, better mechanical and thermal protection of the cable, and less disturbance to the internals of the receiver during replacement operations.

Installation, checkout, and calibration of the position potentiometers (both polar and declination) could have been effected much more conveniently at the location where preassembly of the collector support was conducted than in the field. The major difficulty was experienced in the installation and adjustment of the declination potentiometer, which required work personnel to climb to an inconvenient height and through an area with limited access-an inconvenient procedure that also presented potential hazards to individuals installing and adjusting the potentiometer.

\section{Operation}

System operation has been handicapped with the multitude of start-up problems that have required attention. However, with the knowledge gained in the potential problem areas, and the means to prevent them from recurring, future systems proposing a dish collector STEP should have a relatively unencumbered system start-up.

\section{Maintenance}

The protracted period for initiation of operation has not allowed sufficient time to isolate maintenance requirements from activities necessary to establish an acceptable system. Thus far, no areas have been clearly identified that might require periodic attention. Components already discovered to be susceptible to humidity will, on occasion, exhibit effects of moisture and may require attention. It may be expedient to inspect periodically those components and to reseal units showing evidence of weathering. In addition, points of wear will no doubt require periodic lubrication, and the frequency of such maintenance will no doubt be influenced not only by the constancy of movement but also by the prevailing weather.

The single major factor influencing the status of the Shenandoah STEP is the ubiquitous hygrothermal conditions existing in Shenandoah.

\section{References}

${ }^{1}$ R. R. Peters, A Methodology for Determining the Configuration of the Optimum Solar Total Energy System, SAND79-0422 (Albuquerque, NM: Sandia National Laboratories, May 1979).

${ }^{2}$ W. H. McCulloch, On the Maximum Field Size for Dispersed Solar Thermal Power Systems, SAND79-1425 (Albuquerque, NM: Sandia National Laboratories, Aug 1979).

${ }^{3}$ J. C. Zimmerman et al, Sun Rights Development for the Solar Total Energy-Large Scale Experiment at Shenandoah, Georgia, SAND79-0566A (Albuquerque, NM: Sandia National Laboratories, March 1979).

${ }^{4}$ A. R. Saydah et al, Final Report on Test of STEP, Shenandoah Parabolic Dish Solar Collector Quadrant Facility, General Electric Co., Philadelphia, PA. Contractor Report, SAND82-7153 (Albuquerque, NM: Sandia National Laboratories, April 1983). 


\section{APPENDIX \\ D-2300 Installation Manual*}

*Solar Kinetics, Inc. 


\section{$0-2300$ \\ INSTALLATION MANUAL}

TABLE OF CONTENTS

FRAME INSTALLATION

COUNTERWEIGHT INSTALLATION

REFLECTOR ASSEMBLY

STRUT ASSEMBLY

REFLECTOR-TO-FRAME ASSEMBLY

POTENTIOMETER INSTALLATION

RECEIVER INSTALLATION

RTD \& FIBER OPTICS CABLE INSTALLATION

PIPING \& INSULATION

MAN HOURS TO INSTALL D-2300 DISH
Page Number

D-001

D-004

D-006

D-008

D-010

D-013

D-014

D-016

D-017

D-018 


\section{LIST OF REFERENCED DRAWINGS}

\author{
GE $47 \mathrm{~J} 240735 \mathrm{G} 1$ \\ SKI 09-022C \\ SKI 09-031D \\ SKI 09-011C \\ GE 147D9876, P1, P2, P3, \\ P4 \& P9 \\ GE 184C8022PI \\ GE 147D9880G1, G2 \& G3 \\ GE $47 J 240738$ \\ GE 14709650 \\ GE $14789637 G 2$ \\ GE $184 C 8042$ \\ GE 221B3031 \\ GE $128 \mathrm{C} 8690$ \\ GE $184 C 8043$ \\ GE $147 D 9633 G 4$ \\ GE 147D9633G3 \\ GE $47 \mathrm{~J} 240737$ \\ GE 221B3033 \\ GE $221 B 3032$ \\ GE $47 \mathrm{~J} 240736$
}

\author{
Collector Frame Assembly \\ Counterweight \\ Hub Assembly \\ Rib-Support \\ Panels \\ Spacer \\ Strut \\ Collector Assembly \& Installation \\ Jactuator Machine Screw \\ Drive Assembly \\ Potentiometer Cable Assembly \\ Potentiometer \& Cable Assembly \\ Fiber Optics Harness Assembly \\ RTD Cable \\ Flex Hose Assembly \\ Flex Hose Assembly \\ Reflector \& Receiver Assembly \\ Clamps \\ Clamps \\ Reflector Assembly
}




\section{LIST OF REFERENCED FIGURES}

$\begin{array}{lll}\text { FIGURE } 1 & \text { DISH FRAME } & \underline{\text { Page }} \\ \text { FIGURE } 2 & \begin{array}{l}\text { COUNTERWEIGHT } \\ \text { INSTALLATION }\end{array} & \text { D-003 } \\ \text { FIGURE } 3 & \text { SUPPORT RIB ASSEMBLY } & \text { D-007 } \\ \text { FIGURE } 4 & \text { PANEL INSTALLATION } & \text { D-007 } \\ \text { FIGURE 5 } & \text { STRUT } & \text { D-009 } \\ \text { FIGURE 6 } & \text { TAG LINE TO STRUT } & \text { D-009 } \\ \text { FIGURE 7 } & \text { STRUT INSTALLATION } & \text { D-009 } \\ \text { FIGURE } 8 & \text { REFLECTOR TO FRAME } & \text { D-011 } \\ \text { FIGURE 9 } & \text { RECEIVER INSTALLATION } & \text { D-015 } \\ \text { FIGURE 10 } & \text { SPREADER FIXTURE } & \text { D-015 }\end{array}$




\section{FRAME INSTALLATION}

1. Lift frame 47J240735Gl into position using a 6" wide choker $12 \mathrm{ft}$. long, with the choker wrapped around upper bearing block of polar axis and frame strut shown in Fig. 1. Lift with crane into position over horizontal frame. Lower onto frame and align holes with line-up bar. Have at least one bolt in place on each foot. Use bull pin if required, to line up all 12 mounting holes.

Install 3/4" hardware. Bolt head with flat washer on top of foot; flat washer, lock washer and hex nut under horizontal frame flange. After all 12 bolts are started ( 4 in each foot) tighten to required torque of $100 \mathrm{ft}$. $1 \mathrm{bs}$. Hardware required: 12 ea. 3/4-10 x 3" long bolt, 24 each 3/4 diameter flat washer, 12 each 3/4 diameter split lock washer and 12 each 3/4-10 hex nut.

2. Install motor cable assembly 184C8033. Wire polar motor 1 and polar motor 2 as described on drawing 47J240735G1, diagram M. The connections for both motors are:

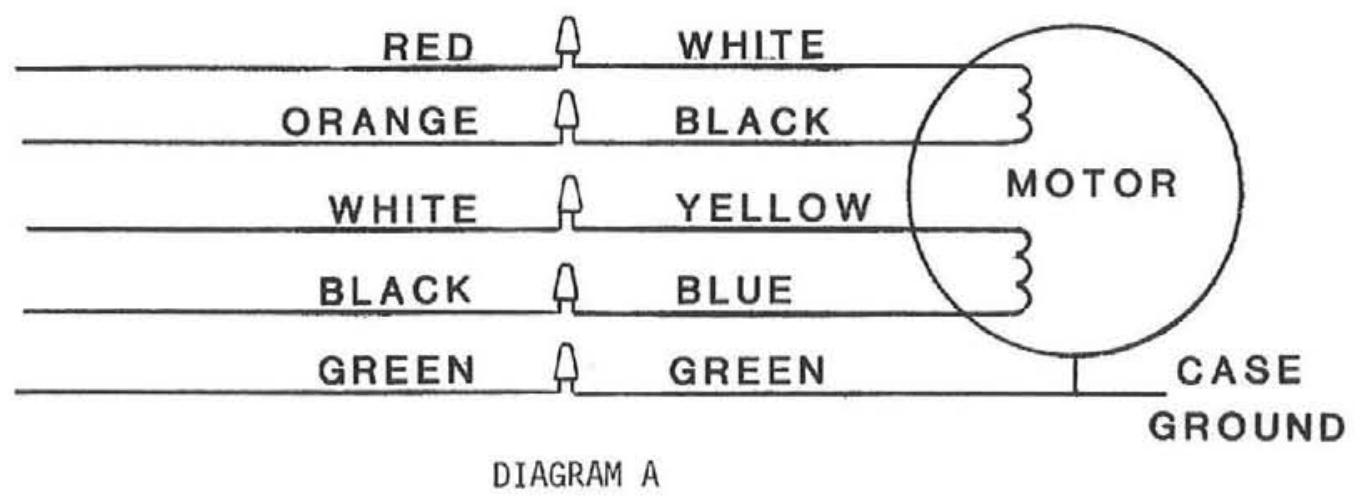

Trim motor leads to a length that will fit into conduit box. Insert cable through watertight fitting. Strip insulation, twist leads, as shown in Diagram $A$, and secure with wire nuts. Put gasket and cover on conduit box and tighten cable clamp to make watertight. Apply sealant around nipple and nut, both at motor and conduit box, to insure watertight fit. 
Temporarily tie cable to northeast leg of frame so counterweight will clear. Also, tie declination motor cable so leads will not short on frame and frame can rotate about polar axis. Cable will be installed permanently at final assembly with RTD cable and fiber optics. 
D -003

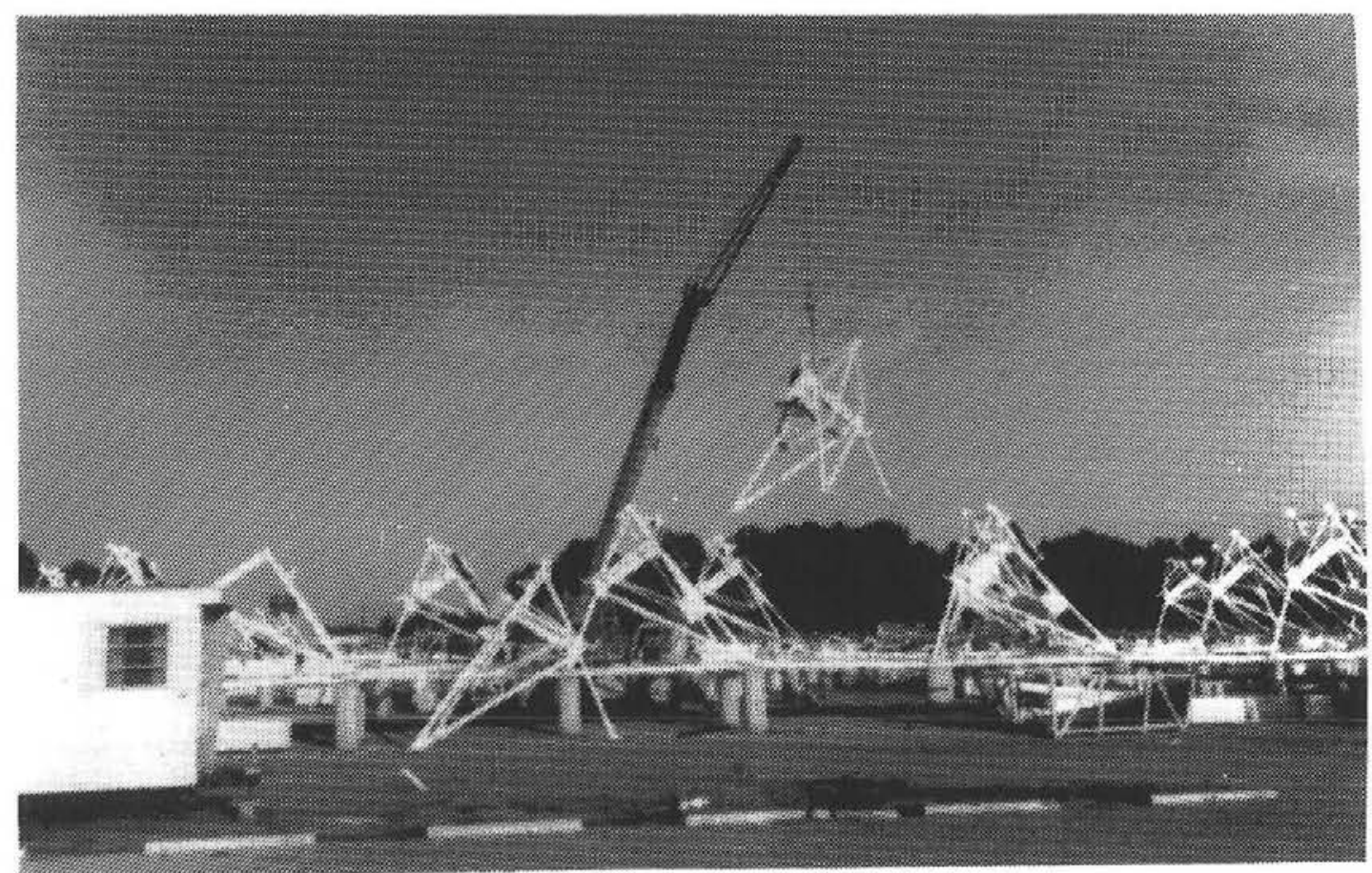

FIGURE 1 


\section{COUNTER WEIGHT INSTALLATION}

1. Rotate frame about polar axis, either east or west. This can be done by plugging motor cable into test box or central control unit (CCU). Turn motors off when fully rotated.

2. Lay counterweight (drawing \#SKI 09-022C) on its side with the studs horizontal and facing the frame. Now determine which end of the counterweight will be the high end and wrap a 6" wide $\times 20^{\prime}$ long choker around this end, 24 " from the end of the counterweight. Let the center line of the choker be 24 " on the bottom of the weight and the outer edge of the choker should be 24 " on the top of the weight. See Fig. 2. These dimensions are important to 1 ift counterweight at an angle which allows studs to go through holes in pads.

Now lift counterweight to proper height and slip all 12 studs through holes in mounting pads. Install flat washer, split lock washer and $1 / 2$ hex nut on each stud. Torque nut to $30 \mathrm{ft}$. 1bs. each.

3. Return frame to null position. Counterweight will be horizontal. 
$D-005$

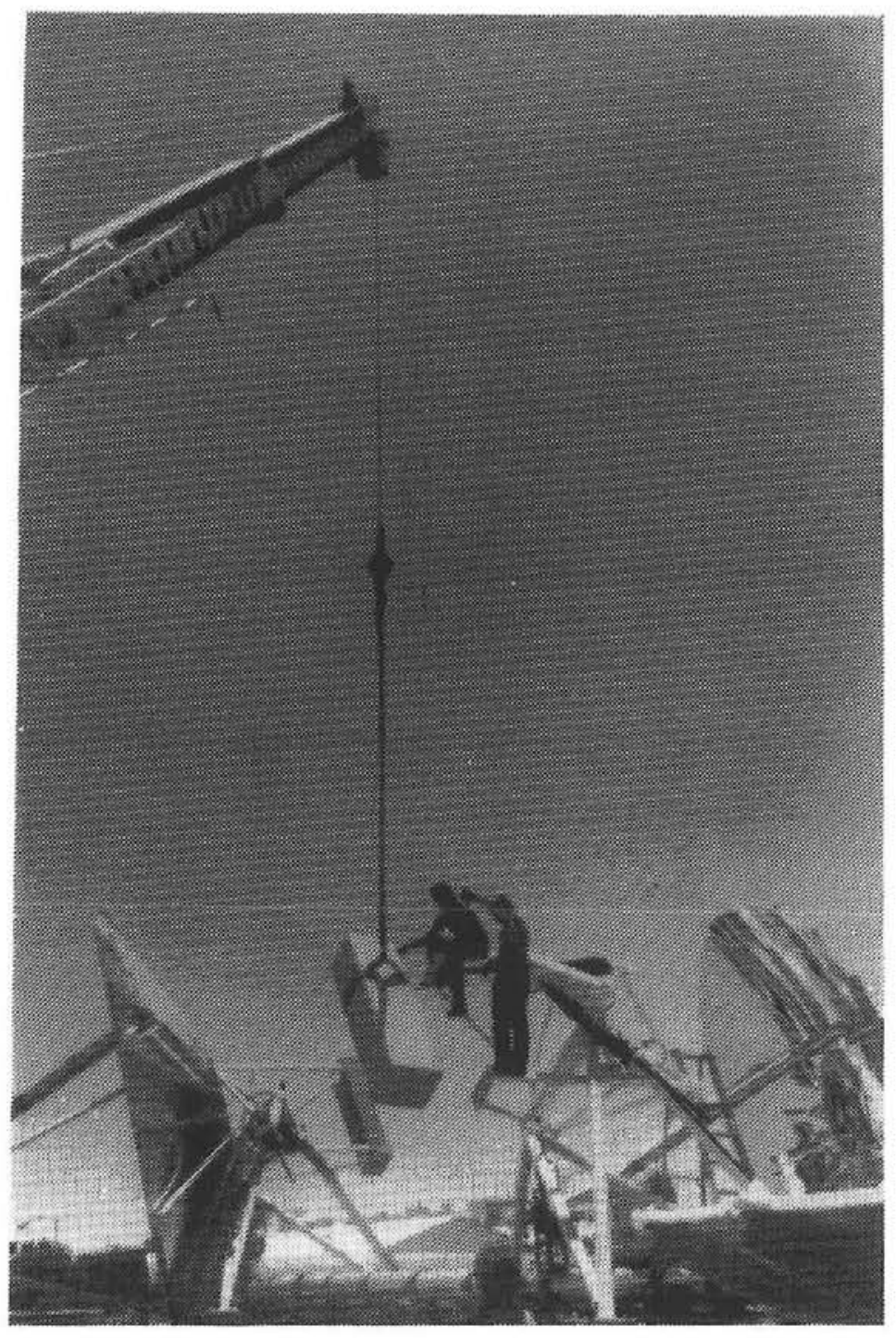

FIGURE 2 


\section{REFLECTOR ASSEMBLY}

1. Set the hub (drawing \#SKI09-031D) on the assembly table with clevis for declination jactuator facing south and down.

2. Assemble 21 support ribs (drawing SKI \#09-011C) to the hub using top and bottom holes only, shown in Fig. 3. Use 3/8-16 $\times 1 \frac{1}{4} " 1$ long hex head cap screws with 2 each flat washer, 1 split lock washer and 1 hex nut. The rib goes on the right-hand side of the hub fin with the flange of the rib down, as shown in Section BB, drawing 47J240736. After a11 21 ribs are in place, install the rest of the hardware; a total of 6 each for each rib, but do not tighten at this time.

3. Install panels with proper hardware as shown on drawing 47J240736. (See Fig. 4) Put only 2 screws through each rib; first, the outside screw and then the third from the inside (this is the first one outside the hub fin). Do not tighten until a11 21 panels are in place.

To install the last panel, the first panel has to be unbolted on the righthand side and the flange moved to the left of the rib. It may be required at this time to use long nose vise grips to pull the flanges together in order to get screws started. Now, install 6 spacers, \#184C8022P1, 2 each, one on either side of the panels the struts fit through; between P3 \& P2, P3 \& P4, and P9 \& P2. At this time, only install screws in the 2 outside holes, using a 5/16-18 × $3 / 4$ " long cap screw with 2 flat washers, 1 lock washer and 1 hex nut.

Now, install the rest of the hardware, but do not tighten at this time. Start on the inside row and tighten all 21 screws. Then, tighten the next row. Work all the way around before starting next row. Continue until all screws are tight on all panels. Then, tighten the $3 / 8$ screws through the ribs to hub. 
D-007

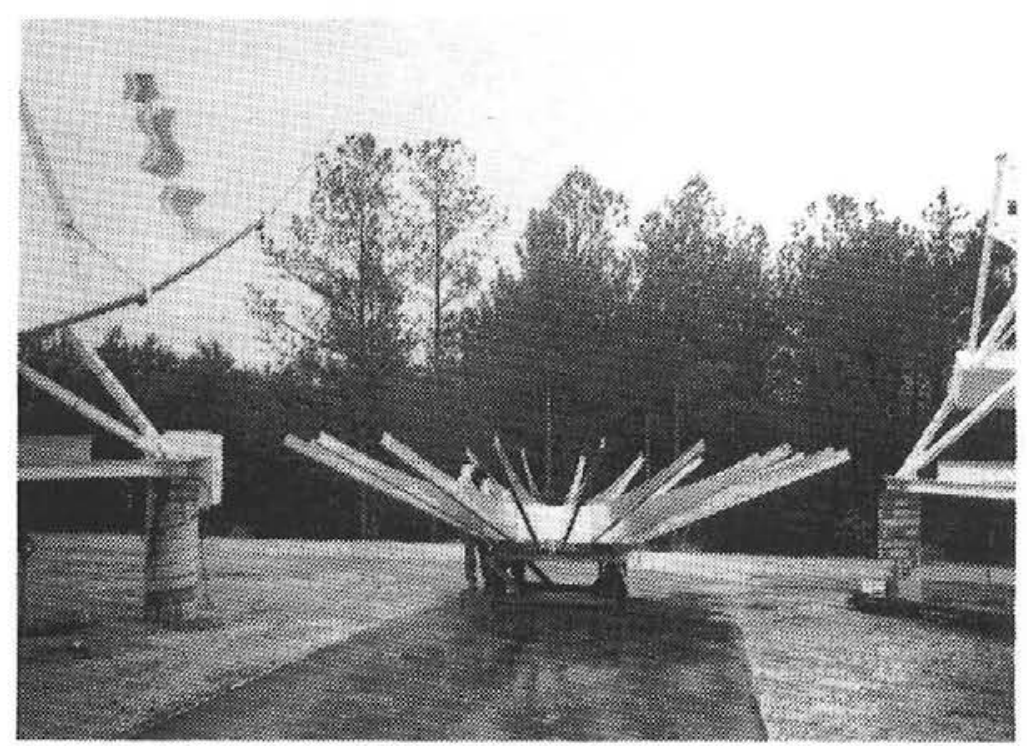

FIGURE 3

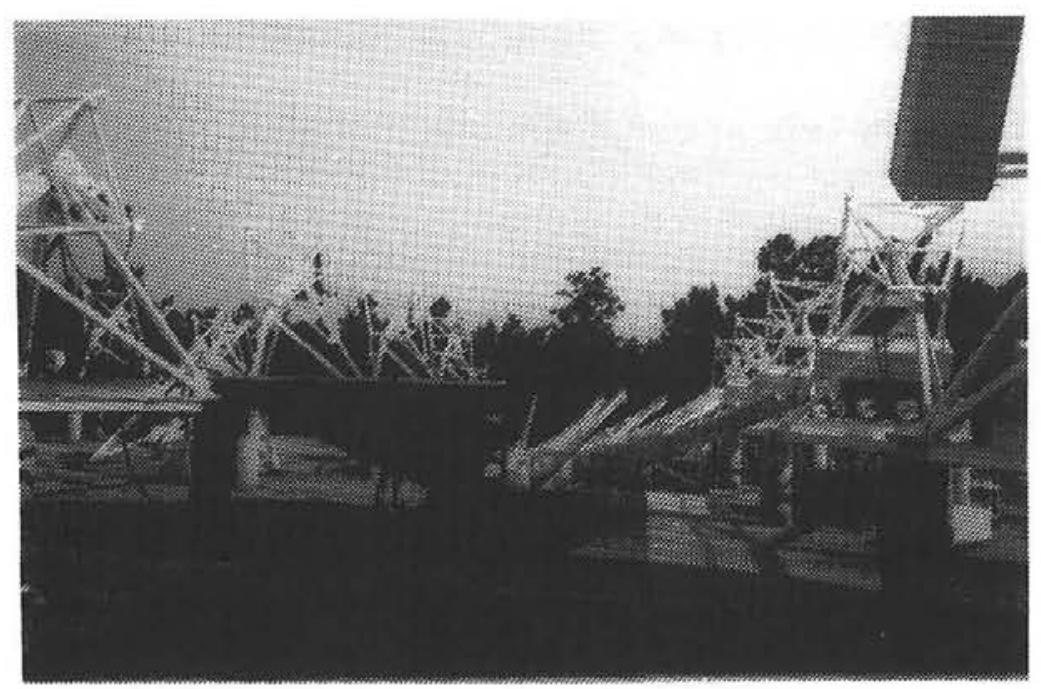

FIGURE 4 


\section{STRUT ASSEMBLY}

1. Lay out on a flat surface, 1 each of Receiver Struts 147D9880G1 (tapped holes on side), 147D9880G2 (plain), and 147D9880G3 (hole for cable). Attach a Gl strut to a receiver frame or an assembly frame with the adjusting strut to the inside and the end that attaches to the reflector away from you. Looking from the receiver end to the reflector end, attach a G2 strut counterclockwise from the G1, with the adjusting strut to the inside.(See Fig. 5) Next, attach a G3 strut counterclockwise from the G2, onto the last leg of the triangle, with the adjusting strut to the inside.

2. Use $3,12 \mathrm{ft}$. long $\times 2 \frac{1}{2}$ " wide chokers. Wrap one around the center of each leg of the triangle. Hook other end in hook of crane. Lift struts to vertical position. Tie the tag line to each strut for guiding into position over reflector. (See Fig. 6)

3. Lift struts above reflector and, with one person attending each tag 1 ine, lower struts onto reflector. Make sure Gl strut, the one with the 6 tapped holes in its side, is on the north side. This strut fits into the panel with the large (9" diameter) hole. Do not let struts touch reflector. Guide each strut into the slots through the panels. You may want to guide the north strut into position through the large hole. See Fig. 7. The other two have to be done from topside. After struts are through panels, straddle spacer underneath, using a line-up bar to align holes. Insert 2, 5/16-18 $\times 2 \frac{1}{4}$ " long hex head cap screws with 2 flat washers (one on either side), 1 lock washer and 1 hex nut through each strut. Remove tag 1 ine from north strut at this time. The others can be removed when reflector is in stow position. 
D-009
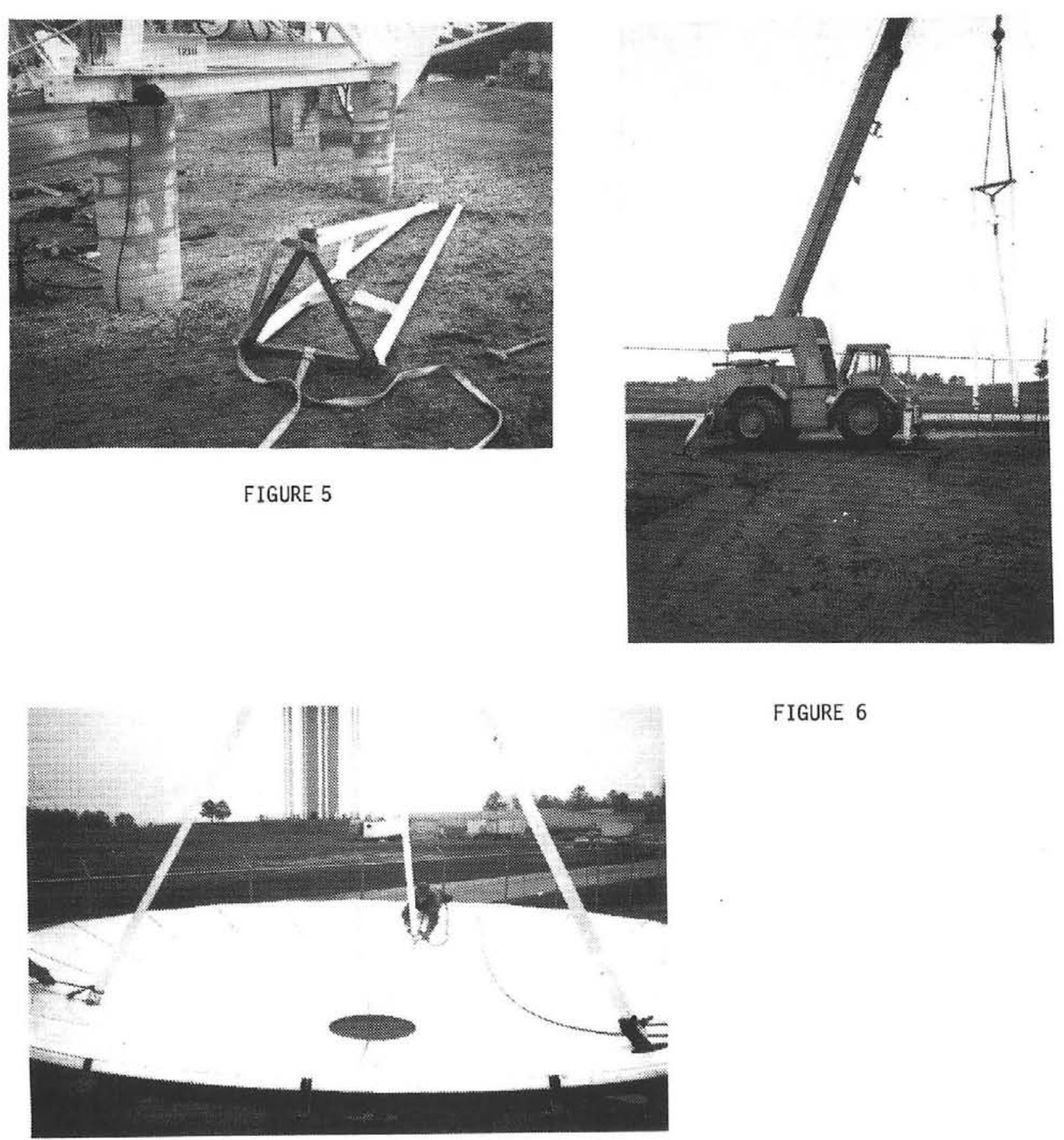

FIGURE 6

FIGURE 7 


\section{REFLECTOR-TO-FRAME ASSEMBLY}

1. With reflector \& struts assembled and still sitting on assembly table, lower headache ball and hook through center of triangle to about a foot above the hole in the center of the reflector. Hook reflector, lifting sling over top edge of hub at 4 places and put rub straps on sling under bottom flange of hub to protect sling. (See Fig. 8) Hook lifting eye into "D" ring of lifting sling. Very slowly, lift reflector until it clears table. If it is not balanced, re-position sling to enable you to pick up reflector level.

2. Turn yolk assembly to null position about the polar axis (counterweight leve1) and install declination drive assembly to frame, Part \#147D9637G2. Note the eye on the tube end fits into clevis of frame. This leaves the shaft of the jactuator to fit into the clevis of the hub. Run the shaft of the jactuator to its fully extended position.

3. With 2 men tending the 2 tag 1 ines left on the struts, pick up the reflector assembly with the crane, using the tag lines to steady the reflector and help guide it. Position reflector over frame assembly and lower bearing housings in hub onto bearing blocks. (See Fig. 8) Have at least one man up on frame to help guide reflector into place. Use line-up bar to align bolt holes. Using the slope washer under bolt head, put bolts in from topside. Put the slope washer on top of channel so that bolt will be $90^{\circ}$ to bearing block. With all four bolts in one bearing block, install on bottomside one flat washer and one lock nut. Torque bolts to $35 \mathrm{ft}$. 1bs. minimum. Repeat bolting procedure on other side. Please note: On the westside bearing block, install a grounding strap from hub to frame. 


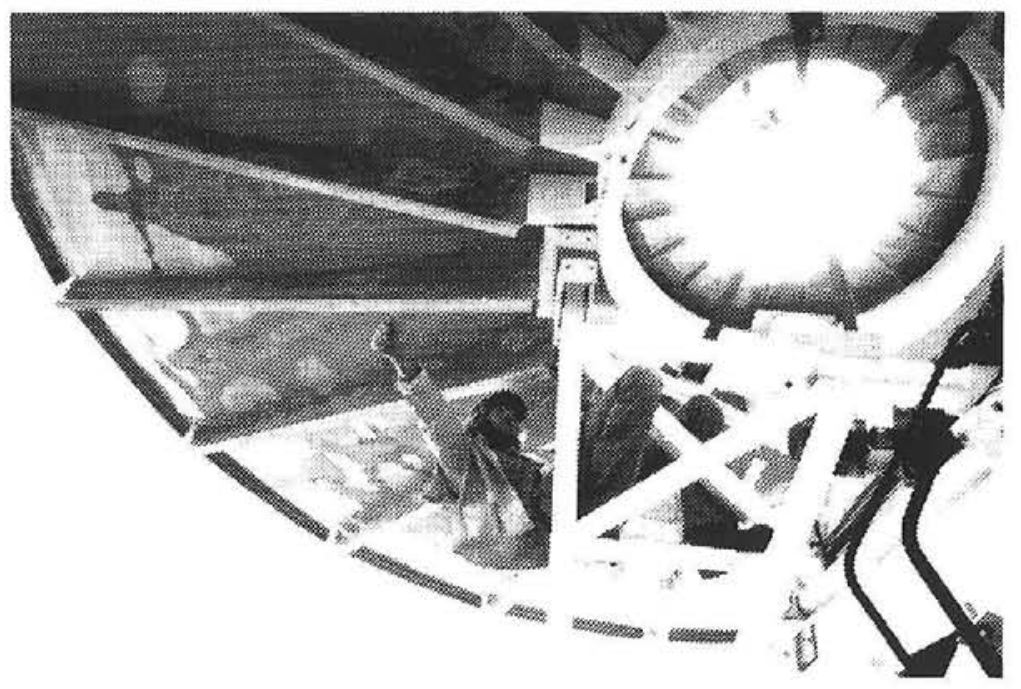

FIGURE 8 
4. Pick up free end of declination drive assembly and very, very slowly start to lower reflector. When shaft end and hub clevis are aligned, insert clevis pin and cotter key. Now, you can let go of reflector with the crane. Un-hook eye and remove sling from the hub.

5. Wire declination motor from cable red wire to white wire, orange wire to black wire, white wire to yellow wire, black wire to blue wire, green wire to green wire.

Twist leads and secure with wire nuts and install conduit gasket and cover. Tighten watertight nut on cable. Now, lower reflector to null position for installation of potentiometers (pots). 


\section{POTENTIOMETER INSTALLATION}

1. Have reflector in null position, both polar and declination.

2. Route potentiometer cable, drawing \#184C8042, on frame.

3. P1ug potentiometers, drawing \#221B3031, into each cable end, P2 to polar pot and P1 to declination pot.

4. Plug P3 into 10 VDC power supply and adjust output to read 10.00 VDC on a digital volt meter.

5. Turn potentiometer shaft to read $2.91 \mathrm{~V}$ across wiper.

6. Install polar pot on lower end of polar bearing using three \#4-40 screws with holding clips. Tighten coupling on both shafts. Move pot to read $2.91 \pm .01$ before tightening coupling to pot shaft.

7. Install declination pot on mounting bracket. Adjust mounting bracket to align pot shaft to mounting pin. With pot set at $2.91 \pm .01 \mathrm{VDC}$, secure bracket and coupling to both shafts. Check \& double check to see coupling does not put a strain on pot shaft.

8. Route cable from polar pot down northeast leg. Route cable from polar pot with motor cable. Do Not Tie Yet. 


\section{RECEIVER INSTALLATION}

1. Bring reflector to summer stow position, all 3 jactuators retracted, south and east.

2. Pick up receiver using a $2 \frac{1}{2} "$ wide $\times 12^{\prime}$ long choker, by wrapping under receiver mounting supports that fit into struts. Position choker so that south support is down, e.g. piping will be up. Use care when picking up this way, to lift on backside of receiver to prevent skirt from digging into ground.

3. Put another $2 \frac{1}{2} "$ wide $\times 12^{\prime}$ long choker around receiver right aft of screw heads about 6 inches back from front and hook loose eye into hook on crane. (See Fig. 9)

4. Put strut spreader fixture between struts and remove triangle from front of struts, as shown in Fig. 10. Extend the leveling pad on south strut to approximately $3^{\prime \prime}$ and retract the other two leveling pads.

5. Move receiver into position and insert bolts through strut and receiver mounting support with 2 flat washers, 1 on either side, 1 lock washer and 1 hex nut. Do not tighten at this time. Adjust leveling pads to approximately same length to center receiver between struts. Now, extend leveling pads until a very slight bow is noticable in each strut. When each strut has the same amount of bow, lock leveling pad with jam nut, then, tighten bolts through receiver mounting supports. 


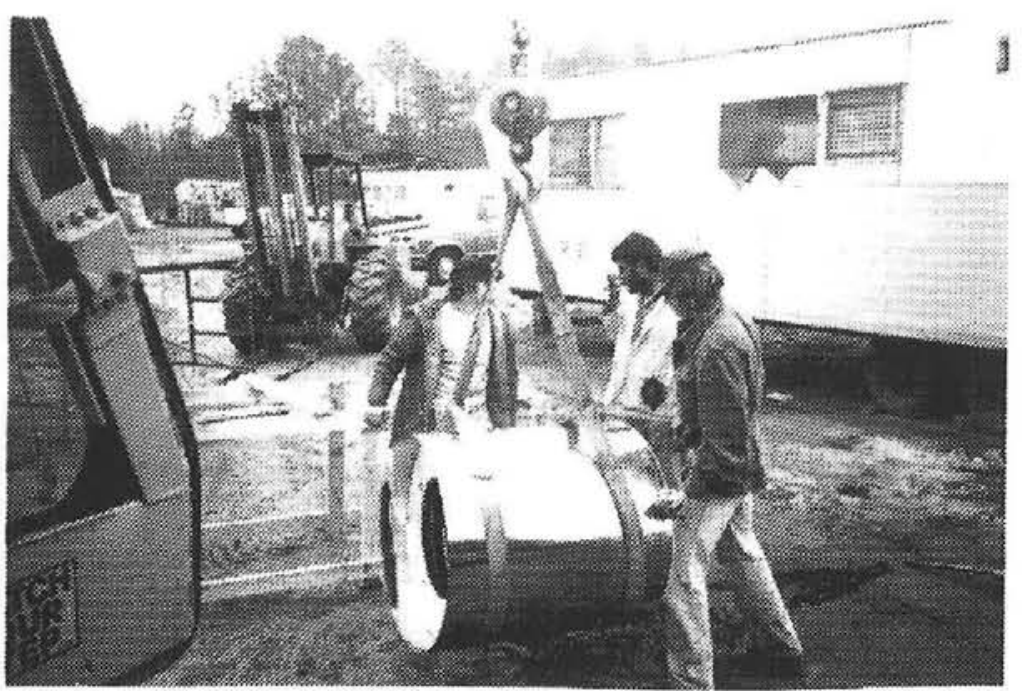

FIGURE 9

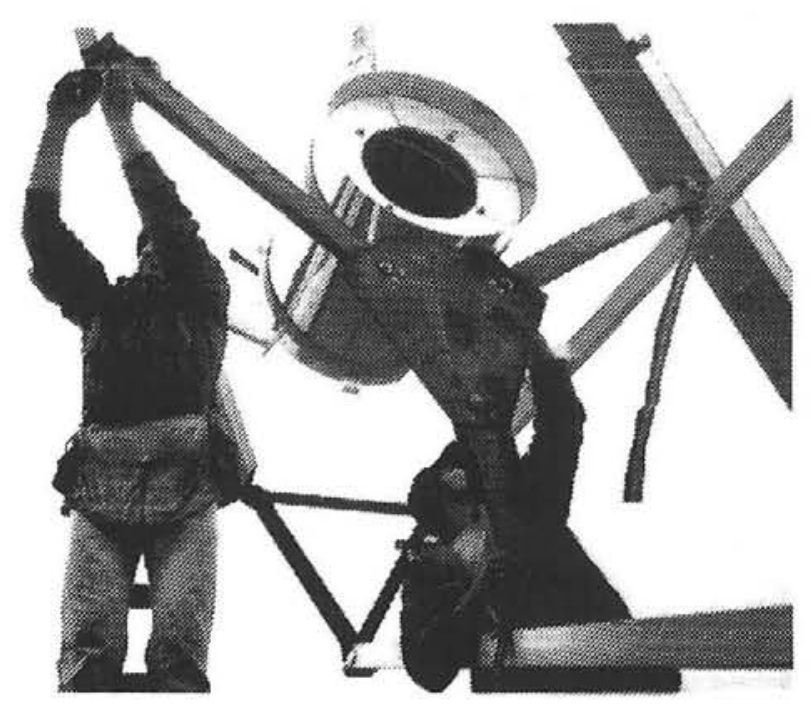

FIGURE 10 


\section{RTD \& FIBER OPTICS CABLE INSTALLATION}

1. Remove access plate from rear of receiver. Examine fiber optics in receiver to make sure it is outside of insulation and not down inside next to coil.

2. Install grommet in hole of P9 panel of reflector assembly.

3. Pul1 RTD cable, dwg. \#184C8043, and fiber optics, dwg. \#128C8690, through strut from reflector to receiver. Pull approximately 4 feet out of strut at receiver end and install heat shield sock over both cables.

4. Insert each cable through cord grip in access plate and hook up RTD cable, per drawing \#221R954. Be very careful not to bend fiber optics at sharp angle and insert each ferrell into its proper hole. Black south, white - north, yellow - east and red - west. Form as large a loop as possible in fiber optics strands and replace access plate. Form a suitable loop outside receiver with cable bundle and adjust heat shield sock to give maximum protection.

5. Install heat shields to adjustable struts, both southeast and southwest struts.

6. Route cable on back side of reflector using cable ties. Drill hole in rib flange as necessary. Route cables over pivot points of polar axis with motor cable and pot cable. Tie with long cable tie at pivot point, swing arm and down northeast leg of frame.

7. Connect into central control unit (CCU). 


\section{PIPING \& INSULATION}

1. Install both flex hose assemblies.

2. Run piping both $3 / 4^{\prime \prime}$ and $1 / 2^{\prime \prime}$ from receiver through reflector. Install bottom half of clamp, drawing \#221B3032, (3) on struts to help support piping.

3. Run piping from $90^{\circ}$ fitting on backside of reflector to topside of 12 " long flex hose, drawing \#147D9633G4.

4. Run piping from bottomside of $12^{\prime \prime}$ flex hose to topside of $30^{\prime \prime}$ flex hose, drawing \#147D9633G3.

5. Tighten all connections. Use special precaution at flex hose. See note 3 on drawing \#47J240738.

6. Plug $3 / 4^{\prime \prime}$ connection on bottomside of $30^{\prime \prime}$ flex hose and attach cylinder to $1 / 2$ " fitting. Pressure test at 100 psi. Use soap bubbles at each joint, to detect leaks.

7. After pressure check, tie into field piping.

8. Space $1 / 2$ " and $3 / 4$ " tubing, as shown in section "CC" on drawing \#47J240737, and insert spun wool between to insulate from each other. Install outer insulation and jacket as specified. Seal all outside seams with caulking.

9. Instal1 clamps, drawing \#221B3033, on struts to hold insulation and dril1 rib to mount clamp on backside of reflector as shown in section "DD" of drawing \#47J240737. 


\section{MAN HOURS TO INSTALL D-2300 DISH COLLECTOR (on a production basis of 20 or more)}

1. Base Frame - 1 man hour, includes crane and operator

2. Support Frame - 1 man hour, includes crane and operator

3. Hub, Ribs, Petals, Struts - $13 \frac{1}{2}$ man hours

4. Hang Mirror - $1 \frac{1}{2}$ man hours, includes crane and operator

5. Hang Receiver - $1 \frac{1}{2}$ man hours, includes crane and operator

6. Bend and Run Plumbing - 4 man hours

7. Insulate - 8 man hours

8. Strip (pre-mask) from Petals - 3 man hours

9. Flex Hose - 1 man hour

10. Hang Counterweight - 1 man hour, includes crane and operator

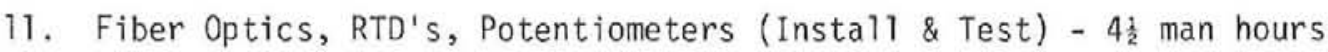

12. Wire Motors, Tie Cable Bundles - 4 man hours 
DISTRIBUTION:

TIC-4500-R73 UC-62b (272)

AA1 Corporation

PO Box 6787

Baltimore, MD 21204

- Acurex Aerotherm (2)

Attn: J. Vindum

H. Morse

485 Clyde Avenue

Mountain View, CA 94042

Advanco Corporation

2250 E. Imperial Hwy, Suite 252

El Segundo, CA 90245

Alpha Solarco

1014 Vine Street, Suite 2230

Cincinatti, OH 45202

Anaconda Metal Hose Co.

Attn: W. Genshino

698 South Main Street

Waterbury, CT 06720

Applied Concepts Corp.

Attn: Stan Pond

2501 S. Larimer County Rd 21

Berthoud, CO 80513

BDM Corporation

Attn: W. E. Schwinkendorf

1801 Randolph Street

Albuquerque, NM 87106

Battelle Memorial Institute

Pacific Northwest Laboratory

Attn: E. Y. Lam

San Francisco, CA 94119

Bechtel National, Inc.

Attn: E. Y. Lam

PO Box 3965

50 Beale Street

San Francisco, CA 94119

Black \& Veatch

Attn: J. C. Grosskreutz

PO Box 8405

Kansas City, MO 64114
Boeing Engineering \& Construction

Attn: J. R. Gintz

PO Box 3707

Seattle, WA 98124

The Budd Company

Attn: W. W. Dickhart

Fort Washington, PA 19034

The Budd Company

Plastic R\&D Center

Attn: J. N. Epel

356 Executive Drive

Troy, MI 48084

Burns \& Roe

Attn: G. Fontana

800 Kinderkamack Road

Oradell, NJ 07649

Burns \& Roe, Inc. (2)

Attn: R. J. Vondrasket

J. Wysocki

185 Crossways Park Drive

Woodbury, NY 11797

Carrier Corporation

Energy System Division

Attn: R. A. English

Summit Landing

PO Box 4895

Syracuse, NY 13221

Chicago Bridge and Iron

Attn: J. M. Shah

800 Jorie Blvd

Oak Brook, IL

Colorado State University

Attn: T. G. Lene

Ft. Collins, CO 80521

Columbia Gas System Service Corp

Attn: J. P. Dechow

1600 Dublin Road

Columbus, $\mathrm{OH} 43215$

Corning Glass Company (2)

Attn: A. F. Shoemaker

W. Baldwin

Corning, NY 14830 


\section{DISTRIBUTION (Cont):}

Custom Engineering, Inc.

Attn: C. Demoraes

2805 South Tejon Street

Englewood, CO 80110

Datron Systems, Inc. 20700 Plummer Street

Chatsworth, CA 91311

DFVLR

Attn: C. Selvage

Apto. 649

Almeria

SPAIN

DSET

Attn: G. A. Zerlaut

Black Canyon Stage

PO Box 185

Phoenix, AZ 85029

Donnelly Mirrors, Inc.

Attn: J. A. Knister

49 West Third Street

Holland, MI 49423

Dow Corning Corporation (2)

Attn: R. S. Woodward

G. A. Lane

Midland, MI 48640

Electric Power Research Institute

Attn: E. A. Demaeo

3412 Hillview Avenue

Palo Alto, CA 94303

Energetics Corporation

Attn: L. Wilson

1201 Richardson Drive, Suite 216

Richardson, TX 75080

Energy Technology Engr. Ctr.

Attn: W. Bigelow

PO Box 1449

Canoga Park, CA 91304

ENTECH, Inc.

Attn: R. R. Walters

PO Box 612246

DFW Airport, TX 75261
Eurodrive, Inc.

2001 W. Main Street

Troy, $\mathrm{OH} 45373$

Florida Solar Energy Center

Attn: Library

300 State Road, Suite 401

Cape Canaveral, FL 32920

Ford Aerospace

Attn: Al Gates

Ford Road

Newport Beach, CA 92663

Ford Motor Company

Glass Div, Technical Center

Attn: V. L. Lindberg

25500 West Outer Drive

Lincoln Park, MI 48246

Foster Wheeler Solar Dev Corp

Attn: M. D. Garber

12 Peach Tree Hill Road

Livingston, NJ 07039

General Atomic

Attn: D. Williamson

PO Box 81608

San Diego, CA 92138

General Motors

Harrison Radiator Division

Attn: L. Brock

Lockport, NY 14094

Georgia Institute of Technology

Attn: T. Stelson

Atlanta, GA

Georgia Power Co. (3)

Attn: J. Roberts

W. Davis

E. Ney

270 Peachtree Stre et

PO Box 4545

Atlanta, GA 309302

Haveg Industries, Inc.

Attn: J. Flynt

1287 E. Imperial Highway

Santa Fe Springs, CA 90670 


\section{DISTRIBUTION (Cont):}

Highland Plating

Attn: D. May

10001 N. Orange Drive

- $\quad$ Los Angeles, CA 90038

Honeywell, Inc.

- Energy Resources Center 2600 Ridgeway Parkway

Minneapolis, MN 55413

Insights West

Attn: D. W. Kearney

14022 Condessa Drive

Del Mar, CA 92014

Institute of Gas Technology

34245 State Street

Chicago, IL 60616

Jacobs Engineering Co.

Attn: M. Schwartz

251 South Lake Avenue

Pasadena, CA 91101

Jet Propulsion Laboratory (2)

Attn: J. Lucas

P. M. McElroy

4800 Oak Grove Drive

MS 502-419

Pasadena, CA 91103

LaJet Energy Co.

Attn: Monte McGlaun

3130 Antilley Road

Abilene, TX 79606

Lawrence Livermore Laboratory

University of California

Attn: W. C. Dickinson

PO Box 808

Livermore, CA 94500

L'Garde, Inc.

Attn: M. Thomas

1555 Placentia Avenue

Newport Beach, CA 92663

Los Alamos National Laboratory (2)

Attn: J. D. Balcomb

Los Alamos, NM 87545
Martin Marietta Corp. (2)

Attn: P. Brown

T. Tracy

PO Box 179

MS S 8120

Denver, CO 80201

McDonnell-Douglas Astronautics Co. (3)

Attn: J. B. Blackmon

J. Rogan

D. Steinmeyer

5301 Bolsa Avenue

Huntington Beach, CA 92647

Mechanical Technology, Inc. (2)

Attn: H. M. Leibowitz

G. R. Dochat

968 Albana Shaker Road

Latham, NY 12110

Midwest Research Institute (2)

Attn: R. L. Martin

J. Williamson

425 Volker Blvd.

Kansas City, MO 64110

NASA Lewis Research Center (2)

Attn: R. Bermand 500-502

W. Goette

21000 Brook Park Road

Cleveland, $\mathrm{OH} 44135$

Naval Civil Engr Laboratory

Attn: L. Huang

Port Hueneme Naval Station

Port Hueneme, CA 93043

New Mexico Solar University

Solar Energy Department

Box 3SOL

Las Cruces, NM 88003

Owens-llinois

Attn: Y. K. Pei

1020 N. Westwood

Toledo, OH 43614

PPG Industries

Attn: C. R. Frownfelter

One Gateway Center

Pittsburgh, PA 15222 


\section{DISTRIBUTION (Cont):}

Parsons of California Attn: D. R. Biddle 3437 S. Airport Way Stockton, CA 95206

Power Kinetics, Inc.

Attn: M. Rice

1223 Peoples Avenue

Troy, NY 12180

Research systems, Inc. Attn: T. A. Chubb Suburban Trust Bldg, Suite 203 5410 Indian Head Hwy.

Oxon Hill, MD 20745

Rocket Research Company

Attn: E. W. Schmidt

11441 Willows Rd NE

Redmond, WA 98052

Rockwell International

Energy systems Group

Attn: T. Springer

8900 De Sota Avenue

Canoga Park, CA 91304

Rockwell International Space

Trans \& Systems Group

Attn: B. Davis

12214 Lakeweek Blvd.

Downey, CA 90241

Sanders Associates

Attn: B. Davis

C.S. 2035

Nashua, NH 03061-2035

Solar Energy Information Center

Attn: R. Ortiz

1536 Cole Blvd.

Golden, CO 80401

Solar Energy Research Inst. (3)

Attn: G. Gross

B. P. Gupta

J. Thornton

1617 Cole Blvd.

Golden, CO. 80401
Shelltech Associates

Attn: C. R. Steele

809 Tolman Drive

Stanford, CA 94305

Solar Kinetics, Inc.

Attn: J. A. Hutchison

PO Box 47045

Dallas, TX 75247

Solar Steam

Attn: D. E. Wood

Old City Hall, Suite 400

625 Commerce Street

Tacoma, CA 98402

Southwest Research Institute

Attn: D. M. Deffenbaugh

PO Box 28510

San Antonio, TX 78284

Stanford Research Institute

Attn: A. J. Slemmons

Menlo Park, CA 94025

Stearns-Roger

Attn: W. R. Lang

4500 Cherry Creek

Denver, CO 80217

W. B. Stine

1230 Grace Drive

Pasadena, CA 91105

Sun Gas Company

Attn: R. I. Benner

3 N Park E, Suite 930

Dallas, TX 75221

Sundstrand Electric Power (2)

Attn: A. W. Adam

B. G. Johnson

4747 Harrison Avenue

Rockford, IL 61101

Sunpower Systems

Attn: W. Matlock

510 S 52 Street

Tempe, AZ 85281

Suntec Systems, Inc.

Attn: H. Randolph

2101 Wooddale Drive

St. Paul, MN 55110 


\section{DISTRIBUTION (Cont):}

Swedlow, Inc. (2)

Attn: E. Nixon

M. M. Friefeld

12122 Western Avenue

Garden Grove, CA 92645

- 3M-Decorative Products Div.

Attn: B. Benson

209-2N 3M Center

St. Paul, MN 55144

3M-Product Development

Energy Control Products

Attn: J. B. Roche

207-1W 3M Center

St. Paul, MN 55144

Texas Tech University

Dept of Electrical Engineering

Attn: E. A. O'Hair

PO Box 4709

Lubbock, TX 79409

Toltec Industries, Inc.

Attn: D. chenault

40th and East Main

Clear Lake, IA 50428

TRW

Space \& Technology Group (3)

Attn: G. M. Reppucci

A. D. Schoenfeld

J. S. Archer

One Space Park

Redondo Beach, CA 90278

US Department of Energy (3)

Albuquerque Operations Office

Attn: D. Graves

D. L. Krenz

J. Weisiger

PO Box 5400

Albuquerque, NM 87185

US Department of Energy

Division of Energy Storage Sys.

Attn: J. Gahimer

Washington, DC 20585
US Department of Energy (6)

Division of Solar Thermal Tech

Attn: H. S. Coleman

C. Carwile

J. E. Greyerbiehl

C. Mangold

M. R. Scheve

F. Wilkins

Washington, DC 20585

US Department of Energy (2)

San Francisco Operations Ofc.

Attn: R. W. Hughey

W. L. Lambert

1333 Broadway

Wells Fargo Building

Oakland, CA 94612

University of Houston

Attn: L. Vant-Hull

Houston, TX 77004

University of New Mexico (2)

Department of Mechanical Engr

Attn: M. W. Wilden

W. A. Gross

Albuquerque, NM 87131

0400 R. P. Stromberg

1510 J. W. Nuziato

1513 D. W. Larson

1520 D. I. McCloskey

1810 R. G. Kepler

1820 R. E. Whan

1830 M. J. Davis

1840 R. J. Eagan

2540 G. N. Beeler

2541 J. P. Abbin

3160 J. E. Mitchell

6200 V. L. Dugan

6220 D. G. Schueler

6221 E. L. Burgess

6222 J. V. Otts

6223 G. J. Jones

6224 D. E. Arvizu

6225 R. H. Braasch

6226 E. C. Boes

6227 J. A. Leonard (50)

6228 J. F. Banas

7262 G. S. Kinoshita (5) 


\section{DISTRIBUTION (Cont):}

8450 J. B. Wright

8452 A. C. Skinrood

8453 J. C. Swearengen

8024 M. A. Pound

3141 C. M. Ostrander (5)

3151 W. L. Garner (3) 